\author{
UNIVERSIDADE DE SÃO PAULO \\ ESCOLA DE ENGENHARIA DE SÃO CARLOS \\ DEPARTAMENTO DE ENGENHARIA DE ESTRUTURAS
}

\title{
ANÁLISE DE CONFIABILIDADE DE PEÇAS DE MADEIRA FLETIDAS DIMENSIONADAS SEGUNDO A NBR: 7190/97
}

\author{
VERSÃO CORRIGIDA \\ O exemplar de defesa encontra-se disponível na Seção de Pós-Graduação da EESC
}

\section{DANIEL VEIGA ADOLFS}

Dissertação apresentada à Escola de Engenharia de São Carlos como parte dos requisitos para obtenção do titulo de Mestre em Engenharia de Estruturas.

Linha de pesquisa: Estruturas de madeira

Orientador: Profo Dro Antônio Alves Dias 
AUTORIZO A REPRODUÇÃO E DIVULGAÇÃO TOTAL OU PARCIAL DESTE TRABALHO, POR QUALQUER MEIO CONVENCIONAL OU ELETRÔNICO, PARA FINS DE ESTUDO E PESQUISA, DESDE QUE CITADA A FONTE.

Ficha catalográfica preparada pela Seção de Tratamento da Informação do Serviço de Biblioteca - EESC/USP

\footnotetext{
Adolfs, Daniel Veiga

Análise de confiabilidade de peças de madeira fletidas dimensionadas segundo a NBR:7190/97. / Daniel Veiga

Adolfs ; orientador Antônio Alves Dias. São Carlos, 2011.

Dissertação (Mestrado - Programa de Pós-Graduação em Engenharia de Estruturas e Área de Concentração em Estrutura de Madeira)-- Escola de Engenharia de São Carlos da Universidade de São Paulo, 2011.

1. Vigas de madeira. 2. Análise de confiabilidade. 3. Calibração de norma. I. Título.
} 
Candidato: Engenheiro DANIEL VEIGA ADOLFS

Título da dissertação: "Análise de confiabilidade de peças de madeira fletidas dimensionadas segundo a NBR: 7190/97".

Data da defesa: 21/11/2011:

\section{Comissão Julgadora:}

Prof. Dr. Antonio Alves Dias (Orientador)

(Escola de Engenharia de São Carlos/EESC)

Prof. Dr. Andrẻ Teófilo Beck

(Escola de Engenharia de São Carlos/EESC)

Prof. Dr. Almir Sales

(Universidade Federal de São Carlos/UFSCar)
Resultado:
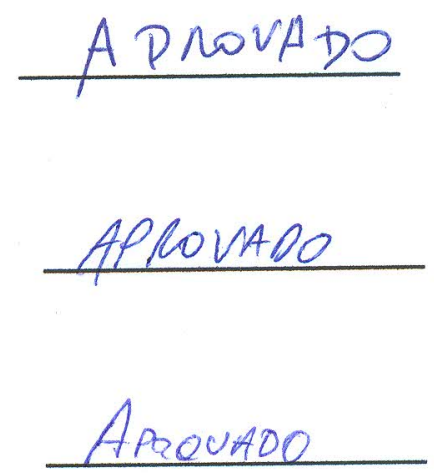

Coordenador do Programa de Pós-Graduação em Engenharia Civil (Engenharia de Estruturas):

Profa. Associada Ana Lucia Homce de Cresce El Debs

Presidente da Comissão de Pós-Graduação:

Prof. Associado Paulo Cesar Lima Segantine 
A Anton Adolfs, que desde cedo mostrou que a engenharia de estruturas é mais que uma profissão. 



\section{AGRADECIMENTOS}

Primeiramente gostaria de agradecer à Deus, por sempre ajudar a escolher caminhos seguros e corretos, e por nunca deixar de abençoar as minhas escolhas.

Aos meus familiares que de alguma forma me passaram todo o incentivo necessário para esta jornada.

À minha saudosa mãe, que sempre lutou com todas as forças possíveis, abdicando inclusive de seus objetivos, para nunca deixar de termos o estudo necessário, por sempre nos incentivar a seguir o caminho da educação. Ao meu pai, Antônio Adolfs, que por várias vezes abriu a minha cabeça nos nossos "bate-papos".

Aos meus avós, principalmente a Anton Adolfs e Valdizia Veiga, que ergueram com muito esforço os pilares das minhas famílias, sempre trazendo a alegria e o bem estar a nossa casa.

Ao meu irmão, Gustavo Adolfs, que sério e compenetrado, soube alegrar os meus momentos de solidão na longe São Carlos.

A ela, Edmarina Paula M ota, que é muito mais que a mulher daminha vida, é exemplo de dedicação e companheirismo, é exemplo de mulher de fibra, é a mãe da minha filha Manuela, a mulher que nunca me deixou faltar paixão, carinho e apoio, a quem eu sempre vou amar e ter gratidão, por tudo o que ela faz por mim, nós conseguimos meu amor!

À sua família, mãe, irmãos e filhos, que me acolheram como mais um filho da casa, e nunca mediram esforços para me ajudar no que fosse preciso. A Jéssika, por ter dividido os últimos momentos em São Carlos conosco, e ter levado mais alegria aos nossos dias.

Aos meus professores, desde os mais longínquos, da época da E.E. Altair Severiano Nunes, até os mais próximos dos dias atuais. Quero agradecer em especial aos professores Flávio Alberto Cantisani de Carvalho e Francisco Anastácio Cantisani de Carvalho, vascaínos fanáticos, que sempre respondem atodas as minhas dúvidas estruturais.

A EESC, que me proporcionou um momento único ao permitir que eu convivesse com os meus ídolos. Em especial ao professor Libânio Miranda, Samuel Giongo e Francisco Antônio Rocco, que muito colaboraram para o meu engrandecimento. A equipe da secretária, que sempre procura ajudar para melhorar o ambiente de estudo.

Ao meu orientador, Antônio Alves Dias, por abraçar este projetoe se mostrar muito mais do que um profissional qualificado e dedicado, por se mostrar um verdadeiro 
amigo na hora de me instruir e ajudar nas decisões. Ao Profo André Beck, por todos os ensinamentos desta nova filosofia de projeto.

A todos os meus amigos de Mestrado, toda a turma SET_MESTRADO_2009. A Socorro Sampaio, por nos apresentar São Carlos e ajudar na nossa chegada. As hermanas cubanas, Indara e Orieta Soto Izquierdo, "quenos ha proporcionadomomentos de felicidadcon sufamilia", muito obrigado pela amizade.

A cidade de São Carlos e os seus moradores. Que fizeram com que nós, eu e minha esposa, sentíssemos em casa, deixando muita saudade ao regressar para Manaus, principalmente a Heloisa Pires e Celso M artinez, que nos ajudaram bastante durante 0 período na cidade, a Sandra eArnaldo e a Vera e M arcelo. 


\section{SUM ÁRIO}

1- INTRODUÇÃO

1.1 - JUSTIFICATIVA

1.2 - OBJETIVOS 4

1.3 - RESUM O DA M ETODOLOGIA EM PREGADA

1.3.1 - Levantamento e análise estatística de experimentos 4

1.3.2 - Dimensionamento via modelo normativo da NBR 7190/97 5

1.3.3 - Estudo de erro de modelo 5

1.3.4 - Análise de confiabilidade 5

1.4 - ORGANIZAÇÃO 6

2- CONCEITOS SOBRE CONFIABIUDADE 7

2.1- CONCEITOS ESTATÍSTICOS

2.1.1- Distribuição de frequência e representação gráfica 7

2.1.2- Variáveis aleatórias 8

2.1.3- Funções de distribuição cumulativa 8

2.1.4- Funções densidade de probabilidade 9

2.1.5- Momentos de uma variável aleatória $\quad 10$

2.2- CONFIABILIDADE ESTRUTURAL 11

2.2.1- Definição 11

2.2.2- Estados limites 12

2.2.3- Probabilidade de falha e índice de confiabilidade 13

2.2.4- M étodos aproximados de análise de confiabilidade: FORM 15

2.2.5- Níveis de análise de confiabilidade 17

2.3- ERRO DE M ODELO

2.4- CALIBRAÇÃO DE NORM AS COM BASE NA CONFIABILIDADE 18

3- DIM ENSIONAM ENTO DE VIGAS À FLEXÃO SEGUNDO A NBR 7190/97 23

3.1- CRITÉRIOS GERAIS PARA DIM ENSIONAMENTO NO ESTADO LIMITE ÚLTIMO

3.2- DIM ENSIONAM ENTO À FLEXÃO NO ESTADO LIMITE ÚLTIMO 25

3.2.1- Tensões devidas ao momento fletor 26

3.2.2- Valores da resistência de cálculo para elementos fletidos 26

a. Coeficiente de modificação $k_{\text {mod }} \quad 27$

b. Fator de ponderação da resistência $\gamma_{w} \quad 29$

c. Resistência característica $f_{w k} \quad 29$

4- OBTENÇÃO DE DADOS DISPONIVEIS 31

4.1- ENSAIO DE FLEXÃO EM VIGAS COM DIMENSÕES ESTRUTURAIS 31

4.2- RESISTÊNCIA À COM PRESSÃO PARALELA ÀS FIBRAS 34 
5- ANÁLSE DE ERRO DE M ODELO 37

5.1- EQUACIONAM ENTO DO ERRO DE M ODELO (EM) 38

5.2- EQUAÇÕES PARA VERIFICAÇÃO DAS TENSÕES NORM AIS NA FLEXÃO 38

5.2.1- PROCEDIM ENTOS ADOTADOS NA VERIFICAÇÃO DA RESISTÊNCIA TEÓRICA

5.2.2- DETERM INAÇÃO DOS $k_{\bmod }$

5.2.3- ESTIM ATIVA DA FORÇA DE RUPTURA 41

5.3- VALORES DE ERRO DE M ODELO E ANÁLISE ESTATÍSTICA

5.4- CORREÇÃO DAS INCERTEZAS DOS ERROS DE M ODELO

6- ANÁLISE DE CONFIABILIDADE DO DIM ENSIONAM ENTO À FLEXÃO DA NBR 7190

6.1- VARIÁVEIS DE RESISTÊNCIA ENVOLVIDAS

6.2- VARIÁVEIS DE SOLICITAÇÃO ENVOLVIDAS

6.3- EQUAÇÕES DE ESTADO LIM ITE

6.3.1- Parcela proporcional de força das aç̃es 53

6.4- RESULTADOS DA ANÁLISE DE CONFIABILIDADE 57

6.4.1- Análises de confiabilidade sem EM e com EM 57

6.4.2- Comparação com o índice alvo do EUROCODE 61

6.4.3- Influência da classificação visual 63

6.4.4- Análises dos coeficientes de sensibilidade 65

7- CONCLUSÃO 69

7.1- OBTENCÇ̃̃O DE DADOS 69

7.2- ERRO DE M ODELO 69

$\begin{array}{ll}\text { 7.3- } & \text { ANÁLISES DE CONFIABILIDADE } \\ \end{array}$

8- REFERÊNCIASBIBLIOGRÁFICAS 73

APÊNDICE A - Carga de ruptura dos 17 grupos de resultados 77 


\section{LISTA DE FIGURAS}

Figura 2.1 - Exemplo de histograma 8

Figura 2.2 - Espaço com a região segura e de falha 13

Figura 3.1 - Evolução das tensões nas bordas de uma viga de madeira 24

Figura 3.2 - Relação $\sigma \times \varepsilon$ para a madeira 25

Figura 4.1 - Ensaio de forças nos terços do vão 33

Figura 4.2 - Ensaio de força no meio do vão 33

Figura 6.1 - Variação de $\beta$ em função das razões de carregamento para a Andiroba (1). $\quad 57$

Figura 6.2 - Variação de $\beta$ em função das razões de carregamento para 0 Tauari (4). $\quad 57$

Figura 6.3 - Variação de $\beta$ em função das razões de carregamento com a introdução do erro de modelo (direita) e sem o erro de modelo (esquerda) para o Tachi Preto (5).

Figura 6.4 - Variação de $\beta$ em função das razões de carregamento com a introdução do erro de modelo para a Pequiá (8). $\quad 60$

Figura 6.5 - Variação de $\beta$ em função das razões de carregamento para os Pinus $(13,14,15$ e 16). 62

Figura 6.6 - Variação de $\beta$ em função das razões de carregamento com a introdução do erro de modelo para os Pinus (15). 64

Figura 6.7 - Exemplo da variação de $\alpha$ em função da razão $W_{n} / D_{n}$ com 0 aumento da razão $L_{n} / D_{n}$ para Pequiá(11).

Figura 6.8 - Exemplo da variação de $\alpha$ em função da razão $W_{n} / D_{n}$ com 0 aumento da razão $L_{n} / D_{n}$ para Pinus(16). 


\section{LISTA DE TABELAS}

Tabela 3.1 - Valores de $k_{\text {mod }, 1} \quad 27$

Tabela 3.2 - Valores de $k_{\text {mod,2 }} \quad 27$

Tabela 3.3 - Valores de $k_{\text {mod,3 }} \quad 28$

Tabela 3.4 - Valores de $k_{\text {mod,3 }}$ para coníferas 28

Tabela 3.5 - Valores de $k_{\text {mod,3 }}$ para dicotiledôneas 28

Tabela 3.6 - Valores dos coeficientes $\gamma_{w} \quad 29$

Tabela 4.1 - Resumo dos resultados dos ensaios 32

Tabela 4.2 - Parâmetros estatísticos das espécies estudadas 36

Tabela 5.1 - Valores das forças $\quad 42$

Tabela 5.2 - Informações estatísticas do erro de modelo 43

Tabela 5.3 - Informações estatísticas adimensionalizadas e corrigidas 47

Tabela 5.4 - Informações estatísticas corrigidas do erro de modelo 48

Tabela 6.1 - Resumo das estatísticas das variáveis de resistência 50

Tabela 6.2 - Resumo das estatísticas das variáveis de solicitação 52

Tabela 6.3 - Coeficientes de segurança adotados para cada combinação 54

Tabela 6.4 - Resistência máxima das espécies calculadas segundo NBR 7190/97 55

Tabela 6.5 - Definição das classes de conseqüência 62 


\section{LISTA DE SIGLAS}

FORM - First Order Reliability Moment

FOSM - First Order Second Moment

NBR - Norma brasileira

LRFD - Loadand Resistence Factor Design

JCSS - Joint Commitee on Structural Safety

CEB - Comité Euro-Internacional du Betón

ASCE - American Society of Civil Engineers

COST - European Cooperation in Science and Technology 


\section{RESUMO}

ADOLFS, D. A. Análise de confiabilidade de peças de madeira fletidas dimensionadas segundo a NBR 7190/97. 2011. 92p. Dissertação (Mestrado) - Escola de Engenharia de São Carlos, Universidade de São Paulo, São Carlos, 2011.

A passagem do método das tensões admissíveis para o método dos estados limites na NBR7190 - Projeto de Estruturas de Madeira, ocorrida em 1997, foi feita por meio de calibração determinística que teve como ponto central a resistência da madeira na compressão paralela às fibras. Um dos aspectos modificados foi o dimensionamento de peças fletidas no tocante à verificação das tensões normais devidas ao momento fletor, em que é utilizada a resistência à compressão paralela às fibras. Com a intenção de averiguar o grau de segurança do modelo de cálculo para esse caso, foram realizadas análises de confiabilidade para vigas fletidas de madeira. Foram coletados dados de 549 testes de flexão de vigas, obtendo-se valores relativos à ruptura, e também foram obtidas informações estatísticas a respeito como a média e o desvio-padrão da resistência à compressão paralela às fibras, das mesmas espécies usadas nas vigas. Nas análises de confiabilidade foram utilizadas 5 variáveis aleatórias, com 5 tipos de combinações diferentes, analisadas com e sem erro de modelo para cada um dos 16 grupos de resultados levantados, totalizando 2752 análises de confiabilidade. Os resultados das análises sem o erro de modelo mostram que a norma não atinge valores suficientes para o índice de confiabilidade e que, com a introdução do erro de modelo, os resultados são mais adequados.Também se verificou que o modelo adotado pela norma é muito conservador, no caso de peças de madeira de Pinus SP classificadas.

Palavras-chave: Vigas de madeira. Análise de confiabilidade. Calibração de norma. 



\section{ABSTRACT}

\section{ADOLFS, D. A. Reliability analysisof bending timber members designed}

accordingNBR7190/97.2011. 92p. Dissertação (Mestrado) - Escola de Engenharia de São Carlos, Universidade de São Paulo, São Carlos, 2011.

The transition of allowable stressto limit state design methods in "NBR-7190 - Projeto de Estruturas de M adeira", in 1997, was made considering the strength in compression parallel to the grain as central point of deterministic calibration. One of the aspects modified was the design of beams, related to tension and compression; in this case is used the strength in compression. A reliability analysis was made for timber beams to determine the security level of the theoretical model. Were collected data related to failure from 549 bending tests in beams, and statistical information about the mean and standard deviation of the strength in compression of the wood species used in the beams. In reliability analysis were used 5 random variables, with 5 different types of combinations, analyzed with and without model error for each of the 16 groups of results collected, resulting 2752 reliability analysis. The results of the analysis without the model error show that the standard doesn't achieve sufficient values for the reliability index and, with the introduction of model error, the results are more adequate. It was also verified that the theoretical model is very conservativein the case of graded members of Pine species

Keywords: Timber beams. Reliability analysis. Code calibration. 



\section{INTRODUÇÃO |Capítulo 1}

Nos primórdios da engenharia estrutural, muitas obras eram feitas baseando-se na intuição ou nos conhecimentos adquiridos em construções passadas. Quando se desejava conceber algo novo, o processo de tentativa e erro era empregado até se chegar a uma dosagem correta dos ingredientes necessários à nova estrutura.

Com a chegada da revolução industrial (metade do século XVIII), essa prática da engenharia tornou-se obsoleta. A utilização de novos materiais permitia aos construtores conceber estruturas até então ousadas e sem precedentes nos arquivos da engenharia, inspirando os mesmos a tentarem padronizar a maneira como esses materiais deveriam ser empregados com a segurança necessária. Já na segunda revolução industrial os conceitos de resistência dos materiais e as bases da teoria do concreto armado já eram conhecidos pelos engenheiros, criando assim os primeiros documentos normativos para padronizar e controlar a qualidade dos materiais e serviços.

Esses documentos, que hoje são conhecidos por normas, se preocupavam com parâmetros e procedimentos que pudessem quantificar a segurança de uma estrutura. Como ponto de partida os comitês normalizadores trataram das intensidades de ações, arbitrando-se valores máximos de cargas que poderiam ser encontradas para cada tipo de construção. Tambémestipulava-se a resistência de certo material ou elemento estrutural através da comparação com estruturas já existentes e de desempenho satisfatório, processo pouco preciso e baseado na experiência.

Valores confiáveis de resistência dos materiais começaram a ser definidos quando houve a introdução de laboratórios para tal. Os ensaios laboratoriais permitiram definir a resistência que deveria ser empregada nos modelos de segurança, surgindo assim o método determinístico das tensões admissíveis. Assim, através de um coeficiente global $\left(\gamma_{\text {global }}\right)$, as tensões médias seriam minoradas para se obter uma quantidade de segurança no dimensionamento, chamada tensão admissível. 
A maioria das normas adotou este método das tensões admissíveis até a metade do século XX, quando foi substituído pelo método dos estados limites. Nesse método, uma visão probabilística das variáveis envolvidas no problema é levantada, fatores como a resistência dos materiais, ações nas estruturas, geometria dos elementos, incertezas e constantes envolvidas na determinação da resistência passam a ser analisados de forma estatística, com as ações e as resistências dos materiais sendo tratadas por valores característicos. Outra mudança importante foi o fato de a margem de segurança passar a ser obtida por coeficientes parciais, podendo usá-los para majorar as ações atuantes e para minorar a resistência do material.

Com o desenvolvimento deste novo modelo, muitos países criaram comitês de estudos para reformular as suas normas de dimensionamento, revendo todos os modelos de cálculo que eram empregados anteriormente e passando-os para o método dos estados limites.

A partir da década de 80, o comitê normalizador brasileiro começou a implementar este método nas normas nacionais, só que houve uma grande diferença nessa adoção, nãoforam feitos estudos de calibração baseados na realidade brasileira para se definir os valores dos coeficientes parciais de segurança, fazendo com que as nossas normas fossem praticamente cópias das principais normas mundiais nesse quesito.

Uma ferramenta que nos permite fazer um procedimento preciso de adequação dos coeficientes centrais para os coeficientes parciais do novo modelo de segurança é a confiabilidade estrutural. Através dela podem-se calibrar os coeficientes adotados no novo modelo de segurança baseando-se nos coeficientes centrais que eram anteriormente empregados, permitindo manter resultados finais de dimensionamento coerentes com os que eram encontrados no modelo anterior, da mesma forma que foi feito nas normas de países que já trabalham com este novo método.

Nesse contexto, neste trabalho foi realizada uma análise de confiabilidade para vigas de madeira, enfocando as tensões normais devidas ao momento fletor.

\subsection{JUSTIFICATIVA}

Os coeficientes parciais da atual norma de projeto de estruturas de madeira, NBR 7190/97 - Projeto de Estruturas de Madeira, não foram calibrados com base na teoria da confiabilidade estrutural. Analisando-se os valores para a nova norma, pode-se dizer que os 
coeficientes parciais preservaram as características dos antigos coeficientes centrais, o que permite iniciar os estudos de calibração da referida norma com base na confiabilidade estrutural.

A importância deste estudo é de criar dadossuficientes para um processo de calibração dos coeficientes parciais de segurança da norma NBR 8681/04 - Ações e Segurança nas Estruturas,e averiguar o nível de confiança apresentado no dimensionamento à flexão da NBR 7190/97.

0 primeiro passo é averiguar como o dimensionamento à flexão pela norma de estruturas de madeira, NBR 7190/97, transmite confiança aos usuários através do índice de confiabilidade dos elementos fletidos de madeira. Com esse passo inicial, muitos outrosserão dados no caminho da avaliação de elementos de madeira submetidos também a outros tipos de solicitação, constituindo, com o passar do tempo, um estudo completo sobre a confiabilidade de estruturas de madeira em geral.

Posteriormente, junto com os estudos desenvolvidos para outros materiais estruturais como o concreto armado, aço, alvenaria e com os dados dos tipos de carregamentos, pode-se partir para um estudo mais amplo de calibração dos coeficientes parciais com base na confiabilidade estrutural. Essa calibração permitirá obter o conjunto de coeficientes que minimizará as variações dos índices de confiabilidade das estruturas projetadas segundo norma, tornando-o mais uniforme em relação ao índice de confiabilidade alvo adotado para a calibração.

Sendo assim, essa pesquisa é de grande importância para a realidade estrutural brasileira, visto que as normas nacionais não passaram por este tipo de calibração e não foi feita uma avaliação sistêmica das incertezas envolvidas no processo de calibração. A obtenção de índices de confiabilidade alvo e coeficientes parciais, determinados através deste índice,com vida útil e níveis de segurança satisfatórios.

\subsection{OBJETIVOS}

O objetivo geral deste trabalho foi realizar uma análise de confiabilidade no caso de peças fletidas dimensionadas segundo a NBR-7190/97, enfocando as tensões normais devidas ao momento fletor, buscando verificar o nível de segurança em que se encontra 0 modelo normativo.

Os objetivos específicos foram: 
Descrevera variável erro de modelo para peças de madeira fletidas para avaliar 0 conservadorismo do modelo teórico proposto pela norma para essas peças.

Verificar como se comporta o índice de confiabilidade em relação às razões de carregamento propostas, avaliando-o nos quesitos de suficiência e uniformidade. Também foi observado o coeficiente de sensibilidade das variáveis aleatórias envolvidas no processo, o que permitiu determinar quais eram as variáveis mais influentes no resultado do índice de confiabilidade para cada análise.

Averiguar, pela confiabilidade, como a classificação visual das peças de madeira de Pinus sp. Influenciam no resultado final do índice de confiabilidade, avaliando se o modelo proposto pela norma para avaliar essas espécies nessas condições reflete, de forma aproximada, a realidade.

\subsection{RESUMO DA METODOLOGIA EM PREGADA}

O método de investigação empregado foi composto de quatro etapas. Levantamento e análise estatística de experimentos, dimensionamento via modelo normativo da NBR 7190/97, quantificação e interpretação do erro de modelo e análise de confiabilidade.

\subsubsection{Levantamento e análise estatística de experimentos}

Foi feita uma análise de trabalhos experimentais realizados no LaM EM e em outros laboratórios, onde as mais variadas espécies de madeira,com largo emprego estrutural, foram transformadas em elementos de vigas e submetidas a ensaios destrutivos de flexão para a obtenção da força de ruptura. De posse de um bom número de ensaios, os dados estatísticos da resistência de todas as espécies utilizadas nos ensaios foram obtidos para utilizá-los no levantamento de erro de modelo e estudos de confiabilidade.

\subsubsection{Dimensionamento via modelo normativo da NBR 7190/97}

Concomitantemente ao item anterior, realizou-se o dimensionamento à flexão dos elementos estruturais de madeira, empregando-se todas as informações disponíveis obtidas no levantamento. O dimensionamento foi feito conforme preconiza a NBR 7190/97, norma que define procedimentos padrões para a obtenção das resistências de cálculo das peças estruturais submetidas à flexão. 
Nesta etapa foram adotadas algumas simplificações necessárias para se verificar 0 grau de conservadorismo do modelo adotado pela norma na tentativa de aproximar o modelo de calculo à realidade estrutural.

\subsubsection{Estudo de erro de modelo}

A seguir, calculou-se a variável erro de modelo $(E M)$. Essa variável erro de modelo permite fazer uma avaliação da precisão da equação de dimensionamento à flexão, ela também foi abordada estatisticamente, montando-se histogramas e ajustando a distribuição de probabilidades que melhor se adaptou aos valores obtidos.

Essa variável foi de suma importância, pois além de definir a quantidade de margem de segurança que foi encontrada na norma ela fez parte do escopo da análise de confiabilidade, verificando-se sua contribuição para melhorias no modelo de norma através das análises dos índices de confiabilidade e dos coeficientes de sensibilidade.

\subsubsection{Análise de confiabilidade}

A etapa final foi o estudo de confiabilidade do modelo de norma. Esta análise foi feita com a utilização de toda a informação estatística dos dados da resistência, obtidos no levantamento das espécies, dos valores encontrados para o erro de modelo e das ações que porventura podem solicitar uma estrutura, todos aplicados em equações de estados limites que envolvam as combinações de ações possíveis para essas variáveis. Todas as análises foram feitas em métodos aproximados como o FORM (First Order Reliability Moment).

Também foi verificado como se comportou a variação dos índices de confiabilidade $\beta$ em relação às razões de carregamento empregadas (proporções de incidência entre as ações permanentes e acidentais) e quando comparados com os índices alvos de normas internacionais que já possuem valores padrões. Outra análise foi como o erro de modelo tendeu a alterar os valores de segurança do modelo de cálculo idealizado e adotado pela NBR 7190/97 para peças fletidas, e como cada variável aleatória influenciou no valor dos índices de confiabilidade através de uma análise de coeficientes de sensibilidade $\alpha$.

Ainda pode ser verificado como a classificação visual influencia o dimensionamento normativo através do coeficiente de modificação, permitindo apontar que mudanças devem ser empregadas para a sua correta avaliação. 
6 INTRODUÇÃO

\subsection{ORGANIZAÇÃO}

No 2 o capítuloé apresentada uma breve revisão sobre o que já foi feito a nível mundial e nacional a respeito de confiabilidade e calibração de normas.

A seguir, no capítulo 3, são apresentadosos procedimentos de dimensionamento de vigas de madeira à flexão para a determinação da força de ruptura. No capítulo 4, sãoapresentados todos os resultados de ruptura de vigas obtidas de pesquisascom ensaios destrutivos e também valores de caracterização das espécies. No capítulo 5 como foi criado e quais foram os resultados estatísticos obtidos para o erro de modelo.

Finalmente no capítulo 6 é detalhada toda a análise de confiabilidade realizada e quais foram os seus resultados. No capítulo 7 comenta-se sobre o que esses resultados expressam e o que é esperado para pesquisas futuras nesse campo. 


\section{CONCEITOS SOBRE CONFIABILIDADE $\mid$ Capítulo 2}

\subsection{CONCEITOS ESTATÍSTICOS}

\subsubsection{Distribuição de freqüência e representação gráfica}

A distribuição de freqüência é uma forma de compactar amostras em intervalos de classes. A quantidade de intervalos de classes pode ser estimada pela regra empírica da equação 2-1.

$$
k=1+3,3 \cdot \log _{10} n
$$

Onde $k$ é 0 intervalo de classes e $n$ é a quantidade de amostras.

A faixa a ser coberta pela classe de intervalos é encontrada pela subtração do maior valor das amostras pelo menor valor e a divisão desta subtração pela quantidade de intervalos nos fornece a largura dos mesmos.

A quantidade de amostras que se agrupam dentro de um intervalo define a altura das barras ou freqüência. Elas podem ser absolutas, quando mostramos a quantidade total de amostras no intervalo, ou relativas, quando mostramos o total de amostras do intervalo dividido pelo total de amostras do experimento.

A representação gráfica desses valores recebe o nome de histograma. No histograma o eixo horizontal apresenta a classe de intervalos e o vertical a quantidade de amostras, sejam elas absolutas ou relativas. 


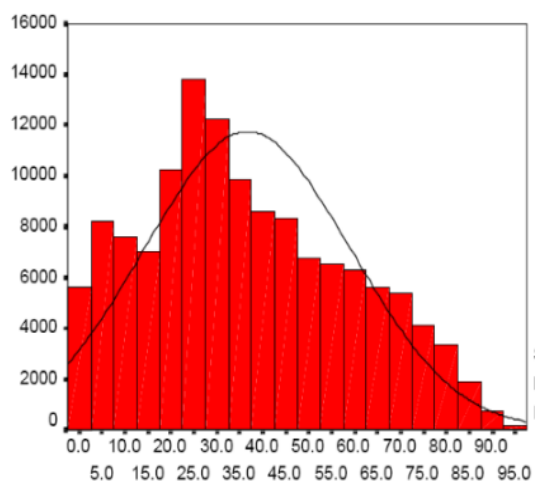

Figura 2.1. - Exemplo de histograma

\subsubsection{Variáveis aleatórias}

Uma variável aleatória é uma função que determina um número real para cada resultado obtido em um experimento aleatório. Em alguns casos é útil associarmos um valor numérico ao resultado contido no espaço amostral de um experimento, essa associação (função) que é então chamada de variável aleatória.

Algumas vezes os resultados de experimentos já são valores numéricos como, por exemplo, o resultado da medida de altura de várias pessoas ao acaso. Para representarmos uma variável aleatória adotamos letras maiúsculas como e para representar um evento desta variável adotamos letras minúsculas como .

O espaço amostral da variável aleatória é também conhecido como o domínio da função e pode ser dividido em dois tipos, discreto e contínuo. Quando a variável aleatória é do tipo discreta, significa que os pontos dentro do domíniosão finitos ou infinitos contáveis, se a variável aleatória é do tipo contínua, estamos querendo dizer que os pontos dentro do domínio da função são infinitos.

\subsubsection{Funções de distribuição cumulativa}

Dado um experimento aleatório, a função de distribuição cumulativa, também conhecida por , é um número que expressa à probabilidade da variável aleatória , discreta ou continua, ser menor que um valor ,definido para qualquer número real no intervalo 


$$
F_{X}(x)=P(X \leq x)
$$

Algumas propriedades devem ser atendidas como:

a) $0 \leq F_{X}(x) \leq 1$

b) $F_{X}(-\infty)=0$ e $F_{X}(+\infty)=1$

c) Se $x \leq y$, então $F_{X}(x) \leq F_{Y}(y)$

d) Para variáveis aleatórias continuas: $F_{X}(x)=\int_{-\infty}^{x} f_{X}(u) d u$

\subsubsection{Funções densidade de probabilidade}

A função de densidade de probabilidade $f_{X}(x)$ serve para descrever a distribuição de probabilidades de uma variável aleatória. Ela fornece uma descrição das probabilidades associadas à variável.

Histogramas são aproximações dessa função visto que a freqüência relativa é uma estimativa da probabilidade de certo resultado cair no intervalo, assim a função densidade de probabilidade serve como lei para definir a curva do histograma e calcular uma área qualquer sob o gráfico que representa a probabilidade da variável aleatória assumir um valor num determinado intervalo.

$$
P(a \leq X \leq b)=\int_{a}^{b} f_{X}(x) d x
$$

A função densidade de probabilidades pode ser obtida derivando-se a função de distribuição cumulativa em relação a $x$, fazendo-se uma distinção em relação aos domínios (continuo ou discreto) das variáveis para saber se é possível aplicar esta derivada (BECK, 2009). Se a variável for contínua a função de distribuição cumulativa possui resolução.

$$
f_{X}(x)=\frac{d F_{X}(x)}{d x}(\text { contínuas })
$$

Algumas propriedades devem ser atendidas como:
a) $f_{X}(x) \geq 0$
b) $\int_{-\infty}^{+\infty} f_{X}(x) d x=1$
c) $P(a \leq X \leq b)=F_{X}(b)-F_{X}(a)=\int_{a}^{b} f_{X}(x) d x$ 


\subsubsection{Momentos de uma variável aleatória}

Quando conhecidas as $n$ amostras de um experimento aleatório pode-se estabelecer propriedades importantes do coletivo de acordo com as necessidades do estudo. Essas propriedades, que servem para sintetizar as informações contidas nos dados originais, são na maioria dos casos a média $(\mu)$ e a variância $\left(\sigma^{2}\right)$, sendo 0 desvio padrão $(\sigma)$ e 0 coeficiente de variação $(\mathrm{CV})$ derivados desses outros dois parâmetros.

O valor esperado de uma distribuição tem a mesma definição do centro de gravidade de corpos, o valor esperado é o ponto aonde a distribuição se "equilibra". Já a variância é uma medida de dispersão dos valores da amostra, a variância mede o quanto a variável aleatória se dispersa em torno da média e, se comparado a um sólido, ela seria correspondente ao momento de inércia do corpo.

O valor esperado, ou média, de uma variável aleatória $X$ é dado por:

$$
E[X]=\mu=\int_{-\infty}^{+\infty} x f_{X}(x) d x(\text { contínuas })
$$

E a variância segue o mesmo processo para variáveis aleatórias.

$$
\operatorname{Var}[X]=E\left[(X-\mu)^{2}\right]=\int_{-\infty}^{+\infty}(x-\mu)^{2} f_{X}(x) d x \text { (contínuas) }
$$

A partir destes dois parâmetros pode-se então definir o desvio-padrão $(\sigma)$ e 0 coeficiente de variação $(C V)$ por:

$$
\begin{gathered}
\sigma=\sqrt{\operatorname{Var}[X]} \\
C V=\frac{\sigma}{\mu}
\end{gathered}
$$




\subsection{CONFIABIUDADE ESTRUTURAL}

\subsubsection{Definição}

Confiabilidade é o grau de confiança de que um sistema não falhe dentro de um período de tempo especificado e respeitado as condições de operação do mesmo (BECK, 2009). Abrangendo esta definição para a engenharia de estruturas, pode-se dizer que confiabilidade estrutural é o grau de confiança de que uma estrutura não falhe durante sua vida útil respeitando as condições de projeto que são estipuladas por um documento normativo.

Como em um projeto estrutural as variáveis de resistência e solicitações não são determinísticas o modelo de segurança a se empregar deve considerar as incertezas inerentes às variáveis para que 0 mesmo fosse de caráter probabilístico. Na abordagem semi-probabilistica do modelo de segurança se considera o grau de incerteza presente nas variáveis e é neste contexto que a teoria da confiabilidade se encaixa, pois permite calcular a probabilidade de falha das estruturas considerando as incertezas nas variáveis de projeto através de distribuições de probabilidade (NOGUEIRA, 2010).

Devido à inclusão das incertezas existente tanto na resistência quanto na solicitação no processo de avaliação da confiabilidade, esses parâmetros serão interpretados como variáveis aleatórias e, portanto a análise de confiabilidade pode ser medida de forma mais precisa através da probabilidade (ANG; TANG, 1975).

\subsubsection{Estados limites}

0 método de dimensionamento baseado nos estados limites começou na Rússia entre 1947 e 1949 (MIOTTO, 2003). A filosofia do estado limite é baseada na suposição de equilíbrio entre as cargas aplicadas ea resposta estrutural (resistência da estrutura) (NOWAK, 2003). Pode-sedizer de modo simplificado, que estado limite é uma equação onde se relacionaa solicitação atuante $(S)$ e a resistência $(R)$ como na equação 2-12. Quando a equação de estado limite obtiver resultados maiores ou iguais a zero, $g(X) \geq 0$, há um resultado seguro, e caso contrário, $g(X)<0$, ocorre falha.

$$
g(X)=R-S
$$


Neste exemplo representa as variáveis aleatórias de projeto envolvidas na equação de estado limite.

A abordagem sobre estados limites é importante tendo em vista que eles definem a fronteira entre falha e segurança de uma estrutura, assim a probabilidade avaliada na análise de confiabilidade, que é a de falha, vai necessitar também das informações das equações de estado limite. A probabilidade de falha nada mais é que a probabilidade de ocorrer um modo de falha,que, como visto anteriormente, é descrito através de uma equação de estado limite como a

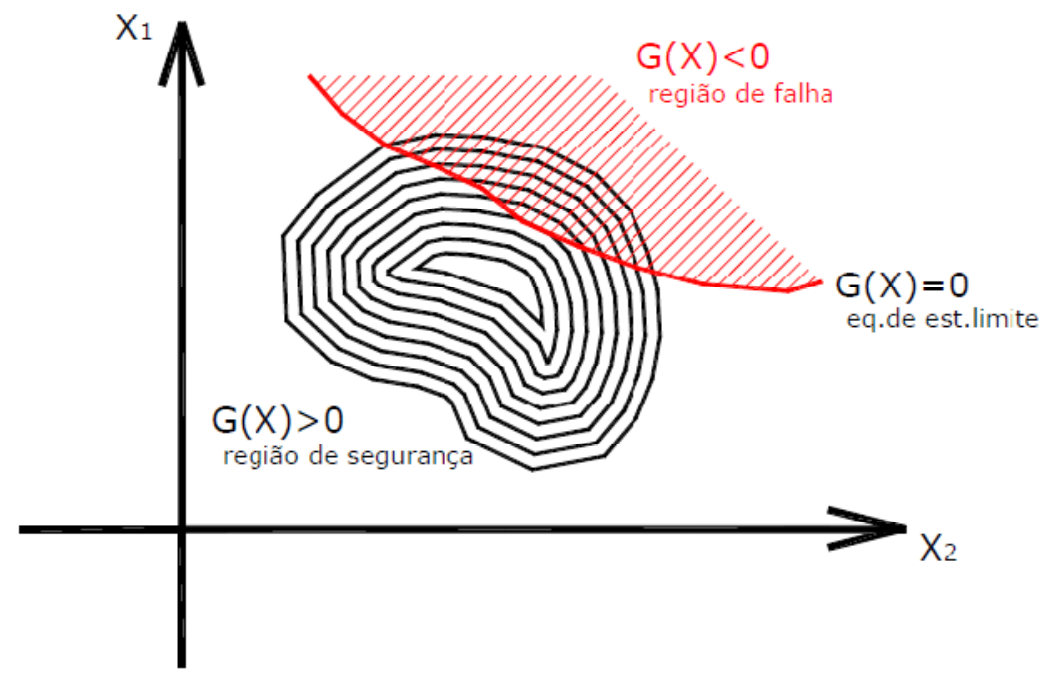

Figura 2.2-Espaço com a região segura e de falha (Fonte: Nogueira, 2010).

Antigamente, eram adotadoscoeficientes para se criar a margem de segurança, tanto sobre a resistência como para as solicitações. Nos dias atuais são usadas resistências e solicitações características, além de coeficientes parciais para se criar a margem de segurança (SORENSEN, 2004).

Mesmo com a utilização destes artifícios nas equações de estado limite (que muitos autores definem como modelo semi-probabilístico de segurança) modos de falha ainda podem ser alcançados devido às incertezas inerentes à cada variável do problema encontradas na equação em análise. 
De acordo com documentos normativos os estados limites podem ser últimos ou de serviço. Os estados limites últimos se referem à capacidade portante da estrutura e os estados limites de serviço à condição de uso da estrutura.

\subsubsection{Probabilidade de falha e índice de confiabilidade}

A probabilidade de falha $\left(P_{F}\right)$ é a medida de violação da segurança estrutural, ela é uma forma de verificar qual a probabilidade de um estado limite ser ultrapassado, ou melhor, qual a probabilidade de um modo de falha ser alcançado.

Sendo a segurança de uma estrutura avaliada pela Equação 2-12 conforme visto,pode-se reescrevê-la na forma da condição de falha, onde a resistência será menor que a solicitação, levando a estrutura a falhar.

$$
g(X)=R-S<0
$$

A análise da probabilidade de ocorrer este evento é o chamado problema fundamental da confiabilidade, definido na Equação 2-14.

$$
P_{F}=P[R<S] \text { ou } P_{F}=P[(R-S<0)]
$$

Todos os resultados encontrados pela condição anterior caracterizam um domínio de falha, determinada pela função de densidade conjunta de probabilidade de $R$ e $S$ (NOGUEIRA, 2010).

$$
P_{F}=\int_{-\infty}^{+\infty} \int_{-\infty}^{s} f_{R, S}(r, s) d r d s
$$

Se as variáveis de resistência e solicitação forem independentes a probabilidade de falha acima pode ser calculada pelo somatório do produto entre as funções densidade de probabilidade de $R$ e $S$. Entretanto, o uso desta equação para se avaliar a probabilidade de falha é muito complexo, adotando-se métodos aproximados ou simulados para se determinar os resultados da operação.

Contudo, definindo-se uma variável chamada margem de segurança $M$, expressa em função das variáveis aleatórias de resistência $R$ e solicitação $S$, conforme a Equação 2-16, também se pode determinar a probabilidade de falha. 


$$
\begin{gathered}
M=R-S \\
P_{F}=\int_{-\infty}^{0} f_{M}(m) d m
\end{gathered}
$$

Sendo as variáveis aleatórias $R$ e $S$ independentes e com distribuição normal de probabilidades, a margem de segurança também será uma variável aleatória com média e desvio padrão dados conforme as Equações 2-18 e 2-19:

$$
\begin{gathered}
\mu_{M}=\mu_{R}-\mu_{S} \\
\sigma_{M}=\sqrt{\sigma_{R}^{2}+\sigma_{S}^{2}}
\end{gathered}
$$

Transformando a variável margem de segurança em uma variável normal padrão $Y$ com média nula e desvio padrão unitário (Equação 2-20), determinam-se as probabilidades dessa variável pela função de distribuição cumulativa normal padrão (Equação 2-21) (GOMES, 2010).

$$
\begin{gathered}
Y=\frac{M-\mu_{M}}{\sigma_{M}} \\
P_{F}=P(M \leq 0)=P\left(Y \leq-\frac{\mu_{M}}{\sigma_{M}}\right)=\Phi\left(-\frac{\mu_{M}}{\sigma_{M}}\right)
\end{gathered}
$$

Como observado por Hasofer\&Lind (1974), a menor distância entre a origem do espaço normal padrão Y e a equação de estado limite é o índice de confiabilidade $\beta$, que é uma medida geométrica da probabilidade de falha.

$$
\beta=\frac{\mu_{R}-\mu_{S}}{\sqrt{\sigma_{R}^{2}+\sigma_{S}^{2}}}=\frac{\mu_{M}}{\sigma_{M}}
$$

Logo, ajustando-se a Equação 2-22 na Equação 2-21 teremos a Equação 2-23. Valores altos do índice beta resultam em uma baixa probabilidade de falha, e uma maior segurança para as estruturas.

$$
P_{F}=\Phi\left(-\frac{\mu_{M}}{\sigma_{M}}\right)=\Phi(-\beta)
$$




\subsubsection{Métodos aproximados de análise de confiabilidade: FORM}

Como notado, a determinação da probabilidade de falha não é fácil, pois a mesma depende da função conjunta de densidade de probabilidade entre a resistência e solicitação. Porém métodos aproximados e métodos de simulação foram desenvolvidos para solucionar o problema.

A simulação é uma técnica numérica utilizada para realizar experimentos no computador, baseados em modelos lógicos e matemáticos para descrever o comportamento de sistemas (RUBINSTEIN, 1981 apud BECK, 2009). 0 método de simulação mais empregado na engenharia é o de Monte Carlo, geralmente ele é adotado como último recurso na determinação da probabilidade de falha, quando os demais métodos não produzem bons resultados (BECK, 2009).

Já os métodos aproximados são tidos como alternativas para a determinação da probabilidade de falha por meio de índices de confiabilidade (NOGUEIRA, 2010). Esses métodos envolvem diferentes aproximações da função conjunta de densidade e do domínio de integração, obtendo-se a probabilidade de falha a partir desses dados (BECK, 2009). Os métodos mais difundidos são o FOSM (First Order Second Moment), FORM (First Order Reliability M ethod) e SORM (Second Order Reliability M ethod).

No método FORM, a análise se fundamenta na construção de uma função conjunta de distribuição de probabilidades $f_{X}(x)$, baseada nas distribuições marginais do problema e da matriz de correlação entre as variáveis, transformando-a em uma distribuição Gaussiana padrão multivariada $f_{Y}(y)$ (GOMES, 2010).

Essa transformação, na prática, pode ser efetuada utilizando o modelo de Nataf (BECK, 2009).Ela consiste em três etapas, na primeira etapa transformam-se as distribuições marginais do problema $\left(X_{i}\right)$ em distribuições normais equivalentes $\left(Z_{i}\right)$ correlacionadas, depois determina-se os coeficientes de correlação para cada uma das distribuições marginais normais para então realizar a eliminação da correlação. Esta transformação é dita composta, pois transforma as variáveis $X$ em $Z$ e depois $Z$ em $Y$. 
A transformação das distribuições marginais $X_{i}$ em normais equivalentes $Z_{i}$ (com média nula e desvio padrão unitário) pode ser realizada através da transformação de Hassofer e Lind (Equação 2-24) e deve ser aplicada a todas as variáveis do problema de confiabilidade estrutural.

$$
Z_{i}=\frac{X_{i}-\mu_{X}}{\sigma_{X}}
$$

Quando as variáveis aleatórias possuírem correlação $\left(\rho_{X_{i j}}\right)$ entre si, deve-se incorporar este dado na análise. Essa incorporação pode ser feita pelo modelo de Nataf (NATAF, 1961 apud BECK, 2009), que constrói uma aproximação Zpara as funções conjuntas de $X$ a partir das funções marginais normais com as correlações incluídas.

A eliminação da correlação pode ser feita para as variáveis correlacionadas com distribuição normal padrão. A decomposição de Cholesky é uma maneira prática de realizar este processo de eliminação da correlação. Essa decomposição consiste em uma transformação linear de $z$ para $y$ através de uma matriz de transformação, que na decomposição de Cholesky pode ser uma matriz Jacobiana.

\subsubsection{Níveis de análise de confiabilidade}

$\mathrm{Na}$ análise de confiabilidade cada método adotado de cálculo possui sua singularidade, portanto para organizá-los de acordo com o tipo de aproximação empregada uma classificação baseada na quantidade de informação disponível e utilizada foi criada (SOUZA JUNIOR, 2009 apud MADSEN, 1986).

- Métodos de nível I: São os métodos de confiabilidade adotados para calibrar as normas de projeto. Podem empregar métodos de nível II ou de nível III.

- Métodos de nível II: A análise de confiabilidade é feita através de informações estatísticas de segunda ordem e correlações. Neste método denominado FOSM todas as variáveis possuem distribuição normal.

- Método de nível III: Nesta análise todas as informações estatísticas das variáveis são utilizadas. Os métodos desse nível são o FORM , SORM, Simulação de Monte Carlo. 
- Método de nível IV: É o método em que a análise é baseada no custo total esperado do projeto. Este método procura aperfeiçoar a relação custo-benefício para obter resultados de máximo aproveitamento.

Como a pesquisa está em busca de verificar um modelo normativo com base em todas as informações estatísticas e criar subsídios para calibração de norma, deve-se adotar os métodos de nível III para realizar as análises de confiabilidade.

\subsection{ERRO DE MODELO}

Trabalhos como os de NOGUEIRA (2006) já apresentam à variável erro de modelo como importante nas análises de confiabilidade e de calibração de normas, mas nenhum pôde utilizar dados próprios para as suas considerações nos respectivos estudos, tendo sido adotados valores retirados de pesquisas internacionais. OLIVEIRA (2008) construiu uma variável erro de modelo e a analisou estatisticamente na sua pesquisa, incluindo esta variável em suas análises de confiabilidade para verificar sua influência no modelo.

0 valor médio do erro de modelo, denominado por $\mu_{E M}$, permite definir o nível de tendenciosidade existente no modelo normativo. Um valor unitário para a média representa que qualquer modelo teórico proposto por uma norma qualquer não possui tendenciosidade a favor ou contra a segurança, portanto ele seria considerado um modelo Ideal. Para valores médios da variável com resultados acima de um,tem-se uma norma com modelo teórico conservador em relação à realidade do material e 0 oposto para um valor abaixo da unidade (OLIVEIRA, 2008).

0 desvio padrão, denominado por $\sigma_{E M}$, corresponde ao erro aleatório do modelo teórico, o que significa uma incapacidade de se prever, em todas as situações de projeto, a verdadeira resistência do elemento(OLIVEIRA et. al. 2008). 0 desvio padrão é uma referência das incertezas existentes no modelo adotado e no material empregado. 


\subsection{CALIBRAÇÃO DE NORM AS COM BASE NA CONFIABILIDADE}

0 objetivo da calibração de normas é ajustar coeficientes de segurança para que 0 projeto da estrutura apresente resultados próximos e uniformes a um nível alvo predeterminado (NOWAK, 2003).

0 estudo de calibração de normas começou na década de 60 com o reconhecimento das deficiências do método de tensão admissível e a conseqüente passagem para o método dos estados limites (ELLINGW OOD et. al., 1982).

Como o método de estados limites é fundamentado em conceitos probabilísticos uma série de estudos sobre parâmetros estatísticos para as cargas e as resistências dos materiais estruturais começaram a ser desenvolvidos em prol do melhor aproveitamento do método. Esses dados estatísticos levantados apresentavam valores que continham as incertezas do cotidiano da engenharia e apenas a ferramenta de confiabilidade poderia realizar esta análise de forma estatística.

A partir das primeiras publicações na década de 60 e com 0 desenvolvimento das técnicas para a resolução de problemas de confiabilidade, normas de projeto estruturais baseadas na probabilidade começaram a ser formuladas. Galambos publicou a primeira versão da LRFD para edifícios de aço em 1978, com escopo limitado e sem considerar a influência de outros materiais ou sistemas construtivos, esse estudo se prolongou até 1985 , quando 0 autor concluiu seus dados (ELLINGWOOD, 2000).

Em 1971 foi criado o JCSS - Joint Committee on Structural Safety, um comitê formado por vários profissionais de países da Europa para desenvolver pesquisas na área de confiabilidade e segurança estrutural (VROUWENVELDER, 1997). Este comitê foi responsável por mais de 50 meetings na área e larga influência no conteúdo de confiabilidade presentes em normas como o CEB e o Eurocode.

Ainda nesta década foram publicados dados estatísticos a respeito das cargas variáveis de edifícios e em seguida dados estatísticos a respeito das cargas de neve nas estruturas (ELLINGWOOD, 1977). Ainda foi publicado um estudo de combinações de cargas para estruturas de concreto armado com coeficientes de ponderação determinados com base em análises de confiabilidade (ELLINGWOOD, 1980). Informações a respeito da 
velocidade de ventos em aeroportos americanos foram levantadas, possibilitando 0 desenvolvimento de parâmetros estatísticos a respeito das cargas de vento (SIMIU et. al., 1980).

Com o fervor das publicações de dados estatísticos das estruturas na década de 70 um projeto para agrupar todos essas informações e criar uma norma foi criado. Um artigo baseado nas pesquisas anteriores e em dados levantados por um grupo de pesquisadores indicava um conjunto de coeficientes ponderadores e combinações de cargas para qualquer tipo de estrutura e forneciam critérios para a determinação de resistências compatíveis com os carregamentos gerados (ELLINGWOOD et. al., 1980). Após a criação deste trabalho, inúmeras outras normas de projeto americanas basearam-senele para desenvolver seus métodos de análise e coeficientes ponderadores.

Somente no final da década de 90 os Eurocodes começaram a implementar o método dos estados limites no seu escopo.A calibração de normas baseada na confiabilidade é um procedimento antigo, mas demorou a ser adotada na Europa devido à mudança gradual das normas nacionais para os Eurocodes (RANTA-M AUNUS, 2001)

A madeira como material estrutural começou a ser analisada por estados limites em 1995 (ELLINGWOOD, 1997). Um LRFD foi publicado pela ASCE Standard 16-95, mas as especificações de projeto começaram a ser definidas desde 1983.

A COST Action E24 foi criada em 2000 e é uma comissão européia para estudo de confiabilidade na área de estruturas de madeiras com objetivo de desenvolver uma norma para projeto de estruturas de madeira baseada em conceitos de confiabilidade em contexto com o modelo de norma probabilística do JCSS (FABER, 2004).

O JCSS propôs em 2004 um modelo probabilístico para as propriedades da madeira estrutural formulado com base em testes laboratoriais com madeiras leves americanas e européias (SORENSEN, 2007). 0 interessante neste trabalho foi que valores de correlação entre as propriedades das madeiras foram estabelecidos com o final da pesquisa em 2006.

No Brasil alguns estudos já apontam para um processo de calibração de coeficientes e modelo de cálculo.Estudos de confiabilidade em pilares curtos de concreto armado foram realizados e verificou-se a influência de diversos parâmetros no modelo, sendo as 
informações estatísticas das variáveis estimadas através de outros estudos (NOGUEIRA, 2006).

Uma análise de confiabilidade para verificar a segurança de pilares mistos preenchidos de seção circular, dimensionados por quatros normas diferentes, apresentou informações importantes (OLIVEIRA et. al, 2008). O trabalho chegou a resultados que mostram a real influência da utilização da variável erro de modelo no índice de confiabilidade, comprovando a necessidade de seu uso no processo de calibração de normas.

Umestudo sobre o modelo de calibração de coeficientes com base em confiabilidade que deve ser feito para as normas brasileiras foi exposto (SOUZA JUNIOR, 2009). Ainda foram apresentados no mesmo trabalho dados estatísticos de vento baseados na realidade brasileira e uma comparação entre os coeficientes parciais adotados na NBR 8800:2008 com os mesmos coeficientes obtidos através do processo de calibração proposto.

Vários trabalhos de confiabilidade das estruturas de madeira já foram produzidos em âmbito nacional, mas nenhum que fosse diretamente voltado para a calibração dos coeficientes de segurança da NBR 7190/97. Alguns trabalhos se destacam como ESPINOSA (2001),ESPINOSA \& STAM ATO (2004) e LINDQUIST (2006). 


\section{DIMENSIONAMENTO DE VIGASÀ FLEXÃO \\ SEGUNDO A NBR 7190/97 \\ Capítulo 3}

\subsection{CRITÉRIOS GERAIS PARA DIM ENSIONAMENTO NO ESTADO UMITE ÚLTIM O}

A NBR 7190/97 adota o método semi-probabilistico para a verificação da segurança. Esse método substituiu o método determinístico da NBR 7190/82 - Cálculo e execução de estruturas de madeira

Essa transformação foi apresentada no anexo $\mathrm{F}$ da norma de 97, e o processo de transição foi feito de forma que os resultados encontrados pelo novo modelo não fossem tão diferentes do modelo antigo, preservando a integridade do antigo modelo e evitando um impacto negativo nos usuários. 0 ponto central de calibração foi a resistência à compressão paralela às fibras (FUSCO, 1995).

O dimensionamento pela NBR 7190/97 deve atender algumas recomendações propostas no seu escopo. Dentre elas são apresentadas algumas que são referentes a determinação de solicitações e resistência como:

- Os materiais devem ser considerados como tendo comportamento elástico linear para a determinação dos esforços atuantes;

- Na determinação dos esforços resistentes, os materiais devem ser considerados com comportamento elastofrágil, com diagrama tensãodeformação linear até a ruptura da peça, tanto na compressão quanto na tração; 
- As ações de projeto devem ser consideradas levando-se em conta o processo de combinação de forças com o uso de coeficientes ponderadores específicos para cada caso analisado.

0 atendimento destas premissas serve para simplificar os modelos de cálculo da norma, tentando ser acessível a todos os usuários, mesmo os que não possuem métodos sofisticados para a consideração de modelos mais realistas a respeito do comportamento do material.

Diversos estudos, como o de BODIG (1982), mostram que a madeira não se comporta de forma elástica linear na flexão, como indicado pela norma. A maioria das espécies de madeira possui resistência à compressão menor que à tração, eisso implica que, a partir de certo nível de carregamento, a borda comprimida atinge o limite deresistênciae começa a plastificar com incrementos de forças, ocorrendo o rebaixamento da linha neutra, até que a ruptura ocorra na borda tracionada, conforme ilustrado nas Figuras 3.1.

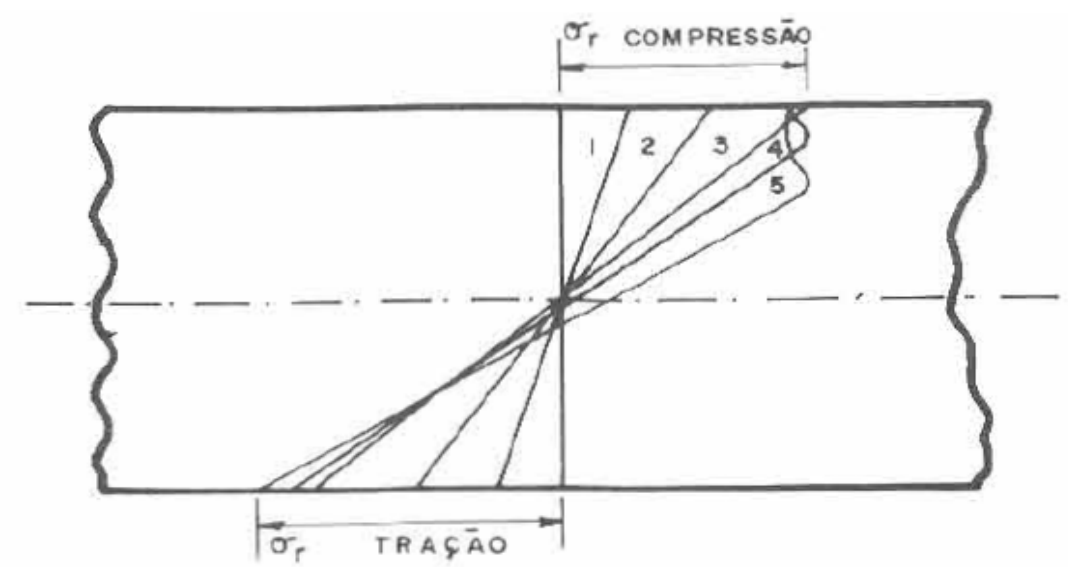

Figura 3.1 - Evolução das tensões nas bordas de uma viga de madeira Fonte: BODIG (1982) apud ROCHA (1988).

O diagrama de tensão/deformação da Figura 3.2 elaborado por BUCHANAN (1990) ilustra as distinções entre as bordas de peças fletidas. Ele também aponta os estágios de evolução da resistência de vigas fletidas. Em espécies com baixa resistência à tração, a resistência da viga é governada somente pela borda tracionada, ocorrendo uma ruína brusca, enquanto que para espécies com maiorresistência à tração, a resistência da viga é governada pela compressão, devido à peça aumentar sua resistência até plastificar, sendo 
que a ruptura também ocorre na borda tracionada de forma brusca. Em alguns casos, o momento fletor máximo aplicado ocorre antes da ruptura por tração.

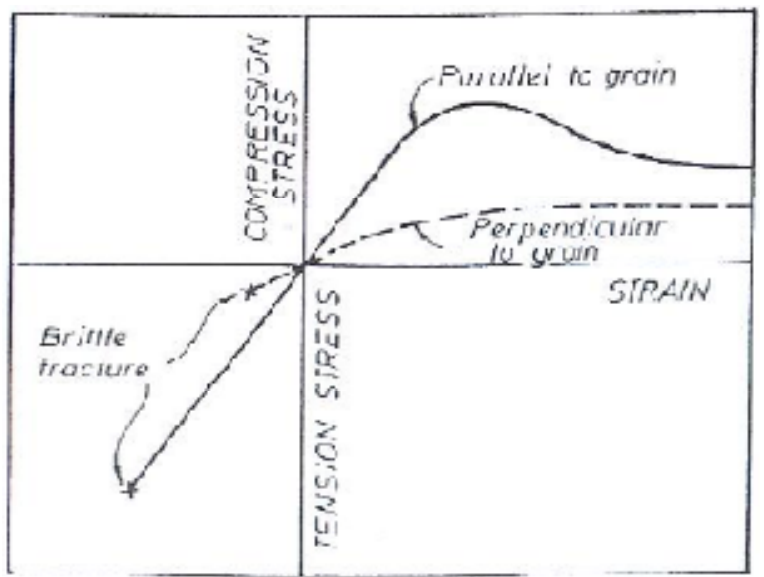

Figura 3.2 - Relação o X ? para a madeira (BUCHANAN, 1990).

\subsection{DIMENSIONAM ENTO À FLEXÃO NO ESTADO LIMITE ÚLTIMO}

Como todos os modelos de segurança baseados no método semi-probabilista, a segurança de vigas solicitadas à flexão pode ser considerada atendida quando a equação 3-1 é confirmada.

Nesta equação é a solicitação de cálculo definida pelas ações atuantes na estrutura, combinadas e majoradas com os devidos coeficientes, e é a resistência de cálculo, determinada a partir da resistência característica e de coeficientes ponderadores e de modificação.

No caso de vigas fletidas, o modelo de segurança apresentado na equação 3-1 deve avaliar as bordas tracionada e comprimida da viga.

Na NBR 7910:1997, em elementos fletidos, os esforços solicitantes de cálculo das bordas devem ser representados por e , com o índice " $c$ " representando a borda comprimida e 0 índice " $\mathrm{t}$ " à tracionada. Os esforços resistentes de cálculo das bordas devem ser representados por e , assim podemos desmembrar a equação 3-1 em outras duas, a 3-2 e a 3-3. 


$$
\begin{aligned}
\sigma_{c d} & \leq f_{c d} \\
\sigma_{t d} & \leq f_{t d}
\end{aligned}
$$

\subsubsection{Tensões devidas ao momento fletor}

As tensões devidas ao Momento flexor, $\sigma_{c d}$ e $\sigma_{t d}$, são respectivamente os valores máximos das tensões de compressão e de tração atuantes, respectivamente. A equação 3-4 apresenta, baseado na teoria da resistência dos materiais para material elástico e linear, a determinação dessas tensões nas duas bordas.

$$
\sigma_{w d}=\frac{M_{d}}{W}
$$

Na equação 3-4, $M_{d}$ é o momento fletor de cálculo, resultante das combinações das ações atuantes e seus coeficientes ponderadores. "W" é o módulo de resistência referente à borda verificada.

\subsubsection{Valores da resistência de cálculo para elementos fletidos}

A NBR 7190/97 define $f_{c d}$ e $f_{t d}$ como sendo as resistências de cálculo da borda comprimida e da borda tracionada, respectivamente. 0 modelo para se determinar o valor resistente é apresentado na equação 3-5.

$$
f_{w d}=k_{\text {mod }} \cdot \frac{f_{w k}}{\gamma_{w}}
$$

Na equação acima, $k_{m o d}$ é um coeficiente de modificação composto pelo produto de três coeficientes parciais que afetam os valores das propriedades da madeira. 0 coeficiente de ponderação $\gamma_{w}$ é usado para minorarmos a resistência da espécie, possuindo um valor especifico para cada borda, e $f_{w k}$ é a resistência característica da espécie de madeira em análise, que também possui um valor específico para cada tipo de solicitação, isto é, tração ou compressão.

Cada item dessa equação será analisado individualmente a seguir, sendo apresentadas as recomendações da norma. 


\section{a. Coeficiente de modificação $\boldsymbol{k}_{\text {mod }}$}

O coeficiente de modificação é um coeficiente de correção que serve para corrigir as diferenças entre as condições existentes nos ensaios e as encontradas numa estrutura real.

Esse coeficiente é composto de três parcelas, $k_{m o d, 1}, k_{m o d, 2}$ e $k_{\text {mod,3 }}$. A primeira parcela tem seu valor determinado em função da classe de carregamento e do tipo de madeira empregada. A classe de carregamento é definida em função da duração acumulada da ação variável principal definida na combinação de carregamento. A Tabela3.1, apresenta os valores para o $k_{m o d, 1}$

\begin{tabular}{|c|c|c|c|c|c|}
\hline \multicolumn{6}{|c|}{ Tabela3.1 - Valores de $\boldsymbol{k}_{\boldsymbol{m o d}, \mathbf{1}}$ - Fonte: NBR 7190/97 } \\
\hline \multirow{2}{*}{\multicolumn{2}{|c|}{$\begin{array}{c}\text { Classes de } \\
\text { carregamento }\end{array}$}} & \multirow{2}{*}{\multicolumn{2}{|c|}{$\begin{array}{l}\text { Ordem de grandeza da } \\
\text { duração acumulada da ação } \\
\text { variável característica }\end{array}$}} & \multicolumn{2}{|c|}{ Tipos de madeira } \\
\hline & & & & $\begin{array}{c}\text { Serrada, } \\
\text { Laminada colada } \\
\text { e compensada }\end{array}$ & Recomposta \\
\hline \multicolumn{2}{|c|}{ Permanente } & \multicolumn{2}{|c|}{ 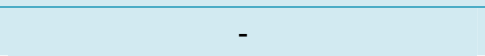 } & 0,60 & 0,30 \\
\hline \multicolumn{2}{|c|}{ Longa duração } & \multicolumn{2}{|c|}{ Mais de seis meses } & 0,70 & 0,45 \\
\hline \multicolumn{2}{|c|}{ M édia duração } & \multicolumn{2}{|c|}{ Uma semana a seis meses } & 0,85 & 0,65 \\
\hline \multicolumn{2}{|c|}{ Curta duração } & \multicolumn{2}{|c|}{ Menos de uma semana } & 1,00 & 1,00 \\
\hline \multicolumn{2}{|c|}{ Instantânea } & \multicolumn{2}{|c|}{ Muito curta } & 1,10 & 1,10 \\
\hline \multicolumn{6}{|c|}{ A Tabela 3.2 apresenta os valores do coeficiente de modificação parcial $k_{m o d, 2}$} \\
\hline \multicolumn{6}{|c|}{ Tabela3.2 - Valores de $\boldsymbol{k}_{\boldsymbol{m o d}, 2}$} \\
\hline \multirow[b]{2}{*}{$\begin{array}{l}\text { Classe de } \\
\text { umidade }\end{array}$} & \multirow{2}{*}{\multicolumn{2}{|c|}{$\begin{array}{l}\text { Umidade relativa } \\
\text { do ambiente } \mathbf{U}_{\mathrm{amb}}\end{array}$}} & \multirow[b]{2}{*}{$\begin{array}{l}\text { Umidade de } \\
\text { equilíbrio da } \\
\text { madeira }\end{array}$} & \multicolumn{2}{|c|}{ Tipo de madeira } \\
\hline & & & & $\begin{array}{c}\text { Serrada, } \\
\text { Laminada colada } \\
\text { e compensada }\end{array}$ & Recomposta \\
\hline 1 & & $\leq 65 \%$ & $12 \%$ & 1,0 & 1,0 \\
\hline 2 & $65 \%$ & $<\mathrm{U}_{\mathrm{amb}} \leq 75 \%$ & $15 \%$ & 1,0 & 1,0 \\
\hline 3 & $75 \%$ & $<\mathrm{U}_{\mathrm{amb}} \leq 85 \%$ & $18 \%$ & 0,8 & 0,9 \\
\hline 4 & & $a m b \geq 85 \%$ & $\geq 25 \%$ & 0,8 & 0,9 \\
\hline
\end{tabular}

A Tabela 3.3 apresenta os valores de $k_{\text {mod,3, }}$, que considera o uso de madeira de primeira ou segunda categoria. Para se classificar a madeira em primeira categoria deve-se fazer a classificação visual e a classificação mecânica normalizadas. Caso contrário ela deve ser enquadrada como de segunda categoria. Também deve ser observado que, para 
madeiras serradas de coníferas, o valor adotado deve ser de 0,8 devido aos defeitos não detectáveis, internos na peça.

\begin{tabular}{ccc}
\hline \multicolumn{3}{c}{ Tabela3.3 - Valores de $\boldsymbol{k}_{\boldsymbol{m o d}, 3}$} \\
\hline Espécie & Categoria & $\boldsymbol{k}_{\boldsymbol{m o d}_{3}}$ \\
\hline Dicotiledôneas & $1 \stackrel{0}{0}$ & 1,0 \\
Coníferas & $\underline{1}^{\circ}$ e $2^{\circ}$ & 0,8 \\
\hline
\end{tabular}

Na versão "draft" da NBR:7190 uma nova classificação é adotada, sendo que a esse coeficiente apresenta valores distintos para espécies sem classificação, com apenas classificação visual e com classificação visual e mecânica. Os novos coeficientes serão apresentados a título de conhecimento e não serão utilizados na pesquisa devido a versão draft ter disponibilizado-os após as análises de confiabilidade já terem sido realizadas. $\mathrm{Na}$ versão "draft", as coníferas sem classificação não devem ser empregadas estruturalmente e, para as folhosas ou dicotiledôneas sem classificação deve ser usado $k_{\text {mod,3 }}=0,7$. Quando as madeiras empregadas passam por uma classificação apenas visual ou visual e mecânica simultaneamente, deve serempregado um $k_{\text {mod,3 }}$ de acordo com a Tabela 3.4, para as coníferas, e de acordo com a Tabela 3.5, para as dicotiledôneas.

\begin{tabular}{cc|cc}
\hline \multicolumn{4}{c}{ Tabela 3.4 - Valores de $\boldsymbol{k}_{\text {mod,3 }}$ para coníferas } \\
\hline \multirow{2}{*}{ Classificação } & Classe & \multicolumn{2}{c}{ Tipo de classificação } \\
& Apenas visual & Visual e Mecânica \\
\hline \multirow{4}{*}{ Densa (D) } & SE-D & 0,70 & 0,90 \\
& S1-D & 0,60 & 0,80 \\
& S2-D & 0,50 & 0,70 \\
& S3-D & 0,40 & 0,60 \\
\hline \multirow{3}{*}{$\begin{array}{c}\text { Não-Densa } \\
\text { (ND) }\end{array}$} & SE-ND & 0,60 & 0,80 \\
& S1-ND & 0,50 & 0,70 \\
& S2-ND & 0,40 & 0,60 \\
& S3-ND & 0,30 & 0,50 \\
\hline
\end{tabular}

\begin{tabular}{|c|c|c|}
\hline \multicolumn{3}{|c|}{ Tabela 3.5 - Valores de $\boldsymbol{k}_{\boldsymbol{m o d}, 3}$ para dicotiledôneas } \\
\hline \multirow{2}{*}{ Classe } & \multicolumn{2}{|c|}{ Tipo de classificação } \\
\hline & Apenas visual & Visual e Mecânica \\
\hline SE & 0,90 & 1,00 \\
\hline S1 & 0,85 & 0,95 \\
\hline $\mathrm{S} 2$ & 0,80 & 0,90 \\
\hline S3 & 0,75 & 0,85 \\
\hline
\end{tabular}




\section{b. Fator de ponderação da resistência $\gamma_{w}$}

Conforme indicado na NBR:7190/97 o coeficiente ponderador $\gamma_{w}$ também é resultante do produto de três coeficientes parciais $\gamma_{w 1}, \gamma_{w 2}$, e $\gamma_{w 3}$, sendo que o primeiro coeficiente trata da variabilidade intrínseca do material dentro do lote analisado; 0 segundo leva em conta as diferenças anatômicas existentes entre o material empregado para confecção de corpos-de-prova e para utilização na estrutura; e o terceiro leva em consideração as imperfeições do modelo de cálculo adotado e os defeitos localizados no material estrutural.

No caso de elementos fletidos são usados dois valores diferentes para os coeficientes de ponderação da resistência, um referente à borda comprimida e outro à tracionada, como mostrado na Tabela 3.6. Deve ser salientado que a norma apresenta relações entre os valores de resistência características na tração e na compressão de forma que, aplicados os coeficientes de ponderação, os valores de resistência de projeto são iguais. Assim, na prática se tem sempre o uso do valor de projeto referente à compressão.

\begin{tabular}{cc}
\hline \multicolumn{2}{c}{ Tabela 3.6- Valores dos coeficientes $\gamma_{\boldsymbol{w}}$} \\
\hline $\begin{array}{c}\text { Tipo de esforço } \\
\text { resistente }\end{array}$ & Coeficiente $\boldsymbol{\gamma}_{\boldsymbol{w}}$ \\
\hline Compressão & 1,4 \\
Tração & 1,8 \\
\hline
\end{tabular}

\section{c. Resistência característica $f_{w k}$}

Como proposto no estudo de LAHR (1990), que serviu de parâmetro para a norma, apontando que os elementos de madeira possuem distribuição estatística normal e que 0 valor característico pode ser determinado pela equação 3-6, usando-se um coeficiente de variação de $18 \%$ para solicitações normais.

$$
f_{k}=f_{m} \cdot(1-1,645 \cdot 0,18)=0,70 \cdot f_{m}
$$




\section{OBTENÇÃO DE DADOS DISPONÍVEIS $\mid$ Capítulo 4}

O levantamento de dados focalizou duas propriedades de resistência da madeira: resistência na flexão e resistência na compressão paralela às fibras. Inicialmente, foram coletadosresultados de ensaios de flexão estática em vigas de madeira com dimensões estruturais, nos quais as peças foram levadas à ruptura, para várias espécies. Posteriormente, para essas mesmas espécies, foi catalogado, além da resistência à compressão, o desvio padrão das amostras, quando fornecido. Dessa forma, foi elaborado um banco de dados com informações necessárias para a análise de confiabilidade.

\subsection{ENSAIO DE FLEXÃO EM VIGAS COM DIMENSÕES ESTRUTURAIS}

Foi realizada uma busca em trabalhos e artigos científicos nacionais que enfocavam ensaios de flexão em vigas de madeira serrada. Os ensaios deveriam ser do tipo destrutivo, e os resultados apresentam as dimensões do elemento e a configuração de carregamento, possibilitando a obtenção da força de ruptura na viga.

Foram selecionadas 4 pesquisas que forneceram 17 grupos de resultados de ensaios em vigas fletidas, com 10 espécies diferentes dividida nesses grupos, resultando em 549 amostras para análise. Os trabalhos escolhidos foram:

- CARREIRA (2003), que forneceu 4 grupos de resultados com 96 amostras de ensaios de 2 espécies de pinus (consideradas de forma agrupada);

- FURIATI (1981), que forneceu 1 grupo de resultado com 38 amostras de ensaios de 1 espécie;

- MELO (1984), que forneceu 6 grupos de resultados com 207 amostras de ensaios de 6 espécies;

- DELLA LÚCIA (1975), que forneceu 6 grupos de resultados com 208 amostras de ensaios de 3 espécies. 
A Tabela 4.1 apresenta informações a respeito dos dados que foram utilizados neste trabalho: numeração dos grupos (de 1 a 17), espécie, a quantidade de ensaios realizados, dimensões nominais das peças, esquema de ensaio, e o autor da pesquisa.

A cada ensaio, corresponde um resultado para força de ruptura, que são mostrados no apêndice $A$.

Tabela4.1 - Resumo dos resultados dos ensaios

\begin{tabular}{|c|c|c|c|c|c|c|c|}
\hline \multirow[b]{2}{*}{ Grupo } & \multirow[b]{2}{*}{$\begin{array}{c}\text { Espécie } \\
\text { Nome Botânico }\end{array}$} & \multirow[b]{2}{*}{$\begin{array}{c}\text { Vigas } \\
\text { ensaiadas }\end{array}$} & \multicolumn{3}{|c|}{ Dimensões } & \multirow[b]{2}{*}{$\begin{array}{l}\text { Esquema } \\
\text { de ensaio }\end{array}$} & \multirow[b]{2}{*}{ Autor } \\
\hline & & & $\begin{array}{c}\text { b } \\
(\mathrm{cm})\end{array}$ & $\begin{array}{c}\mathrm{h} \\
(\mathrm{cm})\end{array}$ & $\begin{array}{c}\mathrm{L} \\
(\mathrm{cm})\end{array}$ & & \\
\hline 1 & $\begin{array}{c}\text { Andiroba } \\
\text { Carapa Guianensis Aubl. }\end{array}$ & 38 & 5,08 & 10,16 & 183 & Figura4.1 & (1) \\
\hline 2 & $\begin{array}{c}\text { Copaíba } \\
\text { Copaifera sp. }\end{array}$ & 34 & 5,08 & 10,16 & 183 & Figura4.1 & $(1)$ \\
\hline 3 & $\begin{array}{c}\text { Mururé } \\
\text { Brosimum acutifolium Huber. }\end{array}$ & 25 & 5,08 & 10,16 & 183 & Figura4.1 & (1) \\
\hline 4 & $\begin{array}{c}\text { Pau jacaré } \\
\text { Laetia Procera Eichl. }\end{array}$ & 36 & 5,08 & 10,16 & 183 & Figura4.1 & (1) \\
\hline 5 & $\begin{array}{l}\text { Tachi Preto } \\
\text { Tachigalia cf. myrmecophylla Ducke }\end{array}$ & 33 & 5,08 & 10,16 & 183 & Figura4.1 & (1) \\
\hline 6 & $\begin{array}{c}\text { Tauari } \\
\text { Couratari guianensis }\end{array}$ & 41 & 5,08 & 10,16 & 183 & Figura4.1 & (1) \\
\hline 7 & $\begin{array}{c}\text { Virola } \\
\text { Virola surinamensis }\end{array}$ & 34 & 5,08 & 10,16 & 183 & Figura4.1 & $(2)$ \\
\hline 8 & $\begin{array}{c}\text { Piquiá } \\
\text { Caryocar villosum pers. }\end{array}$ & 34 & 5,08 & 10,16 & 183 & Figura4.1 & $(2)$ \\
\hline 9 & $\begin{array}{l}\text { Tachi Preto } \\
\text { Tachigalia cf. myrmecophylla Ducke }\end{array}$ & 39 & 5,08 & 10,16 & 183 & Figura4.1 & $(2)$ \\
\hline 10 & $\begin{array}{l}\text { Virola } \\
\text { Virola surinamensis }\end{array}$ & 25 & 5,08 & 15,24 & 183 & Figura4.1 & $(2)$ \\
\hline 11 & $\begin{array}{c}\text { Piquiá } \\
\text { Caryocar villosum pers. }\end{array}$ & 35 & 5,08 & 15,24 & 183 & Figura4.1 & $(2)$ \\
\hline 12 & $\begin{array}{l}\text { Tachi Preto } \\
\text { Tachigalia cf. myrmecophylla Ducke }\end{array}$ & 41 & 5,08 & 15,24 & 183 & Figura4.1 & (2) \\
\hline 13 & $\begin{array}{c}\text { PinusElliotti/Taeda } \\
\text { Pinus elliottii var. elliottii/Taeda L. }\end{array}$ & 24 & 3,50 & 12,50 & 240 & Figura4.1 & (3) \\
\hline 14 & $\begin{array}{c}\text { PinusElliotti/Taeda } \\
\text { Pinus elliottii var. elliottii/Taeda L. }\end{array}$ & 24 & 3,50 & 12,50 & 240 & Figura4.1 & (3) \\
\hline 15 & $\begin{array}{c}\text { PinusElliotti/Taeda } \\
\text { Pinus elliottii var. elliottii/Taeda L. }\end{array}$ & 24 & 3,50 & 12,50 & 240 & Figura4.1 & (3) \\
\hline 16 & $\begin{array}{c}\text { PinusElliotti/Taeda } \\
\text { Pinus elliottii var. elliottii/Taeda L. }\end{array}$ & 24 & 3,50 & 12,50 & 240 & Figura4.1 & (3) \\
\hline 17 & $\begin{array}{c}\text { Peroba Rosa } \\
\text { AspidospermapolyneuronM üll. Arg. }\end{array}$ & 38 & 16,0 & 6,00 & 100 & Figura4.2 & (4) \\
\hline
\end{tabular}


Os grupos de resultados apresentaram somente dois tipos de configuração de carregamento. A primeira configuração, mais frequente, constitui-se em forças aplicadas nos terços do vão livre da viga, conforme mostrado na Figura 4.1, resultando numa flexão pura no trecho central, sem a influência dos esforços cisalhantes,e onde a peça supostamente deve romper. Essa configuração foi encontrada nos ensaios dos grupos 1 a 16. A segunda configuração adotada foi a de força aplicada no meio do vão, conforme Figura 4.2, gerando um diagrama de momento com esforço máximo também no meio do vão, mas triangular. Esse tipo de configuração foi adotada nos ensaios das vigas do grupo 17.

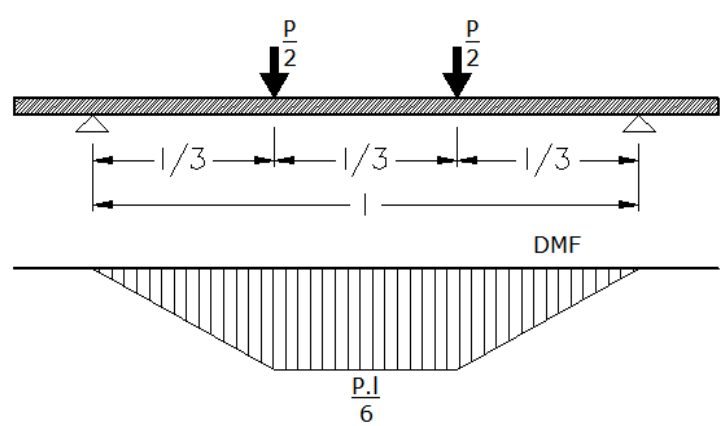

Figura4.1 - Ensaio de forças nos terços do vão.

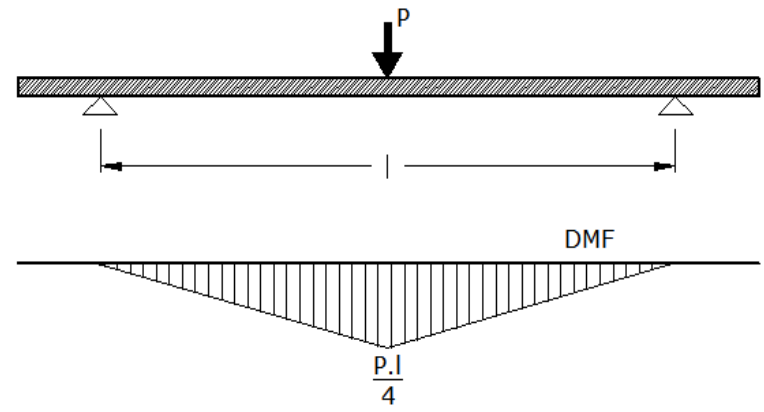

Figura4.2 - Ensaio de força no meio do vão.

É importante salientar que, para alguns casos, foi necessário calcular o valor da força de ruptura, a partir dos valores de tensão de ruptura fornecidos, que foram calculados pelos autores considerando a hipótese de distribuição linear de tensões até a ruptura. Alguns valores tiveram que ser transformados para o Sistema Internacional de Unidades; nesses casos foi considerado $\mathrm{g}=10 \mathrm{~m} / \mathrm{s}^{2}$.

A grande maioria dos ensaios foi conduzida com a flexão ocorrendo em relação ao eixo de maior inércia, com exceção das amostras do grupo 17. Todas as vigas ensaiadas possuíam seção retangular, cujas dimensões são mostradas na Tabela 4.1, sendo b a base e $h$ a altura.

Dentre os grupos de resultados, quatro apresentavam dados de coníferas (grupos 13, 14, 15 e 16), e os demais eram compostos de dicotiledôneas (folhosas).

As coníferas foram encontradas no trabalho de CARREIRA (2003) e as duas espécies foram consideradas de forma agrupada. Foi realizada uma classificação visual prévia que separou as peças nos quatro grupos apontados na Tabela 4.1, considerando a densidade da 
madeira (densa e não densa) avaliada pela quantidade de anéis de crescimento, e a quantidade de defeitos (№3, №2, №1 e SS).

Quanto menos defeitos (SS) e maior densidade (D), maior será a resistência esperada e o módulo de elasticidade do lote. Tendo em vista que a norma NBR 7190/97 passa por

processo de atualização e que parâmetros de classificação visual estão sendo inseridos no seu escopo, a análise de confiabilidade realizada em cada grupo permitirá dizer o quanto essa inspeção visual foi benéfica para o modelo de flexão, e o quanto ela pode influenciar na decisão do tipo de material a se empregar.

\subsection{RESISTÊNCIA À COM PRESSÃO PARALELA ÀS FIBRAS}

Para as espécies abordadas no item anterior, também foram obtidos dados relacionados à resistência à compressão paralela às fibras, importantes para a análise de confiabilidade, tais como valores médios e coeficiente de variação da resistência à compressão paralela às fibras. Esses dados foram coletados em vários artigos e trabalhos tecnológicos e científicos e em banco de dados de órgãos governamentais que tratam desse estudo.

A busca específica por esta propriedade se dá pela sua utilização no modelo de verificação da segurança de peças fletidas, sendo esta propriedade empregada no dimensionamento de vigas fletidas.

Os valores característicos de resistência, a serem usados em projetos,podem ser determinados a partir de informações estatísticas como o valor médio $(\mu)$, o desvio padrão ( $\sigma$ ) e tipo de distribuição da resistência. A norma,no caso da falta de valores experimentais efetivos para a determinação das informações estatísticas, assume que todas as resistências possuam distribuição Normal, sendoque,para elementos que resistam aesforços normais 0 valor do coeficiente de variação (CV) pode ser adotado como 18\% e, para elementos que resistam a esforços tangenciais, podemos adotar um coeficiente de $28 \%$. Esses dados foram admitidos com base no estudo desenvolvido por LAHR (1990) e FUSCO (1977).

Outra relevância desta etapa é a necessidade de incluir esses dados nas análises de confiabilidade, que foi feita via método aproximado FORM (First Order Reliability Method). 
Este método aproximado de confiabilidade, para fornecer bons resultados, necessita das informações estatísticas citadas (média, desvio-padrão e tipo de distribuição. Assim a obtenção destes dados é de importância ímpar, devendo, na sua falta, serem utilizados valores fornecidos pela norma.

Outras informações importantes, como o tipo de distribuição com maior adequação aos valores da resistênciaa compressão e as correlações entre as variáveis do problema, se mostraram escassos na literatura nacional. Portanto, seguindo recomendações da norma, foi adotada a distribuição normal como representativa da resistência e não foi consideradanenhuma correlação entre as variáveis do problema, pois os dados encontrados não se enquadravam para a realidade local.

A pesquisa revelou várias informações a respeito do valor médio da resistência à compressão, sendo que a maioria dos estudos apresentava diferenças nos valores dessa resistência para a mesma espécie. Assim, um procedimento estatístico foi adotado para a determinação de um valor médio único para cada espécie que pudesse ser utilizado no decorrer deste trabalho.

Para a determinação de valores médios da resistência à compressão $\left(\mu_{\mathrm{fco}}\right)$ foi adotada a média de todos os resultados encontrados para a espécie. Quando foram encontrados 5 valores de resistência média à compressão paralela, em 5 pesquisas diferentes, o valor adotado foi a média desses 5 resultados.

Algumas pesquisas também forneciam o número de amostras ensaiadas para a obtenção do valor médio. Quando isso ocorria, o valor médio final da resistência à compressão da espécie foi definido por meio de média ponderada.

Para o desvio-padrão, foi feito um procedimento semelhante, para a definição de um valor único de desvio da espécie $\left(\bar{\sigma}_{\mathrm{fco}}\right)$. Quando havia vários valores, a equação de ponderação estatística 4-1 foi empregada.

$$
\bar{\sigma}_{f_{c 0}}=\sqrt{\frac{{\overline{\sigma_{1}}}^{2} \cdot\left(n_{1}-1\right)+\bar{\sigma}_{2}{ }^{2} \cdot\left(n_{2}-1\right)+\cdots+\bar{\sigma}_{i}{ }^{2} \cdot\left(n_{i}-1\right)}{\left(n_{1}-1\right)+\left(n_{2}-1\right)+\cdots+\left(n_{i}-1\right)}}
$$


Mesmo com a grande quantidade de resultados, alguns grupos não apresentaram valores para a determinação dos parâmetros estatísticos. Para os grupos de resultados 4, 7 e 10 foram adotadas recomendações de norma para se determinar o coeficiente de variação (CV). A Tabela 4.2 apresenta de forma resumida as informaçõesestatísticas obtidas nessa etapa para cada grupo de resultados, todos os grupos possuem distribuição do tipo Normal.

\begin{tabular}{|c|c|c|c|c|}
\hline Grupo & Espécie & $\mu_{\mathrm{fco}}(\mathrm{MPa})$ & $\bar{\sigma}_{\mathrm{fc} 0}(\mathrm{MPa})$ & CV (\%) \\
\hline 1 & Andiroba & 57,39 & 7,25 & 12,64 \\
\hline 2 & Copaíba & 52,35 & 6,77 & 12,93 \\
\hline 3 & Mururé & 62,06 & 4,94 & 7,95 \\
\hline 4 & Pau jacaré & 67,02 & $12,06 *$ & 18,00 \\
\hline 5 & Tachi Preto & 60,47 & 9,74 & 16,11 \\
\hline 6 & Tauari & 55,31 & 7,37 & 13,32 \\
\hline 7 & Virola & 34,72 & $6,25 *$ & 18,00 \\
\hline 8 & Piquiá & 46,94 & 6,43 & 13,70 \\
\hline 9 & Tachi Preto & 60,47 & 9,74 & 16,11 \\
\hline 10 & Virola & 34,72 & $6,25 *$ & 18,00 \\
\hline 11 & Piquiá & 46,94 & 6,43 & 13,70 \\
\hline 12 & Tachi Preto & 60,47 & 9,74 & 16,11 \\
\hline 13 & Pinus Elliotti & 35,86 & 8,23 & 22,95 \\
\hline 14 & Pinus Elliotti & 35,86 & 8,23 & 22,95 \\
\hline 15 & Pinus Elliotti & 35,86 & 8,23 & 22,95 \\
\hline 16 & Pinus Elliotti & 35,86 & 8,23 & 22,95 \\
\hline 17 & Peroba Rosa & 38,68 & 4,25 & 10,99 \\
\hline \multicolumn{5}{|c|}{ * Valores obtidos de acordo com a recomendação da norma } \\
\hline
\end{tabular}




\section{ANÁLSE DE ERRO DE MODELO $\mid$ Capítulo 5}

O erro de modelo é uma medida que serve para avaliar o quanto os modelos teóricos de previsão da resistência de um elemento estrutural diferem dos valores experimentais dessa mesma resistência.

Nas análises de confiabilidade o erro de modelo serve para identificar o quanto a resistência experimental, obtida em vários ensaios, oscila em torno de um valor padrão determinado por equações analíticas normativas, propostas com base na teoria da resistência dos materiais e com simplificações especificas de cada material estrutural. Essa oscilação servirá para concluir se o modelo proposto é conservador ou não em relação ao valor experimental, fixado como o verdadeiro valor da resistência do elemento.

Esse valor do erro de modelo deve ser usado nas análises de confiabilidade como uma variável aleatória do problema de segurança estrutural. Após definir-se o seu valor, a sua inclusão nas análises de confiabilidade ajudará a verificar o impacto no índice de confiabilidade, aumentando o índice de segurança no caso de modelos conservadores, ou diminuindo, no caso de modelos não conservadores.

Na pesquisa realizada, o erro de modelo $(E M)$ foi determinado para o caso de peças de madeira submetidas à flexão. Foram coletados valores experimentais laboratoriais de ruptura à flexão de vigas de madeira já apresentados no capítulo 4 e comparados com os valores teóricos para cada configuração de seção transversal encontrada. Os valores teóricos foram determinados pela equação normativa para elementos estruturais de madeira sob flexão com algumas providencias que serão comentadas a seguir.

Para a sua incorporação nas análises de confiabilidade, foi necessário obter informações estatísticas, tais como o valor médio, coeficiente de variação e tipo de 
distribuição da variável, e corrigir as incertezas do modelo. Essa variável foi calculada para todos os 17 grupos apresentados no capítulo 4. Nas análises estatísticas foi utilizado 0 programa Easy Fit $5.2 \circledR$ como ferramenta auxiliar para obtenção das informações necessárias.

\subsection{EQUACIONAM ENTO DO ERRO DE MODELO (EM)}

Os valores de erro de modelo são obtidos individualmente, para cada ensaio realizado, bastando realizar o dimensionamento de cada elemento ensaiado através das equações disponíveis, levando-se em conta algumas adaptações necessárias. A razão entre a resistência de cada amostra $\left(R_{\text {exp. }}\right)$ e a resistência teórica $\left(R_{\text {teo. }}\right)$ é o erro de modelo (equação 5-1).

$$
E M=\frac{R_{\text {exp }}}{R_{\text {teo }}}
$$

Os valores de $R_{\text {exp. }}$ estão apresentados no apêndice A deste trabalho, e são referentes aos valores das forças de ruptura de cada peça testada. Em cada grupo de resultado, os testes foram conduzidos de forma padronizada (dimensões, vinculações de apoio e configuração de carregamento), o que permitiu utilizar apenas um valor teórico para a força de ruptura $\left(R_{t e o}\right)$.

Como exemplo iremos avaliar o grupo 5, as 33 vigas ensaiadas deste grupo possuíam dimensões e modelo de ensaios conforme indicados na Tabela 4.1, assim, na determinação da força de ruptura, essas dimensões e o modelo estrutural foram adotados de forma única para se obter o valor da força e, com essa força, pôde-se determinar o erro de modelo para cada um dos 33 ensaios através da equação 5-1, com $R_{\text {teo., }}$ como um valor fixo por grupo e $R_{\text {exp. }}$, sendo representado por cada um dos 33 ensaios desse mesmo grupo.

Para se determinar o valor teórico da força de ruptura via modelo teórico, ou $R_{\text {teo.' }}$ foram utilizadas as equações mostradas nas etapas de cálculo do item a seguir. 


\subsection{EQUAÇÕES PARA VERIFICAÇÃO DAS TENSÕES NORMAIS NA FLEXÃO}

As equações para verificação da segurança à flexão, já apresentadas no capítulo 3 (32 e 3-3), podem ser expandidas, permitindo determinar a máxima força que os elementos ensaiados suportariam.

0 processo será apresentado para os dois modelos estáticos encontrados nos ensaios.Assim as equações 3-2 e 3-3 têm suas parcelas escritas como visto nas equações5-2 e 5-3 para o caso de forças nos terços do vão (grupos 1 ao 16), e no meio do vão (grupo 17), respectivamente.

$$
\begin{gathered}
\frac{\gamma_{f} \cdot P \cdot L}{b \cdot h^{2}} \leq k_{\text {mod }} \cdot \frac{f_{w k}}{\gamma_{w}} \\
\frac{6 \cdot \gamma_{f} \cdot P \cdot L}{4 \cdot b \cdot h^{2}} \leq k_{\text {mod }} \cdot \frac{f_{w k}}{\gamma_{w}}
\end{gathered}
$$

Introduzindo as peculiaridades da resistência de cada grupo nas equações 5-2 e 5-3, como a resistência média da espécie, e isolando a variável $P$, obtem-se 0 valor máximo da força de ruptura que cada grupo pode suportar na flexão. A equação 5-4 se aplica aos grupos 1 ao 16 e a equação 5-5 se aplica ao grupo 17.

$$
\begin{gathered}
P \leq k_{\text {mod }} \cdot \frac{0,70 \cdot f_{c 0, m} \cdot b \cdot h^{2}}{\gamma_{w} \cdot \gamma_{f} \cdot L} \\
P \leq k_{\text {mod }} \cdot \frac{4 \cdot 0,70 \cdot f_{c 0, m} \cdot b \cdot h^{2}}{6 \cdot \gamma_{w} \cdot \gamma_{f} \cdot L}
\end{gathered}
$$

Como recomenda a norma, a verificação da segurança à flexão deve ser feita para a borda tracionada e a borda comprimida. É importante observar que, para o equacionamento feito se adequar ao documento normativo, é preciso introduzir os respectivos coeficientes ponderadores para cada caso nas equações 5-4 e 5-5.

A norma recomenda que para a verificação de bordas tracionadas, o valor da resistência à tração seja considerado como sendo igual ao valor da resistência à compressão dividida por 0,77 , o que conduz a valores de resistência de cálculo iguais para tração e compressão. A lista abaixo resume as equações e informações apresentadas. 


\begin{tabular}{|c|c|c|c|}
\hline \multicolumn{4}{|c|}{ Para forças nos terços do vão (grupos 1 a 16) } \\
\hline \multicolumn{2}{|c|}{ Borda comprimida (BC) } & \multicolumn{2}{|c|}{ Borda tracionada (BT) } \\
\hline \multirow{2}{*}{$P \leq \boldsymbol{k}_{\text {mod }}$} & $0,70 \cdot f_{c 0, m} \cdot b \cdot h^{2}$ & \multirow{2}{*}{$P \leq k_{m o d}$} & $0,70 \cdot f_{c 0, m} / 0,77 \cdot b \cdot h^{2}$ \\
\hline & $1,4 \cdot \gamma_{f} \cdot L$ & & $\overline{1,8 \cdot \gamma_{f} \cdot L}$ \\
\hline \multicolumn{4}{|c|}{ Para força no meio do vão (grupo 17) } \\
\hline \multicolumn{2}{|c|}{ Borda comprimida (BC) } & \multicolumn{2}{|c|}{ Borda tracionada (BT) } \\
\hline \multirow{2}{*}{$P \leq \boldsymbol{k}_{\text {mod }}$} & $4 \cdot 0,70 \cdot f_{c 0, m} \cdot b \cdot h^{2}$ & \multirow{2}{*}{$P \leq k_{\bmod }$} & $\cdot 0,70 \cdot f_{c 0, m} / 0,77 \cdot b \cdot h^{2}$ \\
\hline & $6 \cdot 1,4 \cdot \gamma_{f} \cdot L$ & & $6 \cdot 1,8 \cdot \gamma_{f} \cdot L$ \\
\hline
\end{tabular}

\subsubsection{PROCEDIMENTOS ADOTADOS NA VERIFICAÇÃO DA RESISTÊNCIA TEÓRICA}

Para determinar o erro de modelo foi necessário adotar algumas providências,como o uso de valores médios da resistência à compressão da espécie, apresentados no capítulo 3, e coeficientes ponderadores com valores unitários no dimensionamento empregado para $R_{\text {teo }}$.

A adoção dessas providências é necessária para evitar que uma margem de segurança seja incorporada, e assim, permitir uma comparação adequada entre a força de ruptura teórica e a força de ruptura obtida nos ensaios.

É interessante salientar que a situação ideal seria encontrar, no levantamento feito, ensaios com vigas e depois com corpos de prova do mesmo lote. Entretanto, em alguns casos foram obtidos apenas os ensaios em vigas, sem ter sido feita uma caracterização da espécie usada pelo pesquisador.

Outro aspecto a ser salientado é com relação às equações de norma, tendo em vista que o critério de dimensionamento na flexão especifica as verificações das bordas tracionada e comprimida. Nas análises de erro de modelo, só foi considerada a força teórica proveniente da verificação da borda comprimida, pois as tensões atuantes de tração e de compressão possuem o mesmo valor, e a resistência da madeira na tração é superior ao da compressão (ambas sem os coeficientes de minoração). Caso fosse verificada a borda tracionada, de acordo com os critérios da norma NBR 7190/97, mas sem os coeficientes de ponderação, resultaria em um valor teórico da força de ruptura superior, o que não teria 
sentido, pois a ruptura já teria ocorrido por compressão, de acordo com o modelo teórico da norma.

$$
\begin{gathered}
P \leq k_{\text {mod }} \cdot \frac{f_{c 0, m} \cdot b \cdot h^{2}}{1,0 \cdot L} \\
P \leq k_{\text {mod }} \cdot \frac{4 \cdot f_{c 0, m} \cdot b \cdot h^{2}}{6 \cdot 1,0 \cdot L}
\end{gathered}
$$

\subsubsection{DETERM INAÇÃO DOS $\mathrm{k}_{\bmod }$}

0 valor do coeficiente de modificação empregado para a obtenção das forças foi determinado conforme as recomendações apresentadas no capítulo 3, transcritas e comentadas da NBR 7190/97.

Para a determinação do $k_{m o d, 1}$ foi levado em conta que todas as peças ensaiadas eram de madeira serrada e a ação variável principal foi enquadrada na classe de duração instantânea, pois os ensaios realizados duravam poucos minutos até a ruptura, assim o valor adotado para o coeficiente de todos os grupos de resultados foi de 1,10.

Para $k_{m o d, 2}$ a umidade das vigas ensaiadas se enquadravam, na sua totalidade, nas classes 1 e 2, o que nos permite adotar apenas um valor geral para o uso do coeficiente de modificação no dimensionamento, pois como as madeiras utilizadas para todos os grupos de resultado foram do tipo serrada o valor é igual para as duas classes de umidade, sendo então adotado 1,0 para todas as análises.

$0 k_{\text {mod,3 }}$ de todos os casos foi 0,8 , pois a maioria das viga não passou por uma inspeção visual e as que passaram eram coníferas, fato este que leva a norma a recomendar o uso de tal valor, assim o valor do coeficiente para todos os caso foi igual.

Tendo em vista que os coeficientes podem ser empregados igualmente para todos os casos, o valor da força de ruptura de todos os grupos de resultado foi determinado utilizando-se um coeficiente de modificação igual à $k_{\bmod }=1,0 \cdot 1,1 \cdot 0,8=0,88$. 


\subsubsection{ESTIMATIVA DA FORÇA DE RUPTURA}

Aplicando-se os valores das propriedades físicas e geométricas dos materiais de cada grupo de resultado nas equações 5-6 e 5-7, pode-se determinar a força máxima que cada viga suporta $\left(P_{t e o}\right)$ segundo o modelo de flexão da NBR 7190/97.

Os valores das propriedades, físicas como o $f_{c 0, m}$ de cada espécie, e os valores das propriedades geométricas, como dimensões $(b, h)$ e 0 vão $(L)$ da viga, foram apresentados na Tabela 4.1. Com esses dados e juntamente com as recomendações de norma e as simplificações necessárias do modelo, foram obtidos os dados mostrados na Tabela 5.1, que resume os valores das forças teóricas de ruptura para cada grupo de resultado.

Com as forças de ruptura $P_{\text {teo }}$ de cada grupo podem ser feitas as análises de erro de modelo e de confiabilidade, sendo esta última um assunto para os capítulos que seguem.

\begin{tabular}{ccc}
\hline \multicolumn{3}{c}{ Tabela 5.1 - Valores das forças } \\
\hline Grupo & Espécie & $\mathbf{P}_{\text {teo }}(\mathbf{k N})$ \\
\hline 1 & Andiroba & 14,48 \\
\hline 2 & Copaíba & 13,21 \\
3 & Mururé & 15,66 \\
4 & Pau jacaré & 16,91 \\
\hline 5 & Tachi Preto & 15,26 \\
6 & Tauari & 13,96 \\
\hline 7 & Virola & 8,76 \\
8 & Piquiá & 11,84 \\
\hline 9 & Tachi Preto & 15,26 \\
10 & Virola & 19,71 \\
\hline 11 & Piquiá & 26,65 \\
12 & Tachi Preto & 34,33 \\
\hline 13 & Pinus Elliotti & 7,19 \\
14 & Pinus Elliotti & 7,19 \\
\hline 15 & Pinus Elliotti & 7,19 \\
\hline 16 & Pinus Elliotti & 7,19 \\
\hline 17 & Peroba Rosa & 13,07 \\
\hline
\end{tabular}

\subsection{VALORES DE ERRO DE MODELO E ANÁLISE ESTATÍSTICA}

Os valores de erro de modelo para cada grupo de resultados foram determinados pela equação 5-1, onde a resistência teórica $\left(R_{t e o}\right)$ é definida como o próprio valor da força de ruptura $P_{\text {teo }}$, que teve sua definição descrita nos tópicos acima, e os valores 
experimentais das forças de ruptura $\left(R_{\text {exp }}\right)$ para cada viga ensaiada de cada grupo, são apresentados no apêndice $A$.

O número de ensaios de vigas nos grupos determinou o número de valores do erro de modelo para cada grupo. Para cada grupo de resultados, foi realizada uma análise estatística obtendo-se o valor médio, o desvio padrão e o tipo de distribuição que melhor se ajusta aos valores. Um modelo ideal deveria apresentar valor unitário da média e nulo do desvio, correspondendo a um equacionamento sem tendenciosidades e com certeza absoluta de acerto na previsão da força, representando um modelo que refletiria com $100 \%$ de fidelidade a realidade das estruturas.

A escolha do tipo de distribuição foi feita através de análise no programa EasyFit 5.2 que permite montar histogramas e definir parâmetros estatísticos das distribuições disponíveis. A escolha da distribuição foi baseada nos resultados dos índices de significância obtidos e nos testes de hipóteses feitos para cada um dos três métodos utilizados no programa, Kolmogorov-Smirnov, Anderson-Darling e Chi-Squared. A Tabela 5.2 apresenta todos os parâmetros e distribuições obtidas para cada grupo de resultados do erro de modelo.

\begin{tabular}{cccccc}
\hline \multicolumn{5}{c}{ Tabela 5.2 - Informações estatística do erro de modelo } \\
\hline \multirow{2}{*}{ Grupo } & \multirow{2}{*}{ Espécie } & \multicolumn{4}{c}{ Parâmetros estatísticos } \\
\cline { 3 - 5 } & & Distribuição & $\boldsymbol{\mu}_{\text {EM }}$ & $\overline{\boldsymbol{\sigma}}_{\mathbf{E M}}$ & $\mathbf{C V}_{\text {EM }}(\%)$ \\
\hline 1 & Andiroba & Normal & 1,759 & 0,426 & 24,24 \\
2 & Copaíba & Cauchy & 1,032 & 0,212 & 20,58 \\
3 & M ururé & Normal & 1,217 & 0,330 & 27,08 \\
4 & Pau jacaré & Normal & 1,595 & 0,350 & 21,95 \\
5 & Tachi Preto & Weibull M in. & 1,522 & 0,331 & 21,73 \\
6 & Tauari & Normal & 1,683 & 0,227 & 13,47 \\
7 & Virola & Normal & 1,349 & 0,302 & 22,37 \\
8 & Piquiá & Normal & 2,220 & 0,390 & 17,57 \\
9 & Tachi Preto & Normal & 1,404 & 0,329 & 23,41 \\
10 & Virola & Normal & 1,270 & 0,253 & 19,88 \\
11 & Piquiá & Normal & 2,068 & 0,294 & 14,21 \\
12 & Tachi Preto & Normal & 1,449 & 0,281 & 19,36 \\
13 & Pinus Elliotti & Normal & 1,623 & 0,650 & 40,03 \\
14 & Pinus Elliotti & Normal & 2,371 & 1,071 & 45,17 \\
15 & Pinus Elliotti & Normal & 4,015 & 1,105 & 27,51 \\
16 & Pinus Elliotti & Normal & 5,260 & 1,625 & 30,90 \\
17 & Peroba Rosa & Normal & 2,579 & 0,545 & 21,13 \\
\hline
\end{tabular}


Os parâmetros estatísticos escolhidos para se analisar, o fator de tendenciosidade ou média do erro de modelo e o desvio padrão, tem significativa importância para o restante da pesquisa devido à informação que cada um introduz nas análises de confiabilidade.

0 fator de tendenciosidade nada mais é que o valor médio, a média aritmética, do erro de modelo de cada grupo de resultado. Ele avalia a tendência do modelo normativo (se é conservador ou não) e o seu estudo é importante pelo fato do mesmo ser um parâmetro corretivo do modelo analítico normativo, pois ele pode ser utilizado nas equações que previram a força de ruptura como fator corretor das resistências.

Como pode ser visto nos resultados da Tabela 5.2, a equação de norma para flexão representa um modelo conservador para todos os casos analisados, mostrando que 0 valor encontrado através do dimensionamento é menor do que o valor encontrado no ensaio experimental, adotado como representativo da real resistência da madeira à flexão.

Ainda analisando a Tabela 5.2, no caso dos grupos 14, 15 e 16, todos compostos por espécies de Pinus, esse conservadorismo se mostra ainda mais evidente quando uma classificação das peças é realizada, pois cada grupo apresenta uma espécie de Pinus melhorada em relação a anterior devido a classificação imposta e a divisão por grupos realizada, aumentando sua resistência pela menor presença de defeitos. Isto evidencia que uma inspeção visual dos Pinus resultou em aumento da resistência, pois o modelo foi muito conservador as madeiras classificadas e não era preciso tanto conservadorismo.

Outro parâmetro estatístico levantado no estudo e introduzido nas análises foi o desvio padrão. Ele retrata a oscilação dos valores do erro de modelo em torno da média. No caso das madeiras, esse valor geralmente é alto quando comparado com outros materiais.

Os valores de desvio padrão de cada espécie foram obtidos na etapa de levantamento de dados. Sendo assim fica fácil de determinar a quantidade de incerteza existente em cada grupo de madeira utilizado. A importância desta informação é observada no momento de determinarmos as incertezas referentes ao modelo analítico, pois o desviopadrão do erro de modelo levantado nesta pesquisa é resultado da união das incertezas do material e do modelo, e como o nosso interesse é que o erro de modelo reflita somente as 
incertezas do modelo de cálculo, basta efetuar o procedimento estatístico descrito no tópico a seguir, para se determinar a parcela de incerteza referente somente ao modelo de cálculo.

\subsection{CORREÇÃO DAS INCERTEZAS DOS ERROS DE M ODELO}

A incerteza do modelo é representada através do desvio-padrão apresentado na Tabela 5.2. Esse desvio, na forma que foi obtido, reflete as incertezas que são encontradas tanto no material usado quanto no modelo de cálculo empregado (Equação 5-8). Como 0 desvio padrão do erro de modelo aqui proposto pretende apresentar valores que reflitam somente a incerteza do modelo de cálculo, uma correção dos desvios foi realizada a fim denão consideraras incertezas referentes ao material empregado, deixando somente as incertezas do modelo de cálculo como a representativa do erro de modelo.

Esse procedimento tem como principal argumento para o seu emprego o fato de, nas análises de confiabilidade, a incerteza do material ser empregada duplicadamente caso não seja efetuada esta correção, invalidando os resultados devido ao aumento da variação dos índices de confiabilidade, pois a variável aleatória "material" também introduz essa informação através do valor do seu desvio-padrão e a variável "erro de modelo" também o incluiria, como pode ser visto na equação 5-8.

$$
\bar{\sigma}_{E M}=\bar{\sigma}_{M a t}+\bar{\sigma}_{M o d}
$$

A correção dos desvios pode ser feita pela equação de propagação de erros proveniente da estatística, como temos os valores dos desvios do erro de modelo e do material empregado, a equação 5-8 deve se transformar na 5-9 para que esse artifício seja utilizado.

$$
\bar{\sigma}_{E M}^{2}=\bar{\sigma}_{M a t}^{2}+\bar{\sigma}_{M o d}^{2}
$$

Porém, uma correção de dimensão deve ser efetuada. 0 desvio padrão do erro de modelo apresenta-se de forma adimensional e o desvio da resistência dos materiais, apresentado na Tabela 4.2, com os valores em Mega Pascal (MPa). Assim, o valor dos desvios da resistência dos materiais foi corrigido em função da resistência característica, tornando-se adimensional e então podendo ser comparado com o desvio padrão do erro de modelo. A resistência característica foi determinada pela equação 3-6, utilizando as 
informações provenientes do levantamento de dados para o valor do coeficiente de variação, podendo ser reescrita na forma da equação 5-10.

$$
f_{c 0, k}=f_{c 0, m}-1,645 \cdot(1-C V)
$$

Com o valor característico da resistência e o coeficiente de variação determinados para cada espécie a adimensionalização dos parâmetros estatísticos da resistência pode ser feita pelas equações 5-11 e 5-12.

$$
\begin{gathered}
\mu_{a d m}=\frac{\mu_{f c 0, m}}{\mu_{f c 0, k}} \\
\bar{\sigma}_{a d m}=\mu_{a d m} \cdot C V
\end{gathered}
$$

Substituindo esses valores na equação 5-9, aonde $\bar{\sigma}_{a d m}$ representa 0 desvio dos materiais, $\bar{\sigma}_{\text {Mat }}$, obtemos os desvios corrigidos do erro de modelo, referente somente ao modelo analítico.

A Tabela 5.3 apresenta os mesmo valores da Tabela 5.2 juntamente com os

\begin{tabular}{|c|c|c|c|c|c|c|c|c|}
\hline Grupo & Espécie & $\begin{array}{c}\mu_{\mathrm{fcO}} \\
(\mathrm{MPa})\end{array}$ & $\begin{array}{c}\bar{\sigma}_{\mathrm{fc} 0} \\
(\mathrm{MPa})\end{array}$ & $\begin{array}{c}\mathbf{f}_{\mathrm{co}, \mathrm{k}} \\
(\mathrm{MPa})\end{array}$ & $\begin{array}{c}\mu_{\mathrm{fc} 0} \\
(\mathrm{Adm})\end{array}$ & $\begin{array}{c}\bar{\sigma}_{\mathrm{fc} 0} \\
(\mathrm{Adm})\end{array}$ & $\overline{\boldsymbol{\sigma}}_{\mathrm{EM}}$ & $\overline{\boldsymbol{\sigma}}_{\text {mod }}$ \\
\hline 1 & Andiroba & 57,39 & 7,25 & 45,46 & 1,262 & 0,160 & 0,426 & 0,395 \\
\hline 2 & Copaíba & 52,35 & 6,77 & 42,20 & 1,241 & 0,146 & 0,212 & 0,154 \\
\hline 3 & M ururé & 62,06 & 4,94 & 53,94 & 1,151 & 0,092 & 0,330 & 0,317 \\
\hline 4 & Pau jacaré & 67,02 & 12,06 & 47,18 & 1,421 & 0,256 & 0,350 & 0,239 \\
\hline 5 & Tachi Preto & 60,47 & 9,74 & 44,45 & 1,360 & 0,219 & 0,331 & 0,248 \\
\hline 6 & Tauari & 55,31 & 7,37 & 43,98 & 1,258 & 0,157 & 0,227 & 0,164 \\
\hline 7 & Virola & 34,72 & 6,25 & 24,44 & 1,421 & 0,256 & 0,302 & 0,160 \\
\hline 8 & Piquiá & 46,94 & 6,43 & 36,36 & 1,291 & 0,177 & 0,390 & 0,348 \\
\hline 9 & Tachi Preto & 60,47 & 9,74 & 44,45 & 1,360 & 0,219 & 0,329 & 0,245 \\
\hline 10 & Virola & 34,72 & 6,25 & 24,44 & 1,421 & 0,256 & 0,253 & - \\
\hline 11 & Piquiá & 46,94 & 6,43 & 36,36 & 1,291 & 0,177 & 0,294 & 0,235 \\
\hline 12 & Tachi Preto & 60,47 & 9,74 & 44,45 & 1,360 & 0,219 & 0,281 & 0,175 \\
\hline 13 & Pinus Elliotti & 35,86 & 8,23 & 22,68 & 1,581 & 0,353 & 0,650 & 0,546 \\
\hline 14 & Pinus Elliotti & 35,86 & 8,23 & 22,68 & 1,581 & 0,353 & 1,071 & 1,011 \\
\hline 15 & Pinus Elliotti & 35,86 & 8,23 & 22,68 & 1,581 & 0,353 & 1,105 & 1,047 \\
\hline 16 & Pinus Elliotti & 35,86 & 8,23 & 22,68 & 1,581 & 0,353 & 1,625 & 1,587 \\
\hline 17 & Peroba Rosa & 38,68 & 4,25 & 31,69 & 1,221 & 0,134 & 0,545 & 0,528 \\
\hline
\end{tabular}
parâmetros da resistência adimensionalizados encontrados para se realizar o procedimento e as novas informações do desvio padrão do erro de modelo para cada grupo de resultado. 
A espécie do grupo de resultados 10 não pode ter o desvio corrigido, ficando com 0 valor do desvio padrão obtido inicialmente, considerando que este valor representa somente a incerteza do modelo de cálculo. Isso aconteceu devido ao desvio-padrão referente somente ao material possuir uma grande incerteza adimensionalizada, sendo muito superior ao do erro de modelo.

Sendo assim, a Tabela 5.4 resume somente as informações referentes ao erro de modelo que serão utilizadas nas análises de confiabilidade.

\begin{tabular}{cccccc}
\hline \multicolumn{5}{c}{ Tabela 5.4 - Informações estatísticas corrigidas do erro de modelo } \\
\hline \multirow{2}{*}{ Grupo } & \multirow{2}{*}{ Espécie } & \multicolumn{4}{c}{ Parâmetros estatísticos } \\
\cline { 3 - 6 } & Distribuição & $\boldsymbol{\mu}_{\text {EM }}$ & $\overline{\boldsymbol{\sigma}}_{\text {EM }}$ & $\mathbf{C V}_{\text {EM }}(\%)$ \\
\hline 1 & Andiroba & Normal & 1,759 & 0,395 & 24,24 \\
\hline 2 & Copaíba & Cauchy & 1,032 & 0,154 & 20,58 \\
3 & Mururé & Normal & 1,217 & 0,317 & 27,08 \\
4 & Pau jacaré & Normal & 1,595 & 0,239 & 21,95 \\
5 & Tachi Preto & Weibull M in. & 1,522 & 0,248 & 21,73 \\
6 & Tauari & Normal & 1,683 & 0,164 & 13,47 \\
7 & Virola & Normal & 1,349 & 0,160 & 22,37 \\
8 & Piquiá & Normal & 2,220 & 0,348 & 17,57 \\
9 & Tachi Preto & Normal & 1,404 & 0,245 & 23,41 \\
10 & Virola & Normal & 1,270 & 0,253 & 19,88 \\
11 & Piquiá & Normal & 2,068 & 0,235 & 14,21 \\
12 & Tachi Preto & Normal & 1,449 & 0,175 & 19,36 \\
13 & Pinus Elliotti & Normal & 1,623 & 0,546 & 40,03 \\
14 & Pinus Elliotti & Normal & 2,371 & 1,011 & 45,17 \\
15 & Pinus Elliotti & Normal & 4,015 & 1,047 & 27,51 \\
16 & Pinus Elliotti & Normal & 5,260 & 1,587 & 30,90 \\
17 & Peroba Rosa & Normal & 2,579 & 0,528 & 21,13 \\
\hline
\end{tabular}

Os resultados apresentados mostram uma tendenciosidade positiva, uma margem de segurança adicional em todos os grupos de resultados analisados, com valores muito altos para as espécies de Pinus, o conservadorismo acima do ideal da norma varia de3,2\% a até 426\%. Se as espécies de Pinus fossem excluídas, considerando-as a parte, o valor máximo da variação seria de $158 \%$.

Os desvios padrões dos grupos de resultados também têm uma variação muito alta em quase todos os casos,variando de $13 \%$ à $45 \%$. M uito disso se deve ao enquadramento dos Pinus em classes diferentes de classificação visual. Retirando essas espécies, o valor máximo 
seria de $27 \%$, que também é um valor alto, mas muito menor em relação ao anteriormente obtido. 


\section{ANÁLISE DE CONFIABILIDADE $\mid$ Capítulo 6}

Os dados levantados na literatura para ensaios de flexão em vigas e resistência à compressão em corpos de prova, e as informações dos erros de modelo e seus parâmetros estatísticos foram usados para realizar uma análise de confiabilidade do modelo de dimensionamento à flexão da norma NBR7190/97. Foram consideradas ações permanentes e as ações variáveis acidentais e de vento.

Esta análise permitirá definir um conjunto importante de informações, como o nível de segurança e quais são as variáveis mais significativas, apresentando subsídios para um processo de calibração de coeficientes de segurança para estruturas de madeira.

Adota-secomo metodologia as etapas de determinação das variáveis de resistência envolvidas no processo, determinação das variáveis de solicitação, montagem das equações de estado limite e análise de confiabilidade por método aproximado FORM. Esse processo foi feito sem (primeiro grupo de processamento) e com (segundo grupo) a introdução do erro de modelo.

\subsection{VARIÁVEIS DE RESISTÊNCIA ENVOLVIDAS}

Nesta pesquisa foram adotadas como variáveis aleatórias da resistência a resistência do material e o erro de modelo, quando preciso. A geometria da peça e os coeficientes modificadores $k_{\text {mod }}$ serão considerados de forma determinística.

A variável estatística resistência do material $\left(R_{m}\right)$ será expressa através do valor médio da resistência à compressão paralela às fibras e o desvio-padrão, ambos obtidos no levantamento de dados de ensaios em corpos de prova isentos de defeito. Em todos os processamentos assume-se a distribuição Normal como a que melhor representa à 
variávelresistência, conforme apontado na NBR 7190/1997. Essa foi a variável considerada em relação à resistência, além do erro de modelo (EM).

O tipo de distribuição e os parâmetros estatísticos dos erros de modelos, para cada espécie em questão são aqueles apresentados na Tabela 5.4. Essa variável só foiconsiderada nas equações de estado limite do segundo grupo de processamento, permitindo verificar o impacto dessa variável na confiabilidade das vigas e apresentando a precisão que o modelo de cálculo proposto fornece em seus resultados.

A Tabela 6.1 apresenta um resumo das informações estatísticas das variáveis de resistência consideradas nas análises. Todos os dados apresentados já tratam dos valores finais, com as devidas correções realizadas em capítulos anteriores. Devido a nenhum outro tipo de distribuição se adequar ao erro de modelo do grupo 2 de resultados, ele foi excluído das análises de confiabilidade, pois o software utilizado não reconhece essa distribuição. Se evita, assim, alteração da linguagem do programa. Mesmo assim os resultados referentes a esse grupo são apresentados.

\begin{tabular}{|c|c|c|c|c|c|c|c|}
\hline \multirow[b]{2}{*}{ Grupo } & \multirow[b]{2}{*}{ Espécie } & \multicolumn{3}{|c|}{ Resistência do material } & \multicolumn{3}{|c|}{ Erro de modelo } \\
\hline & & Distribuição & $\begin{array}{c}\mu_{R_{m}} \\
(\mathrm{MPa})\end{array}$ & $\begin{array}{c}\sigma_{R_{m}} \\
(\mathrm{MPa})\end{array}$ & Distribuição & $\mu_{E M}$ & $\sigma_{E M}$ \\
\hline 1 & Andiroba & Normal & 57,39 & 7,25 & Normal & 1,759 & 0,395 \\
\hline 2 & Copaíba & Normal & 52,35 & 6,77 & Cauchy & 1,032 & 0,154 \\
\hline 3 & Mururé & Normal & 62,06 & 4,94 & Normal & 1,217 & 0,317 \\
\hline 4 & Pau jacaré & Normal & 67,02 & 12,06 & Normal & 1,595 & 0,239 \\
\hline 5 & Tachi Preto & Normal & 60,47 & 9,74 & Weibull M in. & 1,522 & 0,248 \\
\hline 6 & Tauari & Normal & 55,31 & 7,37 & Normal & 1,683 & 0,164 \\
\hline 7 & Virola & Normal & 34,72 & 6,25 & Normal & 1,349 & 0,160 \\
\hline 8 & Piquiá & Normal & 46,94 & 6,43 & Normal & 2,220 & 0,348 \\
\hline 9 & Tachi Preto & Normal & 60,47 & 9,74 & Normal & 1,404 & 0,245 \\
\hline 10 & Virola & Normal & 34,72 & 6,25 & Normal & 1,270 & 0,253 \\
\hline 11 & Piquiá & Normal & 46,94 & 6,43 & Normal & 2,068 & 0,235 \\
\hline 12 & Tachi Preto & Normal & 60,47 & 9,74 & Normal & 1,449 & 0,175 \\
\hline 13 & Pinus Elliotti & Normal & 35,86 & 8,23 & Normal & 1,623 & 0,546 \\
\hline 14 & Pinus Elliotti & Normal & 35,86 & 8,23 & Normal & 2,371 & 1,011 \\
\hline 15 & Pinus Elliotti & Normal & 35,86 & 8,23 & Normal & 4,015 & 1,047 \\
\hline 16 & Pinus Elliotti & Normal & 35,86 & 8,23 & Normal & 5,260 & 1,587 \\
\hline 17 & Peroba Rosa & Normal & 38,68 & 4,25 & Normal & 2,579 & 0,528 \\
\hline
\end{tabular}




\subsection{VARIÁVEIS DE SOLICITAÇÃO ENVOLVIDAS}

Nas análisesde confiabilidade feitas neste trabalho, foi considerada a combinaçãoentre as ações permanentes e as ações variáveis, as que são geralmente as mais consideradas em estruturas correntes para a determinação da solicitação das peças.

Ainda não existem muitos estudos estatísticos desenvolvidos no Brasil sobre ações permanentes e variáveis. Assumindo que, para essas ações, existam poucas diferenças dos estudos realizados em outros países, adotaremos valores fornecidos por Ellingwood (1980). Entretanto, para a ação variável devida ao vento, serão usados dados referentes a pesquisas nacionais. Nestetrabalhoserão usadas as combinaçõesentre a ação permanente, variável acidental e a variável de vento.

Nos casos com mais de uma ação variável, serão feitas combinações considerando cada uma como a principal. As combinações expressas nas equações 6-2 e 6-4 apresentam a ação acidental ( $\left.L_{50 \text { years }}\right)$ como principal ação variável e as equações 6-3 e 6-5 apresentam 0 vento $\left(W_{\text {50years }}\right)$ como principal ação variável. Assim, foram geradas 5 combinações de ações para serem analisadas.

$$
\begin{gathered}
C_{1}=D \\
C_{2}=D+L_{50 y e a r s} \\
C_{3}=D+W_{50 y e a r s} \\
C_{4}=D+L_{50 y e a r s}+W_{1 \text { year }} \\
C_{5}=D+L_{\text {a.p.t. }}+W_{50 y e a r}
\end{gathered}
$$

A ação permanente, representada por $D$, possui distribuição Normal e apresenta valor médio de $1,05 \cdot D_{n}$ com coeficiente de variação de $10 \%$.

A ação variável acidental é representada por L. Quando é a ação variável principal ( $L_{50 \text { years }}$ ) apresenta distribuição de Gumbel para máximos (tipo I) com valor médio de $1,00 \cdot L_{n}$ e coeficiente de variação de $25 \%$. Quando secundária $\left(L_{\text {a.p.t. }}\right)$, ela apresenta valor médio de $0,25 \cdot L_{n}$ e coeficiente de variação de 55\% para uma distribuição Gamma.

A ação variável de vento, representada por $W$, quando foi a ação variável principal $\left(W_{50 y e a r s}\right)$, assumiu a distribuição de Gumbel para máximos com média de $0,90 \cdot W_{n} \mathrm{e}$ 
coeficiente de variação de 34\%; quando foia secundária ( $W_{1 y e a r}$ ) ela apresentava valor médio de $0,33 \cdot W_{n}$, com coeficiente de variação de $47 \%$ para uma distribuição também de Gumbel para máximos.

Esses dados foram obtidos de ELLINGWOOD et al. (1980) apud SOUZA JR. (2010) e correspondem à um carregamento extremo num período de 50 anos de uso da estrutura. No caso da ação de vento, os dados estatísticos utilizados foram construídos por SOUZA JR. (2010) com base na pesquisa de SANTOS (1989) apud RIEIRA E ROCHA (1998). Por meio da distribuição de extremos da velocidade anual do vento e do vento nominal de norma, encontrado na NBR 6123:1988 - Forças devidas ao vento em edificações, foram obtidos dados estatísticos para os máximos anuais da velocidade do vento e para um extremo de 50 anos, que por sua vez foram transformados em dados estatísticos de pressão de vento pela consideração de outros fatores como a densidade do ar e do coeficiente aerodinâmico.

A Tabela 6.2 resume os dados estatísticos para as variáveis aleatórias utilizadas nas combinações que determinaram as solicitações utilizadas nas análises de confiabilidade.

\begin{tabular}{cccc}
\hline \multicolumn{3}{c}{ Tabela 6.2 - Resumo das estatísticas das variáveis de solicitação } \\
\hline Solicitação & Distribuição & $\boldsymbol{\mu}$ & $\boldsymbol{\sigma}$ \\
Permanente $(\boldsymbol{D})$ & Normal & $1,05 \cdot D_{n}$ & $0,105 \cdot D_{n}$ \\
Acidental $\left(\boldsymbol{L}_{\mathbf{5 0 y e a r s}}\right)$ & Gumbel & $1,00 \cdot L_{n}$ & $0,250 \cdot L_{n}$ \\
Acidental $\left(\boldsymbol{L}_{\text {a.p.t. }}\right)$ & Gamma & $0,25 \cdot L_{n}$ & $0,134 \cdot L_{n}$ \\
Vento $\left(\boldsymbol{W}_{\mathbf{5 0 y e a r s}}\right)$ & Gumbel & $0,90 \cdot W_{n}$ & $0,306 \cdot W_{n}$ \\
Vento $\left(\boldsymbol{W}_{\text {1years }}\right)$ & Gumbel & $0,33 \cdot W_{n}$ & $0,155 \cdot W_{n}$ \\
\hline
\end{tabular}

Como observado, as informações estatísticasdas ações referem-se a valores nominais de cada uma. Segundo SOUZA JR. (2010) valor nominal da ação, é aquele utilizado na elaboração de projetos baseados em normas técnicas, e pode ser definido estatisticamente pela razão entre o valor nominal e o valor médio desta ação, que é obtido estatisticamente.

Nesta pesquisa, para se determinar os valores nominais de cada ação, foram utilizadas razões de carregamento entre as ações que formam as variáveis de solicitação $L_{n} / D_{n}$ e $W_{n} / D_{n}$, aplicadas nas equações de estado limite para se obter cada parcela nominal. 


\subsection{EQUAÇÕES DE ESTADO LIMITE}

A equação 6-6 mostra, de maneira simplificada, a forma de verificação de segurança do método dos estados limites,em que o que o valor da resistência $(R)$ subtraído das solicitações $(S)$ deve ser maior ou igual a zero.

$$
R-S \geq 0
$$

Neste trabalho foram utilizadas as equações 6-7 e 6-8, adotando-se o menor índice $\beta$ entre elas como 0 resultante. Nas análises de confiabilidade realizadas foram utilizadas 2 variáveis de resistência e 3 variáveis de solicitação, sendo que as três variáveis de solicitação geraram 5 tipos de combinações diferentes entre si, resultando em 10 equações de estado limite diferentes, 5 variações da equação 6-7 e cinco variações da equação 6-8.

$$
\begin{gathered}
R\left(X_{1}\right)-\left(X_{3}+X_{4}+X_{5}\right) \geq 0 \\
R\left(X_{1}\right) \cdot X_{2}-\left(X_{3}+X_{4}+X_{5}\right) \geq 0
\end{gathered}
$$

Nas equações acima $X_{i}$ são as variáveis aleatórias do problema aonde:

- $X_{1}$ - Representa a variável de resistência das espécies $\left(R_{m}\right)$;

- $X_{2}$ - Representa a variável erro de modelo (EM);

- $X_{3}$ - Representa a variável ação permanente $\left(D_{n}\right)$;

- $X_{4}$ - Representa a variável ação acidental, principal ou secundária $\left(L_{n}\right)$;

- $X_{5}$ - Representa a variável ação do vento, principal ou secundária $\left(W_{n}\right)$.

A variável de resistência dos materiais $\left(R_{m}\right)$ foi a única variável de resistência utilizada nas primeiras cinco equações de estado limite (equação 6-7), sendo subtraída pelas várias combinações possíveis entre as solicitações. Em seguida a variável erro de modelo $(E M)$ foi introduzida nesta equação (equação 6-8), resultando em mais cinco análises e totalizando as dez equações de estado limite citadas.

\subsubsection{Parcela proporcional de força das ações}

Como as variáveis de solicitação são expressas em função de valores nominais das ações, precisou-se estabelecer quais são esses valores. Esses valores devem corresponder a uma parcela da força nominal máxima (ou de projeto) de ruptura para cada grupo de 
madeira.Essaforça nominal máxima deve ser medida utilizando-se a resistência característica e os coeficientes ponderadores indicados pela NBR 7190/97para as resistências, todos inseridos nas equações daforça de ruptura, equações 5-6 e 5-7.

Cada parcela das açõesé determinada pela equação de estado limite 6-7, a equação 6-8, por incluir o erro de modelo e este não ser um parâmetro normativo, não serve para essa determinação. Para todas as cincopossíveis equações de estado limite, foram adotadas razões entre as ações permanentes e ação acidental $\left(L_{n} / D_{n}\right)$ e razões entre a ação permanente e ação de vento $\left(W_{n} / D_{n}\right)$. Essas razões foram estipuladas de uma forma que várias situações de projeto fossem atendidas, abrangendo desde situações com predominância de ações permanentes até com as ações variáveis como as maiores solicitantes.Seis proporções de valores das ações nominais foram utilizadas para cada razão usada $(0,0$ 0,5 1,0 1,5 2,0 3,0 e 5,0).

A Tabela 6.3 apresenta os coeficientes empregados nas equações de estado limite para determinação das parcelas de forças das ações nominais. Os valores de coeficientes para a ação acidental e a ação de vento que se apresentam com valores inferiores a 1,0 são valores reduzidos pelo coeficiente $\Psi_{0}$, devido à sua consideração como ação variável secundária, tanto para o vento quanto para a ação acidental, considerando que a ação acidental atua em locais que não há predominância de pesos nem de concentração de pessoas.

No caso do vento, não foi considerado um coeficiente redutor de 0,75 quando 0 mesmo era a ação variável principal, conforme recomenda a norma no item 5.5.8, conduzindo a uma situação a favor da segurança, pois esta ação não será reduzida e conduzirá a maiores solicitações nos elementos.

\begin{tabular}{ccccc}
\hline \multicolumn{5}{c}{ Tabela 6.3 - Coeficientes de segurança adotados para cada combinação } \\
\hline $\begin{array}{c}\text { Equação de } \\
\text { Estado limite }\end{array}$ & $\boldsymbol{R}$ & Parâmetro a ser ponderado \\
\hline 1 & 1,4 & $\mathbf{D}$ & $\mathbf{L}$ & $\mathbf{W}$ \\
\hline 2 & 1,4 & 1,4 & - & - \\
3 & 1,4 & 1,4 & 1,4 & - \\
4 & 1,4 & 1,4 & - & 1,4 \\
5 & 1,4 & 1,4 & $0,56^{1}$ & $0,7^{1}$ \\
\hline Valores reduzidos por $\boldsymbol{\Psi}_{\mathbf{0}}=\mathbf{0 , 4}$ para ações acidentais e $\boldsymbol{\Psi}_{\mathbf{0}}=\mathbf{0 , 5}$ para o vento. \\
\hline
\end{tabular}


A Tabela 6.4 apresenta a força nominal máxima que deve ser usada na equação de estado limite para a determinação das parcelas de força das ações nominais. Esses valores foram determinados utilizando-se os coeficientes ponderadores de resistência oriundos da Tabela 6.3 e com a resistência característica, obtida pela equação 3-6. Esses dados são os valores máximos da força, para cada grupo de resultado, segundo as recomendações da NBR $7190 / 97$.

\begin{tabular}{|c|c|c|}
\hline Grupo & Espécie & $P_{\text {teo }}(K N)$ \\
\hline 1 & Andiroba & 7,24 \\
\hline 2 & Copaíba & 6,60 \\
\hline 3 & Mururé & 7,83 \\
\hline 4 & Pau jacaré & 8,46 \\
\hline 5 & Tachi Preto & 7,63 \\
\hline 6 & Tauari & 6,98 \\
\hline 7 & Virola & 4,38 \\
\hline 8 & Piquiá & 5,92 \\
\hline 9 & Tachi Preto & 7,63 \\
\hline 10 & Virola & 9,86 \\
\hline 11 & Piquiá & 13,32 \\
\hline 12 & Tachi Preto & 17,17 \\
\hline 13 & Pinus Elliotti & 3,60 \\
\hline 14 & Pinus Elliotti & 3,60 \\
\hline 15 & Pinus Elliotti & 3,60 \\
\hline 16 & Pinus Elliotti & 3,60 \\
\hline 17 & Peroba Rosa & 6,54 \\
\hline
\end{tabular}

Substituindo força nominal máxima nas equações de estado limite, juntamente com as razões de carregamento e os coeficientes ponderadores específicos de cada situação, pode ser determinada a parcela de força referente a cada ação nominal. Para tornar o entendimento mais fácil, será apresentado um exemplo.

A seguir é exemplificado como se determinam as parcelas de forças de cada ação nominal, para a combinação de ações 5 e razões de carregamento de $L_{n} / D_{n}=2$ e $W_{n} / D_{n}=2$.

- $\quad$ A equação de estado limite será:

$$
g\left(x_{5}\right)=R-(D+L+W)
$$


- Os coeficientes ponderadores serão: $\gamma_{R}=1,4, \gamma_{D}=1,3, \gamma_{L}=1,2, \psi_{o, l}=0,4 \mathrm{e}$ $\gamma_{W}=1,4$

- Aforça nominal máxima $R_{n, m a ́ x}$ corresponde a:

$$
0,70 \cdot R_{n, m a ́ x}
$$

Substituindo os coeficientes ponderadores e a equação 6-10 na equação 6-9 tem-se:

$$
g\left(x_{5}\right)=\frac{0,70 \cdot R_{n, m a ́ x}}{1,4}-\left(1,4 \cdot D_{n}+0,56 \cdot L_{n}+1,4 \cdot W_{n}\right)
$$

Introduzindoos valores das razões de carregamento em 6-11 para se trabalhar com uma variável, como a ação nominal permanente $D$, pode-se escrever:

$$
\begin{aligned}
& L_{n}=2 \cdot D_{n} \\
& W_{n}=2 \cdot D_{n}
\end{aligned}
$$

Assim, aplica-se 6-12 e 6-13 em 6-11, obtendo:

$$
g\left(x_{5}\right)=\frac{0,70 \cdot R_{n, m a x}}{1,4}-\left(1,4 \cdot D_{n}+0,56 \cdot 2 \cdot D_{n}+1,4 \cdot 2 \cdot D_{n}\right)
$$

Igualando a equação 6-14 a zero, condição em que as solicitações se igualam as resistências, obtemos o valor máximo que cada solicitação pode atingir antes da ruptura. Assim, assolicitaçõesdevem ser transportadas para o outro lado da equação, obtendo-se 0 valor da ação nominal permanente em função da força nominal máxima.

$$
\begin{gathered}
\frac{0,70 \cdot R_{n, m a ́ x}}{1,4}=5,32 \cdot D_{n} \\
D_{n}=\frac{R_{n, m a ́ x}}{10,64}
\end{gathered}
$$

Com o valor da ação nominal permanente,pode-se voltar às razões de carregamento e encontrar o valor das outras parcelas.

$$
D_{n}=\frac{R_{n, m a ́ x}}{10,64} ; L_{n}=\frac{R_{n, m a ́ x}}{5,32} ; W_{n}=\frac{R_{n, m a ́ x}}{5,32}
$$


Nesta pesquisa, o $R$ é a força nominal máxima de cada espécie. Este processo deve ser feito para todas as razões de carregamento definidas e considerando todas as cinco combinações de ações. Após a definição de todas as parcelas de forças para as ações nominais, a análise de confiabilidade pode ser realizada.

\subsection{RESULTADOS DA ANÁLISE DE CONFIABILDADE}

Dos 17 grupos de resultados analisados, o grupo 2 foi excluído devido a não adequação das análises estatísticas. Para cada grupo de resultados foram realizadas 172 análises de confiabilidade, resultando em 2.752 índices de confiabilidade para todos os grupos. Foram utilizadas 7 razões de carregamento, tanto para o vento quanto para a ação acidental, 2 equações de estado limite, uma com erro de modelo e outra sem, com 5 tipos de combinações de ações distintas em cada equação para os 16 grupos de resultados selecionados.

Todas as análises de confiabilidade foram feitas em rotinas desenvolvidas no Mathematica $6.0 \circledast$ com base na teoria apresentada do método FORM, tendo como dados de entrada apenas as informações estatísticas das variáveis do problema, emitindo os valores dos índices de confiabilidade e dos coeficientes de sensibilidade para cada configuração adotada.

\subsubsection{Análises de confiabilidade sem o EMe com EM}

Os índices de confiabilidade encontrados para os 16 grupos de resultados do modelo normativo de flexão analisados sem a presença do erro de modelo apresentam valores muito baixos, oscilando em torno de $\beta=1,3$, sendo que muitos grupos apresentaram valores menores que $\beta=1,0$ quando a ação acidental é a ação variável principal. Quando 0 vento é a ação principal esse quadro pouco se altera, fazendo com que os grupos de resultados apresentassem valores entre $\beta=1,4$ e $\beta=1,6$. Em um aspecto geral, esses valores podem ser considerados baixos para a análise de uma estrutura. 


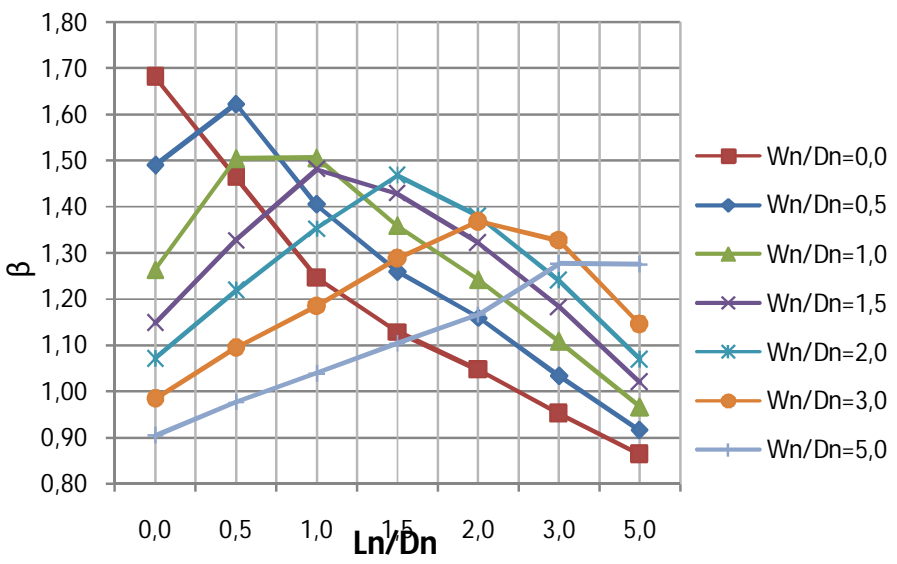

Figura6.1 - Variação de $\beta$ em função das razões de carregamento para a Andiroba (1).

A Figura 6.1 apresenta os valores obtidos para o grupo de resultados 1, da espécie de Andiroba, mas também pode ser interpretada como representativa da maioria dos grupos de resultados, devido a semelhança entres os gráficos. Como pode ser visto, os valores dos índices de confiabilidade tendem a se apresentar em retas crescentes para cada razão de carregamento da variável principal analisada, até o momento em que as ações variáveis secundárias apresentem maiores proporções de carregamento, deste ponto em diante, as retas dos valores de $\beta$ tendem a decrescer.

Outra consideração a respeito dos resultados, é que os índices $\beta$ tendem a ser mais uniformes para altos valores de razõesde carregamento da ação variável secundária. Entretanto, em alguns casos, como nos grupos de resultados 4,7, 13, 14, 15 e 16, isso não foi verificado, como observado na Figura 6.2 que apresenta os resultados do grupo 4, mas que podem ser considerados representativos desses grupos citados acima.

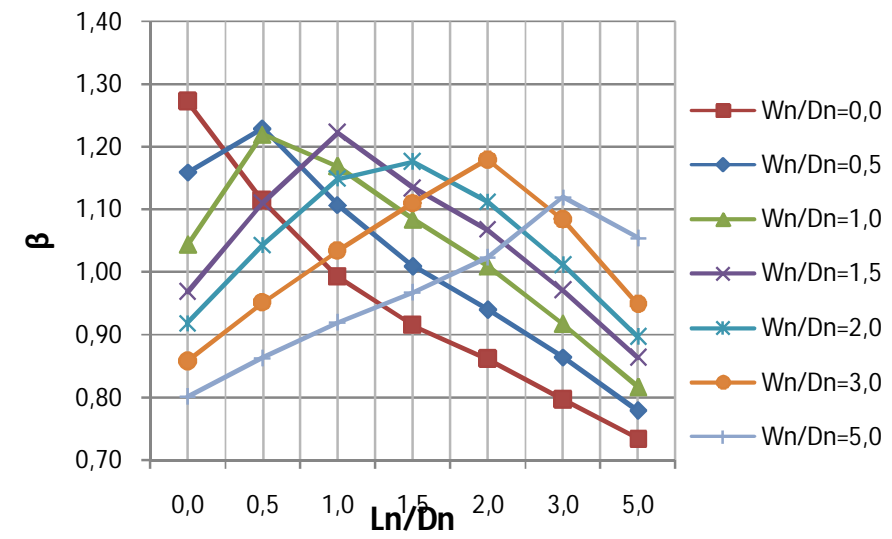

Figura6.2 - Variação de $\beta$ em função das razões de carregamento para oTauari (4). 
No mais, os índices de confiabilidade obtidos não são uniformes, como desejável. A queda de valores, e consequentemente a inclinação das retas, é bem acentuada com 0 aumento das razões de carregamento, seja para a ação variável principal ou secundária. Para normas de projetos, os índices de confiabilidade deveriam resultar valores suficientes e uniformes (OLIVEIRA, 2008). 0 critério de uniformidade diz que os valores dos índices de confiabilidade deveriam se apresentar nos gráficos em linhas retas horizontais, mesmo para aumentos das razões de carregamento, e próximas a valores alvos, definidos com base em calibração de norma. No caso em análise, pode-se afirmar que nenhum grupo apresentou resultados uniformes, sempre seguindo esse modelo tendencioso apresentado. 0 critério de suficiência será tratado em tópico único e posterior.

A variação dos valores do índice de confiabilidade, distâncias entre as retas máximas e mínimas do índice de confiabilidade de um mesmo conjunto de resultados, é grande. Esta constatação indica que coeficientes parciais redutores menores dos que apontado pela norma e utilizado nas análises poderiam ser usados nas combinações, para ambas as ações variáveis, a adoção de coeficientes menores e não constantes,como visto para 0 aumento das proporções de carregamento, reduziria a amplitude de valores encontrados para o $\beta$ e levaria a valores mais uniformes. Esses coeficientes reduzidos podem ser determinados para cada razão de carregamento através de um processo de calibração como o proposto por SOUZA JR. (2009).

O uso de coeficientes ponderadores parciais específicos, determinados por processo de calibração para cada situação que se queira avaliar levaria a valores mais para todas as situações em estudo.

Com a introdução do erro de modelo $(E M)$ nas análises de confiabilidade os valores de $\beta$ apresentam um significativo aumento, devido ao conservadorismo do modelo de flexão da NBR 7190/97. Este fato aconteceu com todas as espécies, como era de se esperar, devido ao valor médio do erro de modelo ser superior a 1,0 em todos os grupos de resultados. Um valor médio para o índice de confiabilidade com a inclusão do EM ficaria em torno de $\beta=2,5$, para qualquer uma das considerações feitas so bre as ações.

Alguns casos, como os dos grupos de resultados $6,8,11,15$ e 17, apresentam valores superiores a $\beta=3,0$ e em algumas situações chegando até a $\beta=4,0$. Por outro lado, 
mesmo com a consideração do EM, os grupos de resultados 3, 10, 13 e 14 continuam com valores muito baixos do índice de confiabilidade, girando em torno de . A pouca variação dos índices mesmo com a imposição do EM se dá pelo baixo valor de conservadorismo encontrado durante as análises de erro de modelo, realizadas em capítulos anteriores, para esses grupos.

A Figura 6.3 apresenta os valores dos índices de confiabilidade com a inclusão do erro de modelo nas retas (curvas) da direita e, nas retas (curvas) da esquerda, os valores do índice de confiabilidade para o modelo de norma sem a presença do erro de modelo. A espécie 5 foi escolhida para representar alguns grupos de resultados, como os 1,3, 10, 13, 14, 15 e 16, os grupos que apresentam um comportamento diferentes dos citados são os 4, $5,6,7,8,9,11,12$ e 17, que tem comportamento semelhante ao da Figura 6.4.
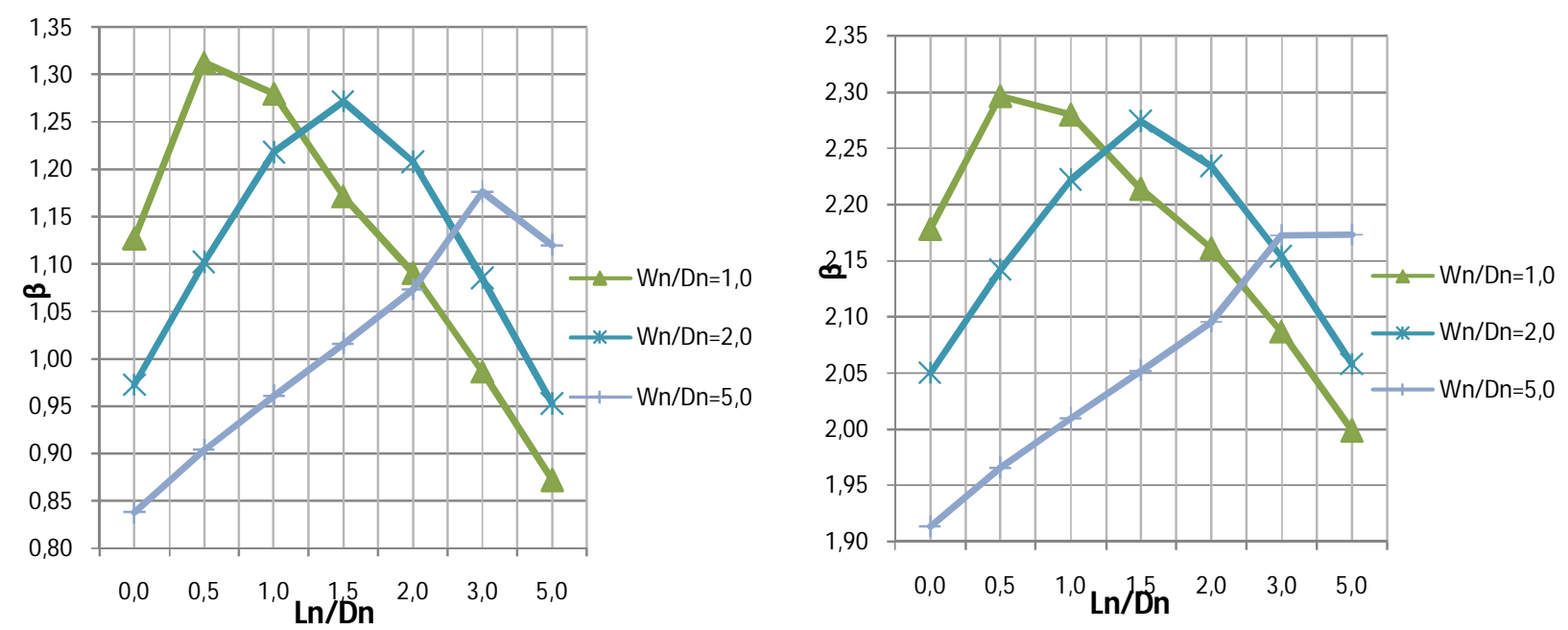

Figura6.3 - Variação de $\beta$ em função das razões de carregamentocom a introdução do erro de modelo (direita) e sem o erro de modelo (esquerda) para o Tachi Preto (5).

Os grupos citados, que são representados pelos índices dos gráficos da Figura6.3, apresentam características como uniformidade, variação de valores e comportamento frente às razões de carregamento iguais aos resultados obtidos para a análise de confiabilidade sem o erro de modelo, a única diferença significativa é o aumento dos valores do índice de confiabilidade, ocasionado pela introdução do EM nas análises do modelo de cálculo. Como o modelo é conservador, seus resultados aumentam devido ao aumento do conservadorismo, aumentando-se a confiabilidade do modelo da NBR 7190/97. 

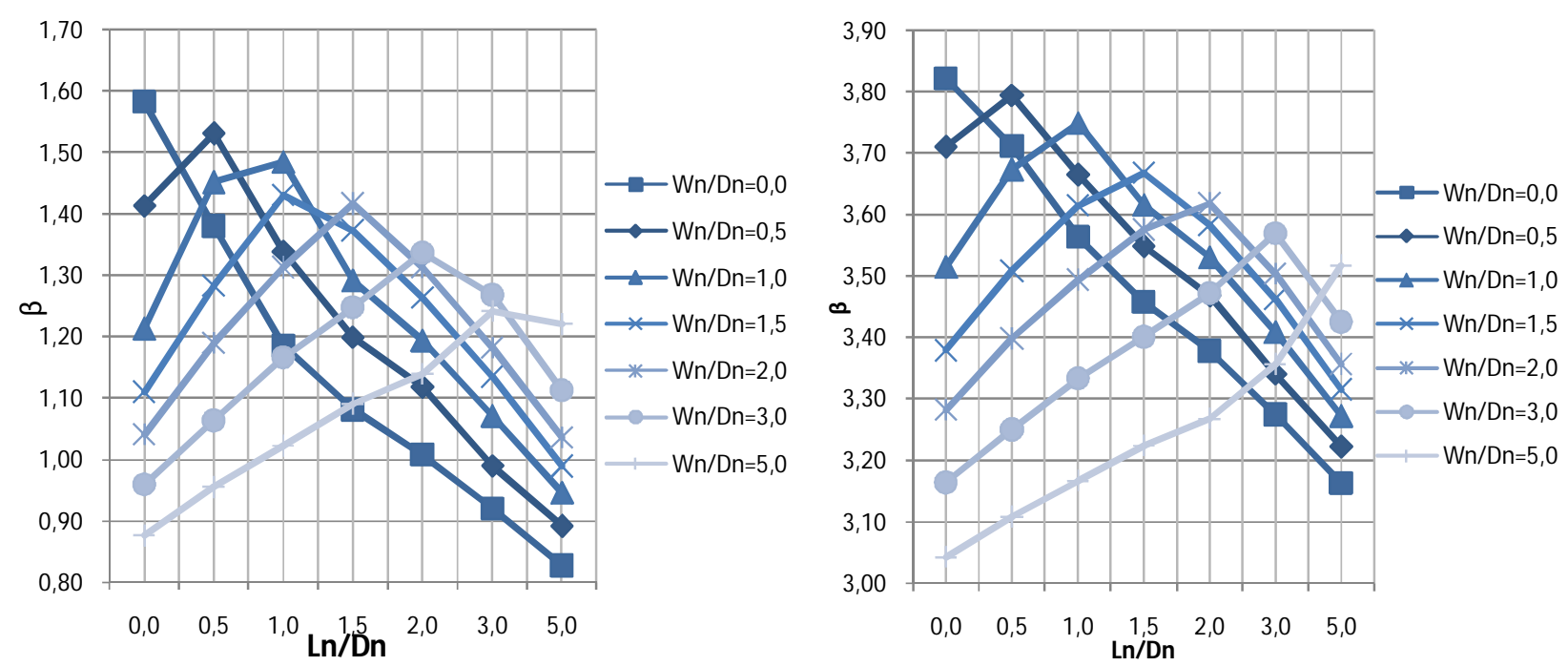

Figura6.4 - Variação de $\beta$ em função das razões de carregamentocom a introdução do erro de modelo para a Pequiá (8).

Os gráficos da Figura 6.4 apresentam apenas valores de índices de confiabilidade obtidos nas análises da equação de norma com a consideração do erro de modelo. Percebese, à medida que os valores da razão de carregamento secundária aumentam, o modelo começa a produzir resultados um pouco mais uniformes (linhas azuis mais claras) e menores para pequenas proporções da ação variável principal.

\subsubsection{Comparação com o índice alvo do EUROCODE}

A comparação dos índices de confiabilidade com os alvos proposto pelo EUROCODE 0 pretende avaliar os valores quanto ao quesito suficiência. Para que os resultados de índice de confiabilidade da pesquisa possam ser comparados com índices alvos fornecidos pelo EUROCODE, primeiramente deve-se apresentar como o código europeu define os alvos a serem atingidos.

0 índice $\beta$ alvo deve ser determinado em função do estado limite analisado, do período de referência ou vida útil de projeto e da classe de confiabilidade (RC) associada a classe de conseqüências (CC).

Como a equação analisada no estudo foi a de flexão para vigas, o estado limite último é o que foi verificado. Todas as considerações de cálculo feitas no projeto são referentes a estruturas com vida útil estimada de 50 anos ou mais como período de referência. A classe 
de conseqüência pôde ser determinada pela Tabela fornecida no próprio EUROCODE 0 e apresentada a seguir.

\begin{tabular}{|c|c|c|}
\hline \multicolumn{3}{|c|}{ Tabela 6.5 - Definição das classes de conseqüência (EUROCODE 0) } \\
\hline $\begin{array}{l}\text { Classes de } \\
\text { conseqüência }\end{array}$ & Descrição & $\begin{array}{c}\text { Exemplos de edifícios e } \\
\text { estruturas civis }\end{array}$ \\
\hline $\mathrm{CC} 3$ & $\begin{array}{l}\text { Alta conseqüência de perdas de vidas } \\
\text { humana ou conseqüências econômicas, } \\
\text { sociais ou ambientais muito altas }\end{array}$ & $\begin{array}{l}\text { Arquibancadas, edifícios públicos } \\
\text { onde a conseqüência de falha é } \\
\text { alta (teatros) }\end{array}$ \\
\hline $\mathrm{CC} 2$ & $\begin{array}{l}\text { Conseqüência média para perda de } \\
\text { vidas humanas, econômicas, sociais ou } \\
\text { ambientais consideráveis }\end{array}$ & $\begin{array}{l}\text { Edifícios residenciais e } \\
\text { comerciais, prédios públicos com } \\
\text { conseqüências de falha medias }\end{array}$ \\
\hline $\mathrm{CCl}$ & $\begin{array}{l}\text { Baixas conseqüências para perdas de } \\
\text { vidas humanas e conseqüências } \\
\text { econômicas, sociais e ambientais baixas } \\
\text { ou negligenciáveis. }\end{array}$ & $\begin{array}{l}\text { Construções agrícolas aonde } \\
\text { pessoas normalmente não } \\
\text { freqüentam (silos), estufas. }\end{array}$ \\
\hline
\end{tabular}

Nesta pesquisapode-se enquadrar as vigas na classe de conseqüência 2 (CC2), por ser a classe que abrange edifícios residenciais e comerciais, assim, a Tabela B2 do EUROCODE 0 define como 3,8 o alvo a ser atingido pelo índice de confiabilidade deste estudo. No caso de pontes e coberturas para ginásios a classe a ser escolhida deveria ser a CC3.

$\mathrm{Na}$ análise de confiabilidade da equação de norma sem erro de modelo,nenhum dos 1.376 índices de confiabilidade atingiu o alvo do EUROCODE, tanto para as combinações com a ação acidental como a principal como para combinações com a ação de vento como a principal ação variável. Portanto, pode-se afirmar que a NBR 7190/97 não alcança índices $\beta$ suficientes para o modelo de flexão. Todos os valores ficam abaixo do alvo, sendo que 0 valor máximo encontrado não chega nem a $\beta=3,0$, ficando, no máximo, próximos a $\beta=2,5$.

Com a introdução do erro de modelo nas análises de confiabilidade,esse quadro mudou para alguns grupos de resultados. 0 valor alvo ainda não chegou a ser atendido na maioria dos grupos, mas devido ao conservadorismo do erro de modelo, os índices aumentaram e resultaram em valores mais razoáveis. Os índices dos grupos de resultados 6 , 8 e 11 alcançaram o índice alvo para todas as combinações e para a maioria das razões de carregamento, atendendo ao critério de suficiência. Nos restantes, 7 grupos ficaram com os índices variando entre $\beta=2,4$ e $\beta=3,3$ para todas as combinações, e 6 grupos ficaram 
com os índices menores que , o que é muito abaixo do esperado quando se é considerada a inclusão do erro de modelo.

Porém, é preciso dizer que esses valores alvos estipulados pelo EUROCODE são muito difíceis de serem alcançados na prática. OLIVEIRA (2008) mostra em seu trabalho que nem as próprias equações do EUROCODE chegam a este valor alvo, outras pesquisas como BECK (2008) confirmam essa alegação, portanto pode-se avaliar que os valores encontrados são, em certo ponto,moderados, podendo ser melhorados para uma probabilidade menor de ocorrência de falha dentro da vida útil (BECK, 2010).

\subsubsection{Influência da classificação de peças de madeira de Pinus}

Atenção especial foi dada nesta pesquisa aos grupos de resultados das espécies de Pinus $(13,14,15$ e 16), pois eles foram considerados em separado devido a classificação visual e mecânica das peças realizada no trabalho de CARREIRA (2003), que definiu classes diferentes para cada grupo.

A Figura 6.5 apresenta os índices de confiabilidade para todos os grupos de resultados de Pinus. Na análise de confiabilidade do modelo de norma, não há nenhuma característica que diferencie o modelo para cada grupo de classificação criado por CARREIRA (2003), portanto os valores são exatamente os mesmos para os 4 grupos de resultados.

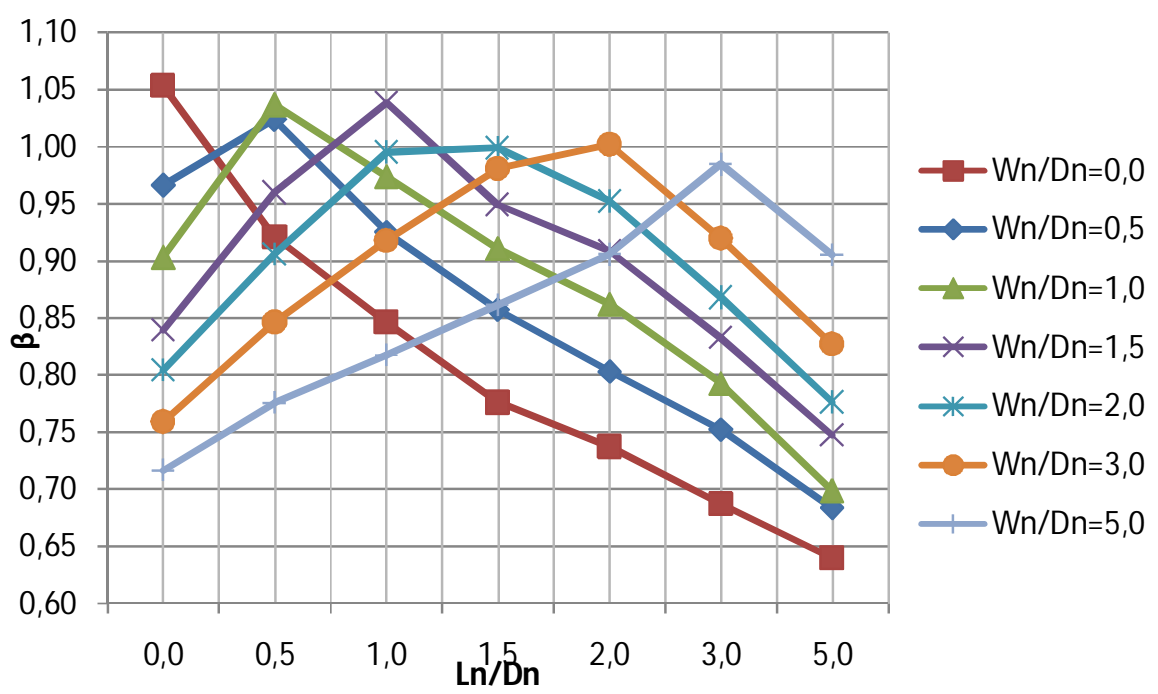

Figura6.5 - Variação de $\beta$ em função das razões de carregamento para os Pinus $(13,14,15$ e 16). 
As peculiaridades dos gráficos são exatamente as mesmas já comentadas para o caso geral da análise de confiabilidade do modelo de norma sem a inclusão da variável erro de modelo. Portanto pode-se evidenciar que para a norma, nas circunstâncias atuais, a classificação das peças de Pinus não interfere no dimensionamento.

A introdução do erro de modelo nas análises de confiabilidade serve para mostrar que a classificação de peças de madeira de Pinus deve ser considerada pela norma de forma mais influente no dimensionamento, pois como pôde ser observado, os valores de erro de modelo não apresentaram o mesmo resultado para todas asespécies de Pinus como 0 dimensionamento normativo apresentou. 0 que acontece é que com a classificação das peças de Pinus foi possível criar 4 grupos distintos dentro da mesma espécie, em que cada grupo apresentava uma espécie de Pinus cada vez mais resistente, comprovada por ensaios mecânicos, e os Pinus melhor qualificados apresentam um desempenho melhor do que 0 previsto pela norma.

A diferença de resistência entre cada grupo foi prevista pela inspeção visual das espécies, realizadas antes dos ensaios, em função dos defeitos, e enquadrando-os em ordem de importância (№3, №2, №1 e SS), selecionando quais as espécies eram as mais prejudicadaspor esses defeitos. Assim, os modelos de norma se mostram cada vez mais conservadores à medida que se aumenta a qualidade da classe (menos defeitos). Com a introdução do erro de modelo (variável que aponta esse conservadorismo) nas análises de confiabilidade a equação de norma passou a apresentar valores do índice maiores e mais próximos dos índices alvos propostos pelo EUROCODE 0.

A Figura 6.6 apresenta esses valores de confiabilidade para o Pinus com a introdução do erro de modelo nas análises para o grupo de resultados 15, um dos grupos de Pinus que mais aumentou os valores de confiabilidade. 


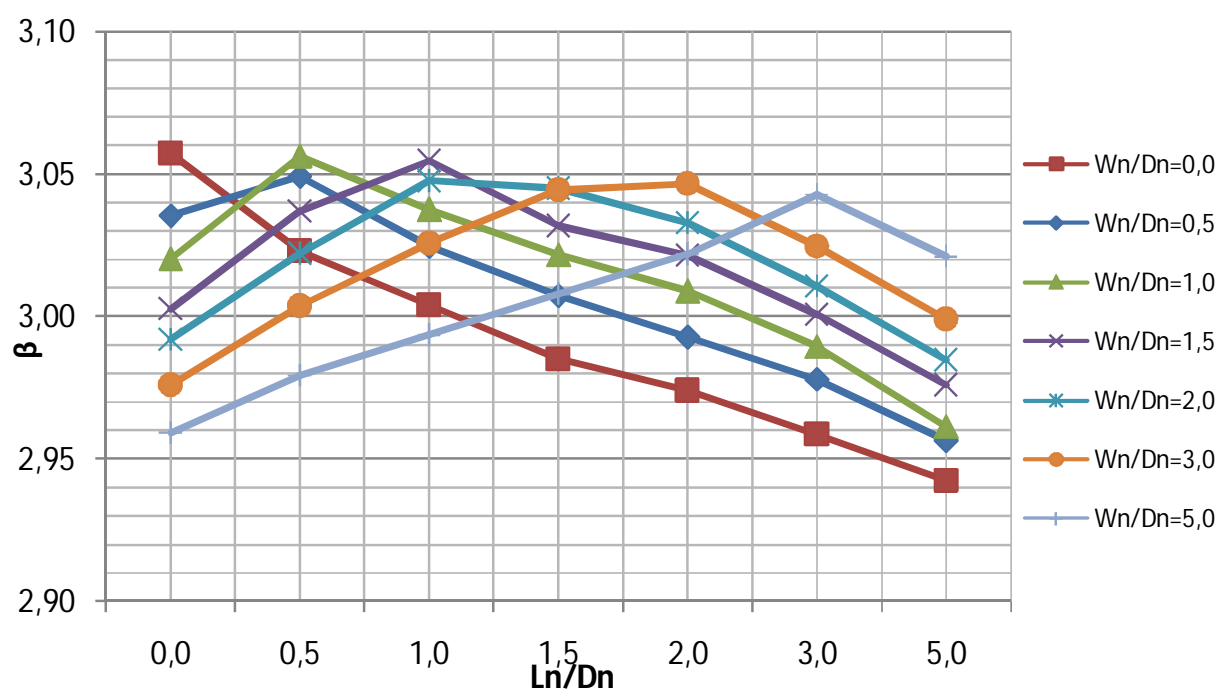

Figura6.6 - Variação de $\beta$ em função das razões de carregamento com a introdução do erro de modelo para os Pinus (15).

$\mathrm{Na}$ análise de suficiência dos índices de confiabilidade, também se percebe que os valores obtidos já são bem mais próximos ao alvo estabelecido, comprovando que uma abordagem menos conservadora do modelo deve ser feita por parte da norma para os Pinus com emprego estrutural.

\subsubsection{Análises dos coeficientes de sensibilidade}

Os coeficientes de sensibilidade obtidos nas análises de confiabilidade têm a função de apontar quais as variáveis mais influentes na determinação do índice de confiabilidade. 0 estudo deste coeficiente é importante para definir quais variáveis podem ser descartadas em futuras análises, diminuindo o custo computacional das análises, devido a sua baixa influência, e quais variáveis merecem um tratamento mais refinado por terem maior influência

Nas análises de sensibilidade das variáveispresentes no modelo de norma, verificado sem erro de modelo, pôde-se constatar que a resistência da madeira é a variável mais influente para razões de carregamento pequenas da ação acidental e de vento, essa constatação foi possível devido a alta variabilidade da resistência da madeira. À medida que as razões de carregamento vão aumentando, a ação variável principal, sendo ela o vento ou a acidental, tende a substituir a resistência da madeira, sendo a variável aleatória mais 
influente na determinação do valor do índice de confiabilidade, como pode ser observado na Figura 6.7.
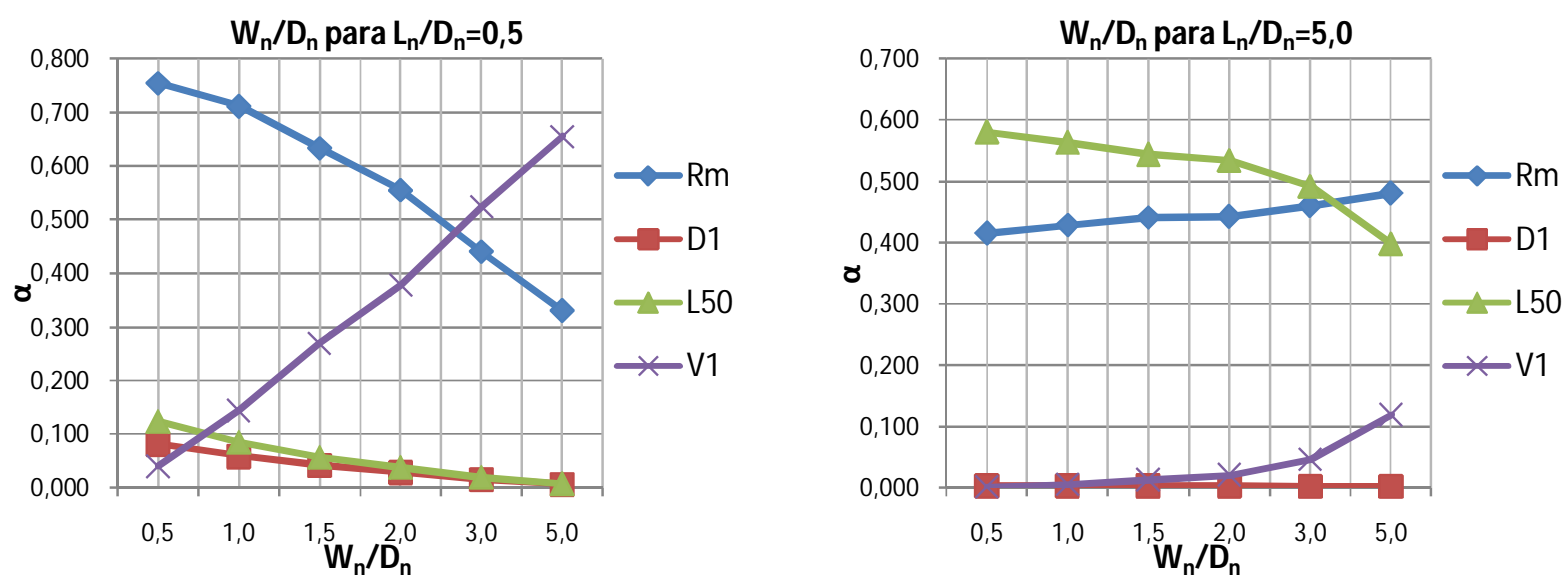

Figura 6.7 - Exemplo da variação de $\alpha$ em função da razão $W_{n} / D_{n}$ com o aumento da razão $L_{n} / D_{n}$ para Pequiá (11).

Quando a ação de vento é a ação variável principal, ela apresenta forte influência nos resultados para alguns grupos como 0 1, 3, 6, 11 e 7, desde pequenas razões de carregamento desta ação. A ação acidental só começa a se tornar influente com o aumento da sua proporção nas análises. 0 comportamento citado não se evidencia para a maioria das análises, porque para a grande parte delas a resistência da madeira ainda é o parâmetro com sensibilidade mais alta, mesmo com o erro de modelo incluso nas análises de confiabilidade.

A introdução do erro de modelo nas análises reduz consideravelmente,para razões de carregamento pequenas, as influências das outras variáveis aleatórias. À medida que as razões de carregamento vão aumentando de proporção, o erro de modelo começa a perder espaço nos resultados da análise, chegando a ser menos influente que outras variáveis, como as de solicitação (L e W). Os altos valores de incertezas justificam tal comportamento desta variável, para qualquer situação de ações principais, da mesma forma que aconteceu com a resistência dos materiais.

Nos grupos de resultados de peças de Pinus, o erro de modelo chega a ter $90 \%$ de influência nas análises de confiabilidade, como pode ser visto na Figura 6.8, principalmente quando os resultados do erro de modelo apontam para um grande valor de 
conservadorismo do modelo de norma, ou seja, quando a madeira se enquadra numa classe mais alta de resistência proposta pela classificaçãode peças de madeira de Pinus.
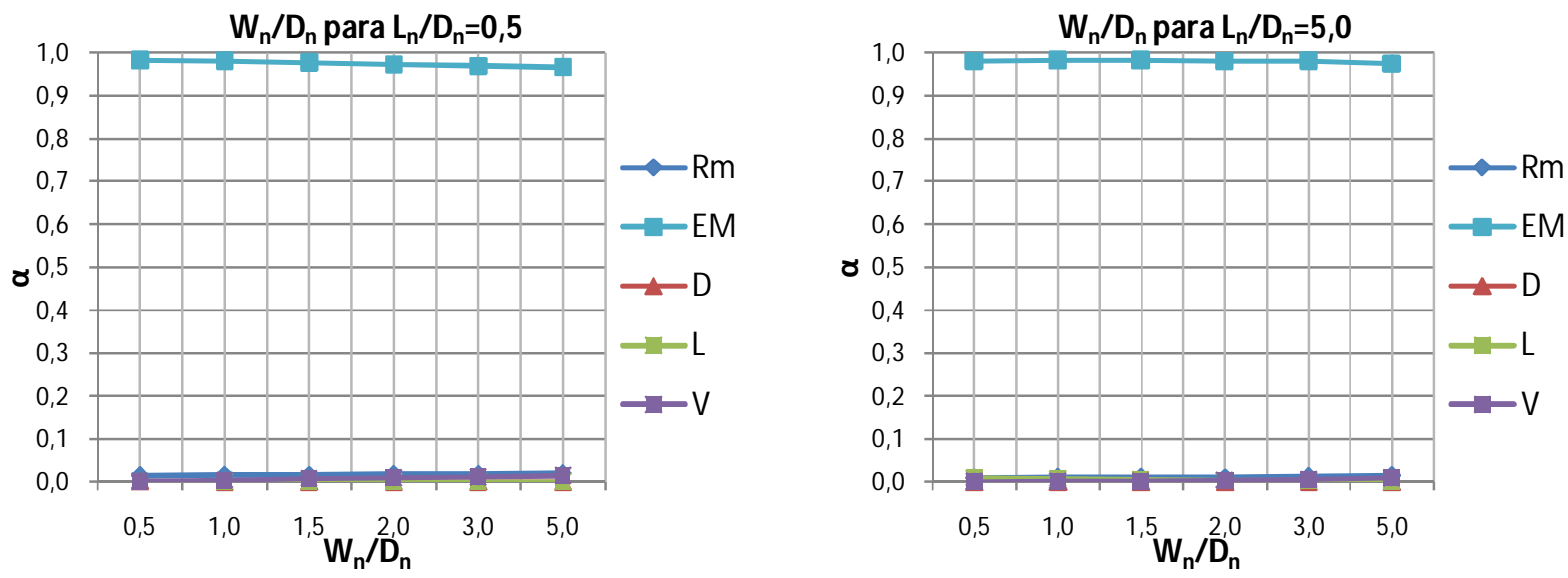

Figura 6.8 - Exemplo da variação de $\alpha$ em função da razão $W_{n} / D_{n}$ com 0 aumento da razão $L_{n} / D_{n}$ para Pinus (16). 


\section{CONCLUSÃo $\mid$ Capítulo 7}

\subsection{OBTENÇÃO DE DADOS}

Trabalhos de vários institutos foram obtidos na pesquisa para levantar as informações estatísticas a respeito da resistência a compressão paralela as fibras e o que ficou evidenciado é que há informação estatística disponível como o valor médio e o desvio padrão dessa propriedade, que pode ser usada nas análises de confiabilidade.

A classificação das peças de Pinus é outra informação de grande valor. As espécies de Pinusdo trabalho que possuíam informações como uma inspeção visual puderam ser mais bem estudadas, os gráficos dos índices de confiabilidade dessas espécies permitem avaliar como essaclassificação das peças de Pinus influenciou de forma positiva os índices de confiabilidade.

\subsection{ERRO DE MODELO}

A equação de norma para flexão foi comprovada comosendo conservadora,com tendenciosidade positiva (acima da unidade), para todos os casos analisados de vigas. Isto pode ser constatado através do valor da força de ruptura encontrada pelo dimensionamento,que foi menor do que 0 valor encontrado nosvários ensaios experimentais, assumido como o valor real de resistência da madeira à flexão.

No caso daspeças de Pinus, esse conservadorismo se mostra ainda mais evidente. A classificação das peças de madeira de Pinus realizada serviu para mostrar que há 


\section{CONCLUSÃO}

divergências sobre os reais valores da sua resistência, neste caso os defeitos naturais encontrados nas análises contribuíram para esta constatação.

Em todos os grupos de erro de modelo, uma margem de segurança adicionalé encontrada, eo conservadorismo da norma varia entre 3,2\% e 426\%, Se as espécies de Pinus fossem excluídas, o valor máximo dessa variação diminuiria para $158 \%$. Os valores dos desvios padrões também são muito altos, variando entre $13 \%$ até $45 \%$, e, sem as peças de Pinus, o valor máximo da variação ficaria em $27 \%$.

\subsection{ANÁUSES DE CONFIABILIDADE}

$\mathrm{Na}$ avaliação dos índices de confiabilidade encontrados para os 16 grupos de resultados, muitos grupos apresentaram valores menores que $\beta=1,0$ para a ação acidental como a principal ação variável, sendo $\beta=1,3$ adotado como um valor médio de todos os resultados. Quando o vento é a ação variável principal esses dados se alteram um pouco, pois os valores ficam um pouco superiores a $\beta=1,4$, mas mesmo assim, em um aspecto geral, esses valores podem ser considerados baixos para uma estrutura.

A tendência encontrada para os índices é se apresentar em retas crescentes para cada razão de carregamento da variável principal analisada, até o momento em que as ações variáveis secundárias apresentem maiores proporções de carregamento, deste ponto em diante, as retas dos valores de $\beta$ tendem a decrescer.

Os índices $\beta$ obtidos não são uniformes, como desejado. Para serem considerados ideais, os valores desses índices de confiabilidade deveriam ser constantes para o aumento das razões de carregamento, apresentando-se nos gráficos como uma linha reta horizontal. 0 que comumente é encontrado nos gráficos são dois padrões, que não se apresentam juntos:

- Os índices de confiabilidade tendem a diminuir à medida que há um aumento da razão de carregamento para a ação variável secundária;

- Os índice de confiabilidade tendem a aumentar para razões de carregamento secundarias pequenas; 
Os índices também apresentam grande variação de valores, com grande dispersão entre as linhas de máximos e mínimos valores dos índices de confiabilidade em função das razões. Pode-se afirmar que os coeficientes de redução das ações poderiam ser reduzidos em relação aos que se encontram na norma e deveriam apresentar valores distintos para cada análise, não sendo constantes.

Com a introdução do erro de modelo nas análises de confiabilidade do modelo normativo de flexão, pode-se nitidamente perceber o aumento do índice de confiabilidade, ficando com valores médios próximos de $\beta=2.5$, em decorrência do modelo de norma ser conservador como verificado nas análises. Essa foi a única alteração significativa verificada entre as duas análises, no restante todas os comportamentos gráficos apresentados para as análises de confiabilidade sem erro de modelo se aplicam as análises com erro de modelo.

Poucos grupos de resultados atingiram o valor alvo especificado pelo EUROCODE 0 que é de $\beta_{\text {alvo }}=3.8$, sejam os resultados correspondentes a análise com erro de modelo ou não, apenas os grupos 6,8 e 11 da equação com erro de modelo atenderam as especificações. Os valores propostos pelo EUROCODE não são atendidos nem pelas suas próprias equações como apontado em OLIVEIRA et. al (2008). Portanto pode-se classificar esses valores como moderados, com uma probabilidade pequena de ocorrer falhas durante a vida útil.

A introdução do erro de modelo na análise também serviu para mostrar que a classificação das peças de Pinus não pode ser desprezada no dimensionamento. Os modelos de norma se mostraram cada vez mais conservadores à medida que os Pinus apresentavam menos defeitos e o erro de modelo reposicionou os valores da equação, de modo que a mesma elevasse seus índices para próximo dos desejados. 0 modelo adotado pela norma (usar a resistência a compressão paralela as fibras para o modelo de flexão) não representa de forma ideal o que acontece na prática, pois a ruptura na flexão ocorre na borda tracionada, na maioria dos casos, que é mais afetada pela presença de defeitos.

Como era de se esperar, as variáveis que apresentavam altos coeficientes de variação como a resistência da madeira (de quaisquer espécies) e os erros de modelo, foram as variáveis que se mostraram mais influentes no dimensionamento. As ações de vento e acidental só passam a influenciar significativamente quando as mesmas possuem altos 
valores de razões de carregamento, mesmo assim isso só se constata para análises sem erro de modelo.Nas espécies de Pinus o erro de modelo influencia sozinho mais de $90 \%$ nos resultados dos índices de confiabilidade. 


\section{REFERÊNCIAS BIBLIOGRÁFICAS}

ALPUIM, M. T. S. H. A. (2009). Probabilidade: Notas de aula - M aterial eletrônico. Lisboa Universidade de Lisboa. Departamento de estatística e investigação operacional. Acesso ao $\begin{array}{lllll}\text { site } & \text { 24.06.2010 link }\end{array}$ http://www.deio.fc.ul.pt/disciplinas/2c est probabilidade.html

ANG, A. H-S.; TANG, W. H.; (1975). Probability Concepts in Engineering Planning and Design, Volume II: Decision, Risk and Reliability; John Wiley $\&$ Sons.

ASSOCIAÇÃO BRASILEIRA DE NORMAS TÉCNICAS. NBR 8681 Ações e segurança nas estruturas - Procedimento. Rio de janeiro, RJ, 2003.

NBR 7190 Projeto de estrutura de

madeira. Rio de janeiro, RJ, 1997.

ASTM - American Society of Testing and M aterials. ASTM D 198-97 Standard Test Methods of StaticTests of Lumber in Structural Sizes.

BECK, A.T. (2009). Curso de confiabilidade estrutural: Notas de aula. São Carlos - EESC-USP.

BUCHANAN, A. H. (1990). Bending Strength of Lumber. Journal of Structural Engineering, $\mathrm{n} \underline{0}$ 116.

CAM ÕES, M. F. G. F. C. (2001). Quantificação da incerteza nas medições analíticas. Versão em português do guia da EURACHEM/CITAC, $2^{\circ}$ Ed.

CARREIRA, M. R. (2003). Critérios para classificação visual de peças estruturais de Pinus Sp. Dissertação (mestrado) - Escola de Engenharia de São Carlos, Universidade de São Paulo, São Carlos.

ELLINGWOOD, B. R.; GALAMBOS, T. V. (1982). Probability-based Criteria for Structural Design. Struct. Saf. 1, 15-26. 
ELLINGW OOD, B. R.; CULVER, C. (1977). Analysis of Live Loads in Office Buildings. J.Struct. Div., ASCE 103, 1551-1560.

ELLINGW OOD, B. R.; GALAMBOS, T. V.; MACGREGOR, J. G.; CORNELL, C. A., (1980). Development of a Probability Based Load Criterion for American National Standard A58. NBS SpecialReport577, U.S. Department of Commerce, National Bureau of Standards, 222 pp.

ELLINGW OOD, B. R. (2000). LRFD: implementing structural reliability in professional practice. Engineering Structures 22 (2000) 106-115.

. (1997). Probability-based LRFD for engineered Wood construction.

Structural Safety vol. 19, No 1, pp 53-65.

FABER, M. H.; KOHLER, J. (2004). Probabilistic model code for design of timber structures. COST E24.

FILHO, P. F. (2009). Introdução ao planejamento e análise estatística de experimentos: Notas de aula. São Carlos - UFSCar.

FURIATI, M. (1981). Classificação estrutural de peças de madeira. Dissertação (mestrado) Escola de Engenharia de São Carlos, Universidade de São Paulo, São Carlos.

FUSCO, P. B. (1977). Estruturas de concreto armado. Fundamentos estatísticos da segurança das estruturas. São Paulo. M cGraw-Hill do Brasil, LTDA.

. (1995). Condições para a mudança do modelo de segurança nas normas de projeto de estruturas. EBRAM EM, Belo Horizonte, Anais... Vol. 2 pp 265 - 269.

GOMES, W. J. S. (2010). Estudo do efeito de incertezas na otimização estrutural. Dissertação (mestrado) - Escola de Engenharia de São Carlos, Universidade de São Paulo, São Carlos.

LAHR, F. A. R. (1990). Considerações a respeito da variabilidade de propriedades de resistência e de elasticidade da madeira. Livre Docência (pós doutorado) - Escola de Engenharia de São Carlos, Universidade de São Paulo, São Carlos. 
(1983). Sobre a determinação de propriedades de elasticidade de madeira.

Tese (doutorado) - Escola de Engenharia de São Carlos, Universidade de São Paulo, São Carlos.

MELO, J. E. de (1984). Classificação mecânica de peças estruturais de madeira. Dissertação (mestrado) - Escola de Engenharia de São Carlos, Universidade de São Paulo, São Carlos.

MIOTTO, J. L. (2003). Avaliação dos critérios de dimensionamento para peças comprimidas e flexocomprimidas de madeira. Dissertação (mestrado) - Escola de Engenharia de São Carlos, Universidade de São Paulo, São Carlos.

MONTGOMERY D. C. e RUNGER, G. C. (2003). Estatística aplicada e probabilidade para engenheiros. LTC editora. $2^{\circ}$ Ed. Rio de Janeiro, RJ.

NOGUEIRA, C. G. (2010). Desenvolvimento de modelos mecânicos de confiabilidade e otimização para aplicação em estruturas de concreto armado. Tese (doutorado) - Escola de Engenharia de São Carlos, Universidade de São Paulo, São Carlos.

NOGUEIRA, H. A. T. (2006). Avaliação da confiabilidade de pilares curtos em concreto armado projetados segundo a NBR 6118:2003. Dissertação (mestrado) - Escola de Engenharia da Universidade Federal de Minas Gerais, Belo Horizonte.

NOWAK, A. S.; SZERSZEN, M. M. (2003).Calibration of design codes for buildings (ACI 318): Part 1 - Statistical model for resistance. ACl Structural Journal, V. 100, No 3, May-June 2003.

. (2003). Calibration of design codes for buildings (ACI 318):

Part 2 - Reliability analysis and resistence factors. ACI Structural Journal, V. 100, No 3, MayJune 2003.

OLIVEIRA, W. L. A.; EL DEBS, A. L. H. C.; BECK, A. T. (2008).Avaliação da segurança de pilares mistos preenchidos de seção circular projetados segundo a norma NBR 8800:2008. Revista IBRACON de estruturas e materiais. Vol1, No 3, pp 212-235. 
RANTA-M AUNUS, A.; FONSELIUS, M.; KURKELA, J.; TORATTI, T. (2001). Reliability analysis of timber structures. In: Espoo 2001. Technical Research Centre of Finland. Research notes 2109. $102 p 3 p$.

RAVINDRA, M. K.;.; GALAMBOS, T. V. (1978).Load and Resistance Factor Design for Steel.J. Struct. Div., ASCE 104, 1337-1353.

ROCHA, J. S.; PAULA, E. V. C. M.; SIQUEIRA, M. L. (1988). Flexão estática em amostras livres de defeito. Manaus - INPA, ACTA AMAZÔNICA, 18 (1-2), pp 147 - 162.

RUBINSTEIN, R. Y. (1981). Simulation and the Monte Carlo method. John Wiley\& Sons.

SORENSEN, J. D.; FABER, M. H.; KOHLER, J. (2007).Probabilistic modeling of timber structures. Structural Safety vol. 29, pp 255-267.

SORENSEN, J. D. (2004). Notes in structural reliability theory and risk analysis. AlborgUniversity, 2004.

SOUZA JUNIOR, A. C. de (2008). Aplicação de confiabilidade na calibração de coeficientes parciais de segurança de normas brasileiras de projeto estrutural. Dissertação (mestrado) Escola de Engenharia de São Carlos, Universidade de São Paulo, São Carlos.

VROUWENVELDER, T. (2001). The JCSS probabilistic model code. Structural Safety vol. 19, No 3, pp 245-251. 


\section{ApêndiceA - Carga de ruptura dos 17 grupos de resultados}

\begin{tabular}{|c|c|}
\hline \multicolumn{2}{|c|}{ Grupo 1} \\
\hline Amostra & $\begin{array}{l}P_{\exp } \\
\text { (KN) }\end{array}$ \\
\hline 1 & 20,03 \\
\hline 2 & 29,96 \\
\hline 3 & 28,83 \\
\hline 4 & 18,46 \\
\hline 5 & 28,60 \\
\hline 6 & 30,99 \\
\hline 7 & 27,48 \\
\hline 8 & 25,18 \\
\hline 9 & 33,05 \\
\hline 10 & 11,07 \\
\hline 11 & 20,12 \\
\hline 12 & 25,07 \\
\hline 13 & 22,48 \\
\hline 14 & 29,70 \\
\hline 15 & 33,64 \\
\hline 16 & 31,44 \\
\hline 17 & 26,41 \\
\hline 18 & 18,43 \\
\hline 19 & 31,11 \\
\hline 20 & 30,97 \\
\hline 21 & 20,51 \\
\hline 22 & 23,35 \\
\hline 23 & 38,25 \\
\hline 24 & 29,56 \\
\hline 25 & 21,92 \\
\hline 26 & 30,60 \\
\hline 27 & 20,82 \\
\hline 28 & 14,86 \\
\hline 29 & 18,88 \\
\hline 30 & 23,49 \\
\hline 31 & 15,37 \\
\hline 32 & 27,74 \\
\hline 33 & 24,53 \\
\hline 34 & 17,87 \\
\hline 35 & 24,34 \\
\hline 36 & 27,09 \\
\hline 37 & 35,18 \\
\hline 38 & 30,74 \\
\hline
\end{tabular}

\begin{tabular}{|c|c|c|c|c|c|}
\hline \multicolumn{2}{|c|}{ Grupo 2} & \multicolumn{2}{|c|}{ Grupo 3} & \multicolumn{2}{|c|}{ Grupo 4} \\
\hline Amostra & $\begin{array}{l}P_{\exp } \\
\text { (KN) }\end{array}$ & Amostra & $\begin{array}{l}P_{\exp } \\
\text { (KN) }\end{array}$ & Amostra & $\begin{array}{l}P_{\exp } \\
\text { (KN) }\end{array}$ \\
\hline 1 & 14,13 & 1 & 19,53 & 1 & 30,99 \\
\hline 2 & 13,57 & 2 & 17,70 & 2 & 29,06 \\
\hline 3 & 14,35 & 3 & 23,69 & 3 & 26,22 \\
\hline 4 & 17,23 & 4 & 23,89 & 4 & 35,97 \\
\hline 5 & 16,66 & 5 & 24,70 & 5 & 20,63 \\
\hline 6 & 13,33 & 6 & 20,82 & 6 & 31,89 \\
\hline 7 & 16,64 & 7 & 25,49 & 7 & 18,24 \\
\hline 8 & 13,43 & 8 & 23,29 & 8 & 30,97 \\
\hline 9 & 17,02 & 9 & 24,36 & 9 & 17,76 \\
\hline 10 & 14,06 & 10 & 22,54 & 10 & 28,41 \\
\hline 11 & 18,34 & 11 & 16,69 & 11 & 29,81 \\
\hline 12 & 14,12 & 12 & 11,94 & 12 & 27,31 \\
\hline 13 & 11,11 & 13 & 21,95 & 13 & 27,00 \\
\hline 14 & 14,18 & 14 & 14,33 & 14 & 34,17 \\
\hline 15 & 13,11 & 15 & 16,55 & 15 & 23,55 \\
\hline 16 & 18,76 & 16 & 15,20 & 16 & 29,79 \\
\hline 17 & 11,69 & 17 & 18,94 & 17 & 20,32 \\
\hline 18 & 10,75 & 18 & 4,30 & 18 & 32,06 \\
\hline 19 & 13,39 & 19 & 11,21 & 19 & 27,12 \\
\hline 20 & 13,80 & 20 & 19,92 & 20 & 26,75 \\
\hline 21 & 12,94 & 21 & 22,20 & 21 & 25,29 \\
\hline 22 & 13,45 & 22 & 21,36 & 22 & 25,60 \\
\hline 23 & 14,26 & 23 & 13,69 & 23 & 33,55 \\
\hline 24 & 5,21 & 24 & 24,03 & 24 & 32,26 \\
\hline 25 & 13,57 & 25 & 18,07 & 25 & 24,03 \\
\hline 26 & 16,66 & & & 26 & 14,75 \\
\hline 27 & 14,74 & & & 27 & 25,96 \\
\hline 28 & 14,42 & & & 28 & 33,44 \\
\hline 29 & 8,18 & & & 29 & 31,78 \\
\hline 30 & 7,94 & & & 30 & 34,14 \\
\hline 31 & 13,52 & & & 31 & 14,70 \\
\hline 32 & 12,22 & & & 32 & 31,08 \\
\hline 33 & 12,60 & & & 33 & 28,27 \\
\hline 34 & 14,11 & & & 34 & 17,67 \\
\hline & & & & 35 & 17,59 \\
\hline & & & & 36 & 33,02 \\
\hline
\end{tabular}

\begin{tabular}{c|c|}
\hline \multicolumn{2}{|c|}{ Grupo 5} \\
\hline Amostra & $\begin{array}{c}\mathbf{P}_{\text {exp }} \\
\text { (KN) }\end{array}$ \\
\hline 1 & 28,80 \\
\hline 2 & 23,89 \\
\hline 3 & 13,88 \\
\hline 4 & 25,71 \\
\hline 5 & 19,64 \\
\hline 6 & 14,36 \\
\hline 7 & 26,41 \\
\hline 8 & 26,61 \\
\hline 9 & 22,76 \\
\hline 10 & 17,65 \\
\hline 11 & 25,04 \\
\hline 12 & 26,86 \\
\hline 13 & 18,04 \\
\hline 14 & 28,13 \\
\hline 15 & 30,29 \\
\hline 16 & 25,21 \\
\hline 17 & 23,86 \\
\hline 18 & 17,87 \\
\hline 19 & 15,71 \\
\hline 20 & 27,40 \\
\hline 21 & 17,79 \\
\hline 22 & 31,44 \\
\hline 23 & 26,84 \\
\hline 24 & 13,10 \\
\hline 25 & 23,94 \\
\hline 26 & 25,54 \\
\hline 27 & 21,13 \\
\hline 28 & 27,17 \\
\hline 29 & 25,94 \\
\hline 30 & 22,31 \\
\hline 31 & 27,31 \\
\hline 32 & 17,48 \\
\hline 33 & 28,13 \\
\hline & \\
\hline
\end{tabular}




\section{Carga de ruptura dos 17 grupos de resultados-continua}

\begin{tabular}{|c|c|c|c|c|c|}
\hline \multicolumn{2}{|c|}{ Grupo 6} & \multicolumn{2}{|c|}{ Grupo 7} & \multicolumn{2}{|c|}{ Grupo 8} \\
\hline Amostra & $\begin{array}{l}P_{\exp } \\
(\mathrm{KN})\end{array}$ & Amostra & $\begin{array}{l}P_{\exp } \\
(\mathrm{KN})\end{array}$ & Amostra & $\begin{array}{l}P_{\exp } \\
\text { (KN) }\end{array}$ \\
\hline 1 & 25,29 & 1 & 13,21 & 1 & 24,70 \\
\hline 2 & 18,72 & 2 & 14,53 & 2 & 17,73 \\
\hline 3 & 25,85 & 3 & 14,41 & 3 & 21,38 \\
\hline 4 & 26,86 & 4 & 10,17 & 4 & 30,29 \\
\hline 5 & 20,17 & 5 & 6,86 & 5 & 29,03 \\
\hline 6 & 24,42 & 6 & 15,43 & 6 & 25,51 \\
\hline 7 & 20,37 & 7 & 13,88 & 7 & 22,23 \\
\hline 8 & 23,60 & 8 & 14,81 & 8 & 25,23 \\
\hline 9 & 29,48 & 9 & 12,98 & 9 & 28,32 \\
\hline 10 & 26,27 & 10 & 13,24 & 10 & 23,35 \\
\hline 11 & 16,72 & 11 & 14,22 & 11 & 23,10 \\
\hline 12 & 20,60 & 12 & 14,64 & 12 & 20,29 \\
\hline 13 & 24,22 & 13 & 6,01 & 13 & 25,15 \\
\hline 14 & 22,62 & 14 & 16,27 & 14 & 22,81 \\
\hline 15 & 22,84 & 15 & 10,12 & 15 & 24,84 \\
\hline 16 & 25,07 & 16 & 11,18 & 16 & 25,74 \\
\hline 17 & 28,89 & 17 & 12,19 & 17 & 27,31 \\
\hline 18 & 20,82 & 18 & 7,76 & 18 & 20,01 \\
\hline 19 & 25,35 & 19 & 12,36 & 19 & 32,34 \\
\hline 20 & 20,23 & 20 & 9,61 & 20 & 28,94 \\
\hline 21 & 24,36 & 21 & 9,98 & 21 & 21,55 \\
\hline 22 & 22,45 & 22 & 12,00 & 22 & 31,13 \\
\hline 23 & 24,70 & 23 & 12,87 & 23 & 30,41 \\
\hline 24 & 27,06 & 24 & 11,69 & 24 & 20,03 \\
\hline 25 & 26,02 & 25 & 13,46 & 25 & 26,02 \\
\hline 26 & 14,13 & 26 & 7,98 & 26 & 25,35 \\
\hline 27 & 19,84 & 27 & 12,31 & 27 & 35,89 \\
\hline 28 & 22,90 & 28 & 6,07 & 28 & 30,91 \\
\hline 29 & 28,75 & 29 & 10,54 & 29 & 33,02 \\
\hline 30 & 22,28 & 30 & 11,97 & 30 & 25,79 \\
\hline 31 & 23,49 & 31 & 11,89 & 31 & 37,37 \\
\hline 32 & 21,05 & 32 & 13,52 & 32 & 29,51 \\
\hline 33 & 21,55 & 33 & 13,43 & 33 & 24,39 \\
\hline 34 & 23,74 & 34 & 10,12 & 34 & 24,14 \\
\hline 35 & 22,98 & & & & \\
\hline 36 & 25,91 & & & & \\
\hline 37 & 23,89 & & & & \\
\hline 38 & 25,88 & & & & \\
\hline 39 & 26,41 & & & & \\
\hline 40 & 24,08 & & & & \\
\hline 41 & 23,21 & & & & \\
\hline
\end{tabular}

\begin{tabular}{|c|c|c|c|}
\hline \multicolumn{2}{|c|}{ Grupo 9} & \multicolumn{2}{|c|}{ Grupo 10} \\
\hline Amostra & $\begin{array}{l}P_{\text {exp }} \\
(K N)\end{array}$ & Amostra & $\begin{array}{l}P_{\text {exp }} \\
\text { (KN) }\end{array}$ \\
\hline 1 & 25,01 & 1 & 31,30 \\
\hline 2 & 24,11 & 2 & 24,53 \\
\hline 3 & 25,21 & 3 & 20,55 \\
\hline 4 & 29,11 & 4 & 22,00 \\
\hline 5 & 23,80 & 5 & 32,69 \\
\hline 6 & 18,43 & 6 & 27,82 \\
\hline 7 & 28,91 & 7 & 26,55 \\
\hline 8 & 24,98 & 8 & 29,21 \\
\hline 9 & 13,26 & 9 & 22,32 \\
\hline 10 & 9,86 & 10 & 21,75 \\
\hline 11 & 19,39 & 11 & 20,80 \\
\hline 12 & 22,03 & 12 & 26,81 \\
\hline 13 & 25,54 & 13 & 18,40 \\
\hline 14 & 25,94 & 14 & 36,35 \\
\hline 15 & 19,61 & 15 & 15,68 \\
\hline 16 & 17,96 & 16 & 24,28 \\
\hline 17 & 24,05 & 17 & 18,34 \\
\hline 18 & 11,94 & 18 & 23,84 \\
\hline 19 & 17,00 & 19 & 29,90 \\
\hline 20 & 28,60 & 20 & 23,08 \\
\hline 21 & 15,29 & 21 & 22,57 \\
\hline 22 & 17,39 & 22 & 28,20 \\
\hline 23 & 10,85 & 23 & 30,85 \\
\hline 24 & 15,74 & 24 & 26,87 \\
\hline 25 & 21,95 & 25 & 21,37 \\
\hline 26 & 25,77 & & \\
\hline 27 & 21,55 & & \\
\hline 28 & 20,29 & & \\
\hline 29 & 23,29 & & \\
\hline 30 & 15,62 & & \\
\hline 31 & 22,65 & & \\
\hline 32 & 25,46 & & \\
\hline 33 & 23,52 & & \\
\hline 34 & 24,65 & & \\
\hline 35 & 25,57 & & \\
\hline 36 & 21,92 & & \\
\hline 37 & 18,18 & & \\
\hline 38 & 27,00 & & \\
\hline 39 & 23,86 & & \\
\hline
\end{tabular}




\section{Carga de ruptura dos 17 grupos de resultados-continuação}

\begin{tabular}{|c|c|c|c|c|c|c|c|c|c|}
\hline \multicolumn{2}{|c|}{ Grupo 11} & \multicolumn{2}{|c|}{ Grupo 12} & \multicolumn{2}{|c|}{ Grupo 13} & \multicolumn{2}{|c|}{ Grupo 14} & \multicolumn{2}{|c|}{ Grupo 15} \\
\hline Amostra & $\begin{array}{l}P_{\text {exp }} \\
\text { (KN) }\end{array}$ & Amostra & $\begin{array}{l}P_{\exp } \\
\text { (KN) }\end{array}$ & Amostra & $\begin{array}{l}P_{\text {exp }} \\
\text { (KN) }\end{array}$ & Amostra & $\begin{array}{l}P_{\exp } \\
\text { (KN) }\end{array}$ & Amostra & $\begin{array}{l}P_{\text {exp }} \\
\text { (KN) }\end{array}$ \\
\hline 1 & 57,35 & 1 & 45,08 & 1 & 7,84 & 1 & 23,49 & 1 & 26,73 \\
\hline 2 & 64,55 & 2 & 45,59 & 2 & 7,31 & 2 & 21,69 & 2 & 26,16 \\
\hline 3 & 41,66 & 3 & 52,29 & 3 & 8,82 & 3 & 9,23 & 3 & 34,98 \\
\hline 4 & 60,13 & 4 & 71,32 & 4 & 15,38 & 4 & 22,06 & 4 & 22,08 \\
\hline 5 & 54,37 & 5 & 31,55 & 5 & 18,59 & 5 & 20,05 & 5 & 27,02 \\
\hline 6 & 61,83 & 6 & 51,85 & 6 & 7,31 & 6 & 10,39 & 6 & 28,10 \\
\hline 7 & 54,88 & 7 & 36,29 & 7 & 21,31 & 7 & 16,45 & 7 & 22,24 \\
\hline 8 & 53,68 & 8 & 59,81 & 8 & 6,86 & 8 & 24,40 & 8 & 35,73 \\
\hline 9 & 59,37 & 9 & 37,43 & 9 & 16,09 & 9 & 10,21 & 9 & 18,37 \\
\hline 10 & 63,86 & 10 & 44,64 & 10 & 13,95 & 10 & 16,00 & 10 & 22,56 \\
\hline 11 & 52,23 & 11 & 46,60 & 11 & 4,42 & 11 & 10,19 & 11 & 23,29 \\
\hline 12 & 48,68 & 12 & 55,39 & 12 & 11,89 & 12 & 9,27 & 12 & 17,25 \\
\hline 13 & 58,86 & 13 & 66,14 & 13 & 11,55 & 13 & 25,29 & 13 & 49,45 \\
\hline 14 & 56,72 & 14 & 55,07 & 14 & 6,47 & 14 & 7,57 & 14 & 28,05 \\
\hline 15 & 49,88 & 15 & 51,21 & 15 & 7,91 & 15 & 26,82 & 15 & 31,31 \\
\hline 16 & 46,66 & 16 & 63,48 & 16 & 13,60 & 16 & 34,66 & 16 & 28,39 \\
\hline 17 & 51,46 & 17 & 22,70 & 17 & 4,63 & 17 & 8,13 & 17 & 31,01 \\
\hline 18 & 50,33 & 18 & 58,10 & 18 & 14,42 & 18 & 29,96 & 18 & 22,92 \\
\hline 19 & 31,05 & 19 & 58,61 & 19 & 12,24 & 19 & 12,10 & 19 & 41,86 \\
\hline 20 & 64,74 & 20 & 55,39 & 20 & 17,55 & 20 & 11,99 & 20 & 28,71 \\
\hline 21 & 72,65 & 21 & 31,68 & 21 & 9,48 & 21 & 8,80 & 21 & 38,53 \\
\hline 22 & 49,19 & 22 & 49,06 & 22 & 10,53 & 22 & 17,11 & 22 & 29,74 \\
\hline 23 & 54,94 & 23 & 48,05 & 23 & 14,31 & 23 & 13,24 & 23 & 18,94 \\
\hline 24 & 50,45 & 24 & 49,82 & 24 & 17,71 & 24 & 20,12 & 24 & 39,49 \\
\hline 25 & 57,47 & 25 & 52,98 & & & & & & \\
\hline 26 & 56,90 & 26 & 59,50 & & & & & & \\
\hline 27 & 53,17 & 27 & 40,34 & & & & & & \\
\hline 28 & 49,13 & 28 & 51,91 & & & & & & \\
\hline 29 & 58,61 & 29 & 49,63 & & & & & & \\
\hline 30 & 65,63 & 30 & 49,82 & & & & & & \\
\hline 31 & 52,54 & 31 & 51,03 & & & & & & \\
\hline 32 & 47,17 & 32 & 50,39 & & & & & & \\
\hline 33 & 64,11 & 33 & 41,28 & & & & & & \\
\hline 34 & 51,03 & 34 & 41,92 & & & & & & \\
\hline \multirow[t]{7}{*}{35} & 63,23 & 35 & 54,82 & & & & & & \\
\hline & & 36 & 60,19 & & & & & & \\
\hline & & 37 & 49,00 & & & & & & \\
\hline & & 38 & 39,39 & & & & & & \\
\hline & & 39 & 51,72 & & & & & & \\
\hline & & 40 & 56,72 & & & & & & \\
\hline & & 41 & 51,66 & & & & & & \\
\hline
\end{tabular}




\section{Carga de ruptura dos 17 grupos de resultados-conclusão}

\begin{tabular}{|c|c|c|c|}
\hline \multicolumn{2}{|c|}{ Grupo 16} & \multicolumn{2}{|c|}{ Grupo 17} \\
\hline Amostra & $\begin{array}{l}P_{\exp } \\
(K N)\end{array}$ & Amostra & $\begin{array}{c}P_{\exp } \\
\text { (KN) }\end{array}$ \\
\hline 1 & 67,15 & 1 & 21,69 \\
\hline 2 & 32,49 & 2 & 34,49 \\
\hline 3 & 38,99 & 3 & 34,31 \\
\hline 4 & 42,34 & 4 & 27,31 \\
\hline 5 & 57,81 & 5 & 20,73 \\
\hline 6 & 14,58 & 6 & 35,50 \\
\hline 7 & 44,07 & 7 & 36,23 \\
\hline 8 & 36,69 & 8 & 33,75 \\
\hline 9 & 46,21 & 9 & 37,91 \\
\hline 10 & 32,08 & 10 & 45,67 \\
\hline 11 & 30,94 & 11 & 33,07 \\
\hline 12 & 34,13 & 12 & 42,96 \\
\hline 13 & 31,72 & 13 & 42,23 \\
\hline 14 & 28,14 & 14 & 30,60 \\
\hline 15 & 46,21 & 15 & 31,14 \\
\hline 16 & 40,92 & 16 & 34,13 \\
\hline 17 & 27,91 & 17 & 36,39 \\
\hline 18 & 38,33 & 18 & 37,68 \\
\hline 19 & 35,59 & 19 & 34,32 \\
\hline 20 & 19,96 & 20 & 23,52 \\
\hline 21 & 32,36 & 21 & 40,79 \\
\hline 22 & 57,60 & 22 & 32,77 \\
\hline 23 & 32,24 & 23 & 25,63 \\
\hline 24 & 39,22 & 24 & 27,35 \\
\hline & & 25 & 17,16 \\
\hline & & 26 & 38,33 \\
\hline & & 27 & 24,34 \\
\hline & & 28 & 37,68 \\
\hline & & 29 & 37,57 \\
\hline & & 30 & 37,37 \\
\hline & & 31 & 40,93 \\
\hline & & 32 & 32,08 \\
\hline & & 33 & 25,53 \\
\hline & & 34 & 37,12 \\
\hline & & 35 & 24,80 \\
\hline & & 36 & 45,33 \\
\hline & & 37 & 42,31 \\
\hline & & 38 & 40,35 \\
\hline
\end{tabular}

